UNIVERSIDADE DE SÃO PAULO

INSTITUTO DE FÍSICA

\title{
MODIFICAÇÃO DE SUPERFÍCIE DE DIAMANTE UTILIZANDO PLASMA E CARACTERIZAÇÃO POR KELVIN FORCE MICROSCOPY
}

WAGNER WLYSSES RODRIGUES DE ARAÚJO

Orientadora: Prof $^{\mathrm{a}}$. Dr ${ }^{\mathrm{a}}$. Maria Cecília Barbosa Silveira Salvadori

Dissertação apresentada ao Instituto de Física para a obtenção do título de Mestre em Ciências

\section{Banca Examinadora:}

Prof $^{\mathrm{a}}$. Dr ${ }^{\mathrm{a}}$. Maria Cecília Barbosa Silveira Salvadori (IF/USP)

Prof. Dr. Antonio Domingues dos Santos (IF/USP)

Prof $^{\mathrm{a}}$. Dr ${ }^{\mathrm{a}}$. Denise Freitas Siqueira Petri (IQ/USP)

SÃO PAULO 


\section{FICHA CATALOGRÁFICA}

\section{Preparada pelo Serviço de Biblioteca e Informação do Instituto de Física da Universidade de São Paulo}

\begin{tabular}{|l|}
\hline Araújo, Wagner Wlysses Rodrigues de \\
Modificação de superfície de diamante utilizando \\
plasma e caracterização por Kelvin force microscopy. São \\
Paulo, 2010. \\
Dissertação (Mestrado) Universidade de São Paulo. \\
Instituto de Física. Depto. de Física Aplicada. \\
Orientadora: Prof ${ }^{\text {a }}$ Dr ${ }^{\text {a }}$. Maria Cecília Barbosa \\
Silveira Salvadori \\
Área de Concentração: Matéria Condensada \\
Unitermos: 1. Filmes Finos; \\
2. Superfície Física; \\
3. Física da Matéria Condensada; \\
4. Potencial Elétrico. \\
USP/IF/SBI-075/2010
\end{tabular}


WAGNER WLYSSES RODRIGUES DE ARAÚJO

MODIFICAÇÃO DE SUPERFÍCIE DE DIAMANTE UTILIZANDO PLASMA E CARACTERIZAÇÃO POR KELVIN FORCE MICROSCOPY 
A meus Pais

José Evangelista de Araújo e Ana Lúcia Rodrigues de Araújo, é claro! 


\section{Sumário}

Sumário $\quad$ p.i

$\begin{array}{ll}\text { Agradecimentos } & \text { p.iv }\end{array}$

Epígrafe $\quad$ p.vi

1 INTRODUÇÃOO p. 1

2 MATERIAIS E MÉTODOS. P. 4

2.1 Deposição de Filmes de Diamante . . . . . . . . . . . . . p. 4

2.2 Microscopia Eletrônica de Varredura (MEV) e o sistema de litografia. . . . . p. 7

2.2.1 Espalhamento dos Elétrons em sólidos. . . . . . . . . . p 8

2.2.2 Sistema de Geração de Padrões Litográficos . . . . . . . . . . . . . . p. 10

2.3 Litografia por feixe de elétrons. . . . . . . . . . . . p. 11

2.3.1 Elétrons-Resistes. . . . . . . . . . . . . . p. 11

2.4 Preparação de amostras. . . . . . . . . . . . . . . . . . p. 12

2.4.1 Polimento do Substrato . . . . . . . . . . . . . . p. 12

2.4.2 Limpeza dos Substratos . . . . . . . . . . . . p. 13

2.4.3 Recobrimento do Substrato com o Elétron-Resiste . . . . . . . p. 13

2.4 .4 Secagem ............................. 14 
2.4.5 Geração de Padrões . . . . . . . . . . . . . . . . . . . . p. 14

2.4.6 Transferência de padrões . . . . . . . . . . . . . p. 15

2.4.7 Revelação do Elétron-Resiste . . . . . . . . . . . . . p. 17

2.5 Modificação da Superfície de Diamante . . . . . . . . . . . p. 18

2.5.1 Modificação da Superfície de Diamante com tratamento de plasma

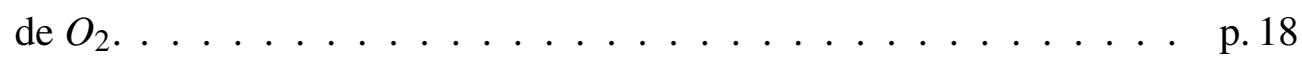

2.5.2 Modificação da Superfície de Diamante com tratamento de plasma

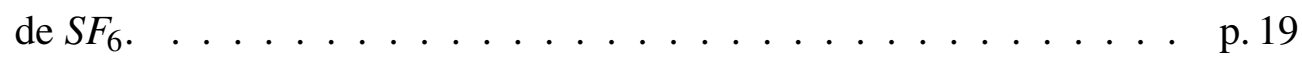

2.6 Preparação das amostras contendo regiões adjacentes de flúor e oxigênio. . p. 19

3 TÉCNICAS DE CARACTERIZAÇÕES p. 21

3.1 Espectroscopia de espalhamento Raman. . . . . . . . . . . . . . . . p. 21

3.2 Difração de Raios-X. . . . . . . . . . . . . . . . . p. 22

3.3 Microscopia de Força Atômica. . . . . . . . . . . . . . . p. 23

3.3.1 Descrição dos Modos AFM . . . . . . . . . . . . p. 24

3.3.2 Descrição do Modo AFM de Contato . . . . . . . . . . . . . p. 24

3.3.3 Kelvin Force Microscopy $(\mathrm{KFM}) \ldots \ldots \ldots$ p. . . . . . . . . . . 25

3.4 Montagem para realizar medidas de AFM/KFM em atmosfera controlada . . p. 27

3.5 Ângulo de Contato e Energia Livre de Superfície . . . . . . . . . . . . . . . p. 29

4 RESULTADOS EXPERIMENTAIS E DISCUSSÃO. P. 34

4.1 Espectroscopia Raman dos Filmes de Diamante depositados no Equipamento

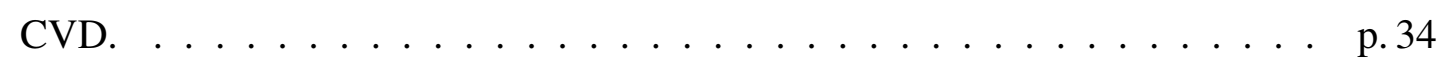

4.2 Difratometria de raios-X e MEV dos Filmes de Diamante depositados no Equipamento CVD . . . . . . . . . . . . . . p. 36

4.3 Resultados para litografia por feixe de elétrons. . . . . . . . . . . p. 37

4.4 Resultados da modificação de superfície utilizando gás de $O_{2}$. . . . . . . . p. 39

4.5 Resultados da modificação de superfície utilizando gás de $S F_{6} \ldots \ldots$. . . . . . p. 44 
4.6 Resultados da modificação de superfície com plasma de $O_{2}$ para amostra com terminação de Flúor. . . . . . . . . . . . . . . . . . . . . . . . p.49

4.7 Resultados para amostra contendo regiões com terminações de superfície de hidrogênio, de flúor e de oxigênio. . . . . . . . . . . . . . p.53

4.8 Resultados das Medidas de ângulo de Contato e energia livre de superfície. . p.60

\section{SUMÁRIO E CONCLUSÕES}

A Resultados preliminares para modificação das superfícies de diamante.

A.1 Resultados da modificação de superfície utilizando gás de $O_{2}$. . . . . . . p. p7

A.2 Resultados da modificação de superfície utilizando gás de $S F_{6} \ldots \ldots \ldots$. . . p. 70

A.3 Resultados Para amostra contendo as terminações de superfície flúor e oxigênio. p. 72

A.4 Resultados Para amostra contendo as terminações de superfície de hidrogênio, flúor e oxigênio. . . . . . . . . . . . . . . . . . . . . p.74 


\section{Agradecimentos}

- A DEUS por minha vida;

- A meus PAIS, José Evangelista de Araújo e Ana Lúcia Rodrigues de Araújo, pela educação e apoio em todos os momentos de minha vida, e meus irmãos Hérica Gabriela R. de Araújo e José Maria de Araújo Netto por todo apoio;

- A alguns membros da familia, pelo apoio e ambiente oferecido;

- A Prof ${ }^{\mathrm{a}}$. Dra ${ }^{\mathrm{a}}$ Maria Cecília Barbosa da Silveira Salvadori pela oportunidade, a toda ajuda, dedicação e constante orientação a mim concedido. Não somente por acreditar mas por me fazer acreditar também em mim;

- A talentosa especialista de laboratório e Dra . Fernanda de Sá Teixeira, agradeço a dedicação, as tantas ajudas, discussões e atenção prestada tanto no compêndio científico quanto, em algumas vezes, aos valiosos conselhos pessoais[;)];

- A todos meus AMIGOS, que me aturaram até agora (que continue assim...), pela amizade e compreensão;

- Aos NOBRES companheiros de Laboratório, Márcio Roberto, Guido Gabriel, Leandro Toshio, Leonardo Sgubin e ao demais espalhados pelo Brasil afora [:)];

- Ao Conselho de Aperfeiçoamento do Ensino Superior - CAPES ao Conselho Nacional de Pesquisa - CNPq e a Fundação de Amparo a Pesquisa do Estado de São Paulo - FAPESP pelo suporte financeiro e oportunidades;

- Aos meus professores de graduação, Helder Nunes da Cunha e José Pimentel de Lima pela disponibilidade e orientação e por todo o apoio e orientação, apoio este que foi ponto de partida para que pudesse chegar até aqui e a concluir mais esta etapa da minha formação; 
- Ao Prof. Dr. Francisco Tadeu Degasperi pelos diversos ensinamentos em Técnologia do vácuo;

- Aos Professores Mauro Cattani e Ian Brown pelas suas colaboraçoes, ajuda e dedicação aos trabalhos realizados no Laboratório de Filmes Finos;

- A todos que contribuirão direta e indiretamente para que este trabalho fosse realizado deixo aqui um grande, SOU-TE GRATO!. 
"The quieter you become the more you are able to hear." Autor desconhecido. 


\section{Lista de Figuras}

1.1 Superfícies de diamante (001) com terminações de hidrogênio (à esquerda) e com terminações de oxigênio (à direita) $[6] \ldots \ldots \ldots$. . . . . . . . . .

2.1 Cavidade ressonante de microondas. Sua lateral é construída com uma folha de alumínio estampada com orifícios de $1 \mathrm{~mm}$ de diâmetro. O topo da cavidade consiste em uma placa circular onde se apóia a válvula magnetron. Esta placa pode ser movimentada na direção vertical através de quatro parafusos. .

2.2 A foto da esquerda mostra o reator CVD completo, sendo que na porção de baixo se encontra o porta amostras. A foto da direita apresenta o ajuste de altura do porta amostras em detalhe. . . . . . . . . . . . . . .

2.3 Câmara de reação formada por uma campânula de quartzo apoiada sobre a base da cavidade, um cilindro de quartzo que guia os gases reagentes até o topo da amostra, e o porta objeto ajustável, também de quartzo. . . . . . . . . p. 6

2.4 Coluna óptico-eletrônica de um Microcópio Eletrônico de Varredura. . . . . . p. 8

2.5 Volume de interação na amostra atingida pelo feixe de elétrons . . . . . . . p.9

2.6 Ilustração esquemática da formação de imagem em um MEV . . . . . . . . . . p p. 10

2.7 Ciclo de Controle do Sistema NPGS acoplado ao MEV . . . . . . . . . . . p. 10

2.8 Ilustração mostrando a diferença entre elétron-resistes positivos e negativos. . p. 12

2.9 spin coater modelo P6700 da empresa Specialty Coating Sistems INC . . . . p. 14

$2.10 \mathrm{Na}$ esquerda padrão utilizado na litografia por feixe de elétrons com $5 \times$ $5 \mathrm{~cm}^{2}$, Na direita padrão utilizado na litografia por feixe de elétrons com $3 \times 3 \mathrm{~cm}^{2} \ldots \ldots \ldots \ldots \ldots \ldots \ldots$ p. . . . . . . . . . . . . . . 
2.11 A figura da esquerda mostra as dimensões (em mm) de fabricação do Faraday Cup. A figura da direita apresenta o corte transversal do arranjo. . . . . . . p. 16

2.12 Micrografia do Faraday Cup em detalhes. . . . . . . . . . . . . . . . . . p. 16

2.13 Ilustração esquemática do canhão de plasma. . . . . . . . . . . . . . p. 18

2.14 Esquema ilustrando a divisão da superfície para litografar vários padrões. p.19

3.1 Esquema ilustrativo do funcionamento do AFM. . . . . . . . . . . . . . p. 23

3.2 Esquema apresentando o princípio básico de funcionamento de um AFM de

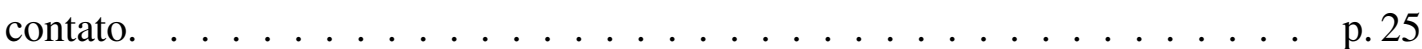

3.3 Diagrama de Energia dos elétrons de duas placas de metal (M1 e M2) (a) eletricamente desconectadas (b) eletricamente conectadas. . . . . . . . . . . p. 26

3.4 Descrição do recurso interleave que permite a obtenção de duas modalidades diferentes de imagem simultaneamente, numa mesma área de varredura. (a) Interleave desabilitado e (b)interleave habilitado. . . . . . . . . . . . . . p.28

3.5 Imagem ilustrando a câmpanula de controle atmosférico do equipamento AFM. p. 29

3.6 Esquema ilustrando as interfaces sólido/líquido, sólido/vapor e líquido/vapor e indicando a formação do ângulo de contato . . . . . . . . . . . . . . . p. 29

3.7 Imagem do ajuste do ângulo de contato calculado pelo software de controle do equipamento CAM200. Nessa imagem a amostra está inclinação de aproximadamente $50^{\circ}$ com inclinação realizado pelo equipamento. . . . . . . . . p.33

3.8 Ângulo de contato para superfícies hidrofílicas e superfícies hidrofóbicas. . . p.33

4.1 Espectros Raman normalizado com relação ao pico mais intenso $\left(1580 \mathrm{~cm}^{-1}\right)$ das amostras de filme de diamante obtidos variando-se a quantidade de nitrogênio $\mathrm{N}_{2}$ adicionado à mistura de hidrogênio $\mathrm{H}_{2}$ e metano $\mathrm{CH}_{4} \quad \ldots \ldots$. . . . p.35

4.2 Espectro de difração de raios-X típico das amostras de filme de diamante obtidos com $300 \mathrm{sccm}$ de hidrogênio 3,00 sccm de metano e 3,00 sccm de

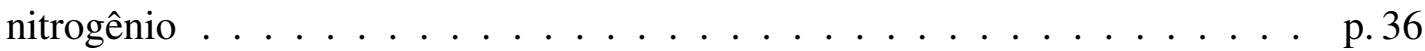

4.3 Imagem MEV típica dos filmes de diamante usados neste trabalho. . . . . . . p. 37

4.4 Micrografia ótica panorâmica de uma amostra de diamante policristalino com padrão litografado cobrindo uma área total de $3 \times 3 \mathrm{~mm}^{2} \ldots \ldots$. . . . . . p. 38 
4.5 Imagem MEV da superfície do filme de diamante exposta ao plasma de oxigênio por 5 minutos com regiões adjacentes com terminações de hidrogênio, nas regiões claras, e de oxigênio nas regiões escuras. . . . . . . . . . . . p.41

4.6 Micrografia de AFM (à esquerda) e de KFM (à direita) da amostra do filme de diamante exposto ao plasma de oxigênio por 5 minutos. Na figura da esquerda temos a morfologia do filme de diamante e na direita temos o respectivo mapeamento do potencial de superfície para a mesma região onde, as regiões claras correspondem a terminações de oxigênio e as regiões escuras correspondem a terminações de hidrogênio. . . . . . . . . . . . . . p.41

4.7 Tela do NanoScope IIIa apresentando a medida da diferença de potencial entre as regiões adjacentes de hidrogênio e oxigênio através da ferramenta cross section . . . . . . . . . . . . . . . . . . . . p. . . . . . . .

4.8 Perfil médio de potencial calculado a partir do dados obtidos na primeira imagem KFM capturada. . . . . . . . . . . . . . . . . . .

4.9 Gráfico da diferença de potencial entre regiões com terminações de oxigênio e de hidrogênio calculado a partir das imagens KFM ao longo do tempo $t$ no qual a superfície era banhada com hélio gasoso. As várias curvas correspondem a diferentes tempos de exposição ao plasma de oxigênio. . . . . . . . p. p.43

4.10 Micrografia MEV da superfície de diamante exposta ao plasma de $S F_{6}$ por 9 minutos. Apresentando regiões adjacentes com terminações de hidrogênio(regiões escuras) e flúor nas regiões claras. . . . . . . . . . . . . . . p. 46

4.11 Micrografia de AFM (à esquerda) e de KFM (a direita) da amostra do filme de diamante exposto ao plasma de $S F_{6}$ por 9 minutos. Na figura da esquerda temos a morfologia do filme de diamante e na direita temos o respectivo mapeamento do potencial de superfície para a mesma região onde, as regiões claras correspondem a terminações de hidrogênio e as regiões escuras correspondem a terminações de flúor. . . . . . . . . . . . . . . . . p.46

4.12 Tela do NanoScope IIIa apresentando a medida do perfil de potencial entre as regiões adjacentes de hidrogênio e flúor através da ferramenta cross section. p.47

4.13 Perfil médio de potencial calculado a partir do dados obtidos na primeira imagem KFM capturada. . . . . . . . . . . . . . . . . . . . p. 47 
4.14 Gráfico da diferença de potencial entre as regiões com terminações de flúor e de hidrogênio obtidos a partir das imagens KFM ao longo do tempo $t$ no qual a superfície era banhada com hélio gasoso. As várias curvas correspondem a diferentes tempos de exposição ao plasma de $S F_{6} \ldots \ldots \ldots$. . . . . . . . 48

4.15 Micrografia MEV da amostra do filme de diamante exposto ao plasma de $S F_{6}$ por 5 minutos e em seguida, oxidado por 5 minutos. Apresentando regiões adjacentes com terminações de flúor (quadrados) e oxigênio nas demais regiões. p. 50

4.16 Imagens de AFM (à esquerda) e KFM (à direita) da amostra do filme de diamante exposto ao plasma de $S F_{6}$ por 5 minutos e em seguida, oxidado por 5 minutos. Na imagem de KFM, as regiões escuras correspondem às terminações de flúor e as regiões claras correspondem às terminações de

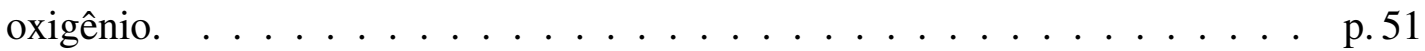

4.17 Tela do NanoScope IIIa apresentando a medida do perfil de potencial entre as regiões adjacentes de flúor e de oxigênio através da ferramenta cross section.

4.18 Perfil de médio potencial calculado a partir dos dados obtidos na primeira imagem KFM capturada. . . . . . . . . . . . . . . . . . . . . . . .

4.19 Gráfico da diferença de potencial entre as regiões com terminações de flúor e de oxigênio obtidos a partir das imagens KFM ao longo do tempo no qual a superfície era banhada com hélio gasoso. As várias curvas correspondem a diferentes tempos de exposição ao plasma de oxigênio. . . . . . . . . . . .

4.20 Micrografia MEV utilizada para identificar a intersecção entre as regiões com terminações de hidrogênio, de flúor e de oxigênio, para o caso da amostra tratada por 3 minutos com plasma de $S F_{6}$ e 2 minutos com plasma de $O_{2}$. . .

4.21 Micrografias de AFM e KFM, sendo a imagem da esquerda (AFM) referente a topografia da amostra e a imagem da direita (KFM) referente ao mapeamento do potencial de superfície. As regiões mais claras (faixas) correspondem a terminações de flúor, as regiões mais escuras (círculos) correspondem a terminação de oxigênio e as demais correspondem as terminações de hi-

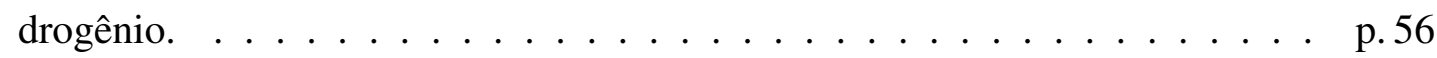

4.22 Tela no NanoScope IIIa apresentando o perfil de potencial de superfície medido para a amostra HF3O2, medido utilizando a ferramenta de cross-section. 
4.23 Perfil de Potencial de superfície referente às linhas traçadas na figura 4.22, na forma de gráfico do software ORIGIN . . . . . . . . . . . . . . . . p.57

4.24 Potenciais das regiões com diferentes terminações da amostra HF3O2 obtidos a partir de imagens de KFM em função do tempo $t$ no qual a superfície era banhada com hélio gasoso. Os potenciais referentes as regiões com terminações de oxigênio estão designadas com índices $O_{(F)}$ para o caso onde havia anteriormente terminações de $\mathrm{F}$ e com índice $O_{(H)}$ quando as terminações eram

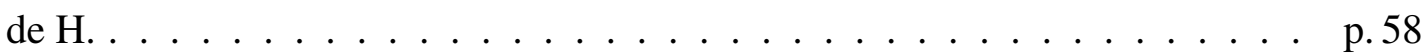

4.25 Diferenças de potencial entre as diferentes regiões especificas na figura 4.24 . p.58

4.26 Potenciais das regiões com diferentes terminações da amostra HF5O4 obtido a partir de imagens de KFM em função do tempo $t$ no qual a superfície era banhada com hélio gasoso. . . . . . . . . . . . . . . . . p.59

4.27 Diferença de potencial entre as diferentes regiões especificas na figura 4.26. . p.59

4.28 Micrografia óptica de superfície do filme de diamante contendo regiões adjacentes com terminações de superfície de hidrogênio e oxigênio. . . . . . . . p.62

4.29 Micrografia óptica de superfície do filme de diamante contendo regiões adjacentes com terminações de superfície de hidrogênio e oxigênio, com a superfície molhada mostrando as regiões hidrofílicas com terminação de oxigênio. p. 62

4.30 Gráfico das energias livres de superfície obtido pelo método de Fowkes (média geométrica) e pelo método de Wu (média harmônica) $\ldots \ldots$. . . . . . p.63

4.31 Gráfico das componentes dispersivas e polares obtidas pelo método de Fowkes (média geométrica) e pelo método de Wu (média harmônica) . . . . . . . p.64

A.1 Imagem MEV da superfície do filme de diamante apresentando regiões adjacentes com terminações de hidrogênio, nas regiões escuras, e de oxigênio nas regiões claras. . . . . . . . . . . . . . . . . . . . 68

A.2 Micrografia da Amostra do Filme de diamante exposto ao plasma de Oxigênio por 2 minutos. Na figura da esquerda temos a morfologia do filme de diamante obtido por AFM e na direita temos o respectivo mapeamento do potencial de superfície para a mesma região obtido por KFM. . . . . . . . . . . p.69

A.3 Medida da diferença de potencial entre as regiões adjacentes de hidrogênio e de oxigênio obtido através da ferramenta cross section . . . . . . . . . . . p.69 
A.4 Micrografia da Amostra do Filme de diamante exposto ao plasma de $S F_{6}$ por 5 minutos. As regiões claras correspondem à regiões com terminações de flúor. p. 71

A.5 AFM/KFM da Amostra do Filme de diamante exposto ao plasma de $S F_{6}$ por 5 minutos. As regiões escuras correspondem à regiões com terminações de flúor. . . . . . . . . . . . . . . . . . p. 71

A.6 AFM/KFM da Amostra do Filme de diamante exposto ao plasma de $S F_{6}$ por 5 minutos e em seguida, exposta ao plasma de oxigênio pelo tempo de 1 minuto. p. 72

A.7 Micrografia obtida por MEV, referente ao mapeamento do potencial de superfície, desde que o contraste é devido diferente propriedades elétricas, onde as regiões mais claras correspondem a terminações de hidrogênio a região mais escura corresponde a terminação de flúor e a região com tonalidade cinza corresponde a terminações de oxigênio. . . . . . . . . . . . . . p.74

A.8 Micrografia obtida por AFM e KFM, sendo a imagem da esquerda referente a topografia da amostra e a imagem da direita referente ao mapeamento do potencial de superfície, onde as regiões mais claras correspondem a terminações de oxigênio, a região mais escura corresponde a terminação de flúor e as.demais correspondem as terminações de hidrogênio. . . . . . . . p.75

A.9 Perfil de potencial médio obtido para a amostra contendo regiões com terminações de hidrogênio, de flúor e de oxigênio, medido utilizando a ferramenta de cross-section. . . . . . . . . . . . . . . . p. 75 


\section{Lista de Tabelas}

2.1 Principais características do Jeol 6460-LV e acessórios $\ldots \ldots \ldots \ldots$ p. . . . . .

4.1 Diferença de potencial medido para as superfícies de diamante em atmosfera controlada de hélio gasoso para diversos tempos de exposição ao plasma de

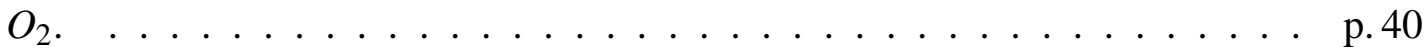

4.2 Diferença de potencial medido para as superfícies de diamante em atmosfera controlada de hélio gasoso para diversos tempos de exposição ao plasma $S F_{6}$.

4.3 Diferença de potencial medido para as superfícies de diamante em atmosfera controlada de hélio gasoso para diversos tempos de exposição ao plasma $\mathrm{O}_{2}$ para superfície de diamante previamente exposta ao plasma de $S F_{6}$. . . . . p.50

4.4 Potenciais em valores médios das regiões com terminações de hidrogênio, de flúor e de oxigênio. Para a amostra HF5O4 foi subtraído $14 \mathrm{mV}$ de todos os

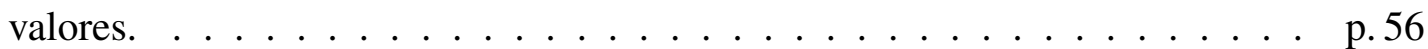

4.5 Diferença de potencial médio obtido entre as regiões com diferentes terminações

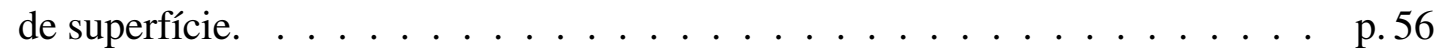

4.6 Energias livres de superfície calculadas utilizando o método geométrico para as diferentes terminações de superfície . . . . . . . . . . . . . p.63

4.7 Energias livres de superfície calculadas utilizando o método harmônico para as diferentes terminações de superfície . . . . . . . . . . . . . p.63

A.1 Diferença de potencial obtido para diversos tempos de exposição ao plasma

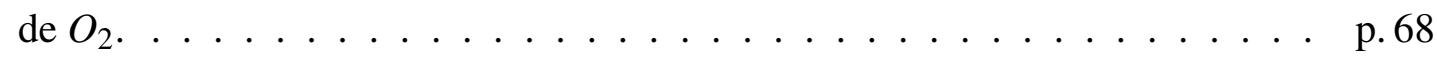

A.2 Diferença de potencial medido através da ferramenta de cross section para diversos tempos de exposição ao plasma de $S F_{6} \ldots \ldots$. . . . . . . . p. 70 
A.3 Diferença de Potencial medido através da ferramenta de cross section para superfície contendo regiões com terminações de flúor e de oxigênio. . . . . . p.73

A.4 Diferença de Potencial medido através da ferramenta de cross section para amostra contendo regiões com diferentes terminações. . . . . . . . . p.76 


\section{Lista de Abreviaturas}

$A C \quad$ Ângulo de Contato

AFM Atomic Force Microscopy

CAM - 200 Contact Angle Measurements-200

CCD Dispositivo de Carga Acoplada (Charge-Coupled Device)

FAPESP Fundação de Amparo a Pesquisa do Estado de São Paulo

KFM Kelvin Force Microscopy

NPGS Nano Pattern Generation System

MEV Microscopia Eletrônica de Varredura

LFF Laboratório de Filmes Finos

IFUSP Instituto de Física da Universidade de São Paulo

SCCM Centímetro cúbico por minuto nas CNTP (Standard Centimeter Cubic per minute)

SPM Scanning Probe Microscopy

RMS Raiz média quadrática (Root Mean Square)

PMMA Poli(metacrilato de metila)

XRD Difração de Raios-X (X-ray Diffraction) 


\section{Lista de Símbolos}

$x \quad$ Coordenada $\mathrm{x}$ do plano cartesiano;

y Coordenada y do plano cartesiano;

C Constante de Calibração;

$v_{o} \quad$ Frequência da radiação incidente;

$v_{k} \quad$ Frequência da radiação atômica;

$\theta_{i} \quad$ Ângulo de incidência;

$\theta_{r} \quad$ Ângulo de reflexão;

$\lambda \quad$ Comprimento de onda;

d Distância interplanar;

I Corrente elétrica;

V Potencial elétrico;

F Módulo da Força;

$k \quad$ Constante de mola;

$x \quad$ deflexão do cantiléver;

$E_{v a c}$ Energia de um elétron livre no vácuo;

$E_{F} \quad$ Energia do nível de Fermi;

$\phi \quad$ Função trabalho; 
$\Phi \quad$ Potencial de contato;

e Carga elementar do elétron

$V_{A C}$ Tensão oscilante aplicada na ponta;

$\omega$ Frequência angular;

$t$ tempo;

$\gamma_{S L} \quad$ Tensão interfacial sólido/líquido;

$\gamma_{S V}$ Tensão interfacial sólido/vapor;

$\gamma_{L V} \quad$ Tensão superficial da interface líquido vapor;

$\Theta \quad$ Ângulo de contato

W Trabalho 


\section{Resumo}

Neste trabalho nós produzimos e caracterizamos superfícies de diamante policristalino com áreas seletivas oxidadas e fluoradas a partir de superfícies originalmente hidrogenadas, usando um canhão de plasma para bombardear a superfície do diamante. A técnica que foi utilizada para a produção de filmes de diamante com superfícies hidrogenadas foi a deposição química a vapor por plasma de microondas. A seletividade de área para posterior oxidação foi realizada através de litografia por feixe de elétrons. A oxidação e a fluoração das áreas selecionadas foi feita por plasma de oxigênio e hexaflureto de enxofre, respectivamente. As caracterizações foram realizadas através de microscopia eletrônica de varredura convencional, microscopia de força atômica, Kelvin Force Microscopy e medida de ângulo de contato. 


\section{Abstract}

In this work we have formed and characterized polycrystaline diamond films with surfaces having hydrogen terminations, oxygen terminations, or fluorine terminations, using a plasma gun to bombard the diamond surface. The technique used for diamond films deposition with surfaces having hydrogen terminations was microwave plasma assisted chemical vapor deposition. The selected areas for oxidation and fluorination were prepared by electron beam lithography. The oxidation and fluorination of the selected areas were performed using oxygen and sulfur hexafluoride plasma, respectively. The samples were characterized by conventional scanning electron microscopy, atomic force microscopy, Kelvin force microscopy and contact angle measurement. 
$\Gamma_{\text {Capítulo } 1}$

\section{INTRODUÇÃO}

O diamante é um material conhecido desde nossos primórdios [1, 2]. A palavra diamante tem etimologia do latim adamas e do grego adámas, que significa inquebrável, invencível, imbatível, indomável, dado em referência a sua dureza extrema. O diamante é de fato o material mais duro conhecido até o presente momento, e usado como referência de dureza máxima na escala de Mohs.

O diamante reúne uma série de características que o torna um material único para um grande número de aplicações tecnológicas. Tais como; baixo coeficiente de atrito com ele mesmo, que é tipicamente metade do coeficiente de atrito de metais lubrificados entre si. Reduzida taxa de desgaste, em geral, mais de duas ordens de grandeza menor que a da safira. Excelente condutor térmico, conduz calor melhor que qualquer outro material, sendo que à temperatura ambiente sua condutividade térmica é cerca de 1,6 a 4,8 maior do que a da prata metálica e 4 vezes a do cobre metálico. Quando puro é isolante elétrico, e quando dopado, torna-se semicondutor

de banda larga. É oticamente transparente desde o visível até o ultravioleta, e, na região do infravermelho, apresenta bandas de absorção entre 2 e $6 \mu \mathrm{m}$; além disto, ele é quimicamente inerte [3].

Aplicações tecnológicas dos filmes de diamante abrangem várias áreas. Alguns produtos são comercialmente disponíveis, incluindo ferramentas de corte e brocas recobertas, dissipadores de calor para microeletrônica, diafragmas para alto-falantes, janelas para lasers e raios-X, coberturas de lentes e estruturas óticas, entre outras. Um grande número de aplicações ainda está em desenvolvimento, como: dispositivos microeletrônicos, semicondutores (diodos, transistores, lasers de estado sólido que funcionam no ultravioleta, etc.), recobrimento de superfícies redutoras de atrito e desgaste (mancais e partes móveis de motores, bicos de extrusão, entre outros) $[3,4]$. 
O diamante apesar de ser o material mais duro conhecido, apresenta alguns planos de clivagem. À clivagem, por exemplo, no plano (001) faz com que os átomos de carbono da superfície, que realizam quatro ligações no cristal, fiquem com duas ligações rompidas, essas ligações livres são chamada de dangling bonds. Outros planos de clivagem também geram ligações livres, o que faz com que a superfície do diamante apresente alta reatividade química, em despeito a baixa reatividade do cristal no volume. Essa propriedade faz do diamante um grande candidato para aplicações que envolvem modificação de superfície [5].

Quando essas ligações livres da superfície geram ligações com átomos de hidrogênio, dizemos que a superfície é hidrogenada, nomenclatura similar se dá para as superfícies com ligações com átomos de oxigênio e com flúor, denominadas superfícies oxidadas e superfícies fluoradas, respectivamente.

Superfícies hidrogenadas de diamante apresentam propriedades consideravelmente distintas das superfícies oxidadas. Ilustrações apresentando superfícies de diamante (001) com terminações de hidrogênio e com terminações de oxigênio são fornecidas na figura 1.1

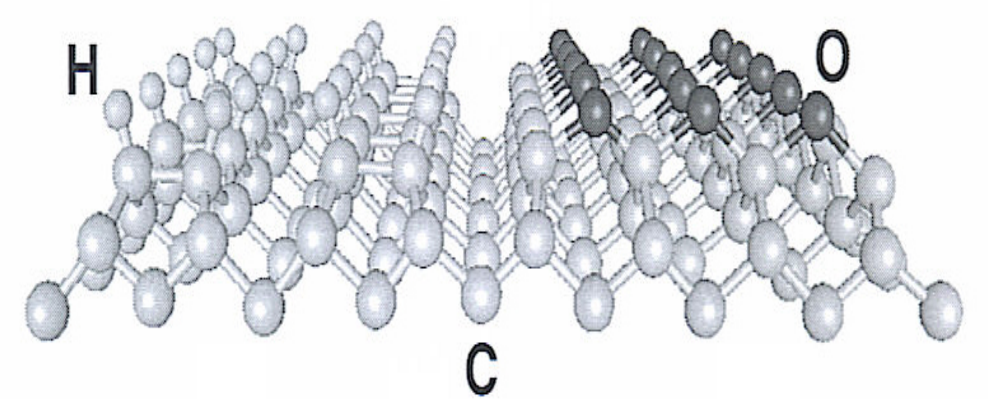

Figura 1.1: Superfícies de diamante (001) com terminações de hidrogênio (à esquerda) e com terminações de oxigênio (à direita) [6].

Superfícies hidrogenadas de diamante exibem eletroafinidade negativa, tornando-se suscetíveis a injeção de buracos por meio de adsorção de estruturas aceitadoras. As superfície nestas condições induzem uma condução na superfície do tipo $p$, mesmo em diamante não dopado, enquanto que superfícies oxidadas são isolantes [6,7]. A possibilidade das propriedades da superfície do filme depender da presença de moléculas adsorvidas permite o acesso in situ à informação a cerca de grupos moleculares que fazem parte do recobrimento da superfície, tornando o material atraente à aplicação em dispositivos como sensores e biosensores. Nos últimos anos, carbono e nanomateriais de carbono tem recebido uma atenção crescente para aplicação em ciências biológicas [8]. Estudos recentes em nanomateriais de carbono para 
aplicações biológicas revelaram que nanocristais de diamante são muito mais biocompátivel do que qualquer outro material de carbono, incluindo nanotubo de carbono [9].

A diferença entre superfícies de diamante hidrogenadas e oxidadas não se limita ás propriedades elétricas, mas inclui também a hidrofobia, a hidrofilia $[10,11]$ e a afinidade eletrônica da superfície [12].

Especificamente neste trabalho produzimos e caracterizamos superfícies de diamante com áreas seletivas oxidadas ou fluoradas a partir de superfícies originalmente hidrogenadas. As amostras foram caracterizadas por microscopia eletrônica de varredura (MEV ou SEM Scanning Electron Microscopy) microscopia de força atômica (AFM Atomic Force Microscopy), Kelvin Force Microscopy (KFM) e ainda através de medida de ângulo de contato. 


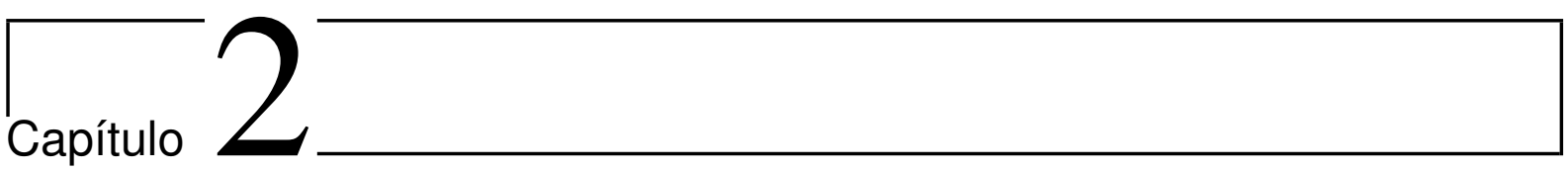

\section{MATERIAIS E MÉTODOS.}

A seguir apresentaremos os procedimentos experimentais usados na produção e caracterização das superfícies de diamante com diferentes terminações de superfície. Primeiramente, iremos abordar a deposição dos filmes de diamante no reator de deposição química a vapor (CVD Chemical Vapor Deposition. Em seguida, abordaremos os processos de litografia onde se gera um padrão sobre a superfície do diamante e este é utilizado para proteger algumas regiões e as demais serem posteriormente expostas a plasma para obtermos regiões adjacentes com diferentes terminações de superfície. A técnica de caracterização MEV (Microscopia Eletrônica de Varredura) que é baseada na medida do sinal de elétrons secundários para a formação das imagens será utiliza para identificarmos as regiões com diferentes terminações, desde que, este sinal apresenta contraste para as superfícies com diferentes propriedades elétricas.

\subsection{Deposição de Filmes de Diamante}

Inicialmente foram produzidos filmes de diamante através de deposição química a vapor por plasma de microondas. O reator utilizado foi inteiramente construído no Laboratório de Filmes Finos do Instituto de Física da USP (Processo FAPESP n ${ }^{0}$ 91/5214-8), estando em funcionamento desde 1993 [13].

Mais especificamente este sistema é conhecido como MPCVD (Microwave Plasma assisted Chemical Vapor Deposition). A radiação de microondas necessária para a produção de plasma é gerada por uma válvula magnetron operando em 2,45 GHz, com uma potência útil de $700 \mathrm{~W}$. A cavidade ressonante de microondas é cilíndrica (ver Figura 2.1), sendo sua lateral construída com uma folha de alumínio estampada com orifícios de $1 \mathrm{~mm}$ de diâmetro. Esta estampa, forma um tipo de malha que permite a observação do interior da cavidade, mas evita vazamento 
de microondas. O topo da cavidade consiste em uma placa circular onde se apóia a válvula magnetron. Esta placa pode ser movimentada na direção vertical através de quatro parafusos (ver Figura 2.1), variando a altura da cavidade. Assim, a sintonia da cavidade ressonante de microondas pode ser feita através da variação de sua geometria, aumentando ou diminuindo sua altura. A base da cavidade é uma placa de cobre resfriada com água e que possui as conexões para entrada e saída dos gases reagentes.

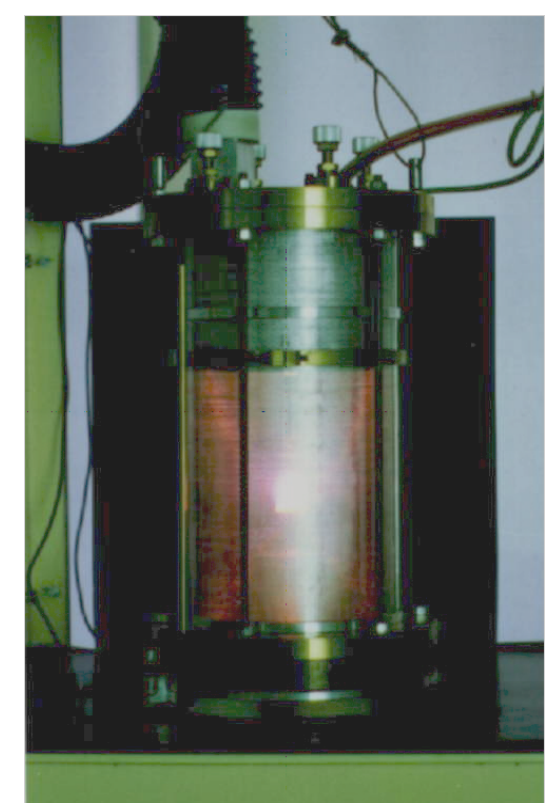

Figura 2.1: Cavidade ressonante de microondas. Sua lateral é construída com uma folha de alumínio estampada com orifícios de $1 \mathrm{~mm}$ de diâmetro. O topo da cavidade consiste em uma placa circular onde se apóia a válvula magnetron. Esta placa pode ser movimentada na direção vertical através de quatro parafusos.

O porta amostras (ver Figura 2.2) consiste em um cilindro de quartzo com $25 \mathrm{~mm}$ de diâmetro, fechado também em quartzo na parte superior, e colado a um tubo de latão na outra extremidade. A parte de quartzo é introduzida no interior da cavidade ressonante através de um orifício na base desta. O tubo de latão, que avança para o exterior da cavidade, possui um comprimento suficiente para que a intensidade da onda decaia a praticamente zero, evitando vazamentos de microondas. Desta forma temos um porta objeto de altura ajustável e transparente, permitindo a medição da temperatura da amostra através de um pirômetro.

A câmara de reação é formada por uma campânula de quartzo (ver Figura 2.3) apoiada sobre um anel de viton, na base de cobre da cavidade ressonante de microondas. No interior desta campânula, os gases reagentes são introduzidos pela base e guiados por um cilindro, também de quartzo, até o topo da amostra. Para tanto, a mistura de gases é introduzida na região externa ao cilindro e bombeada, também na base, mas no interior do cilindro de quartzo. 

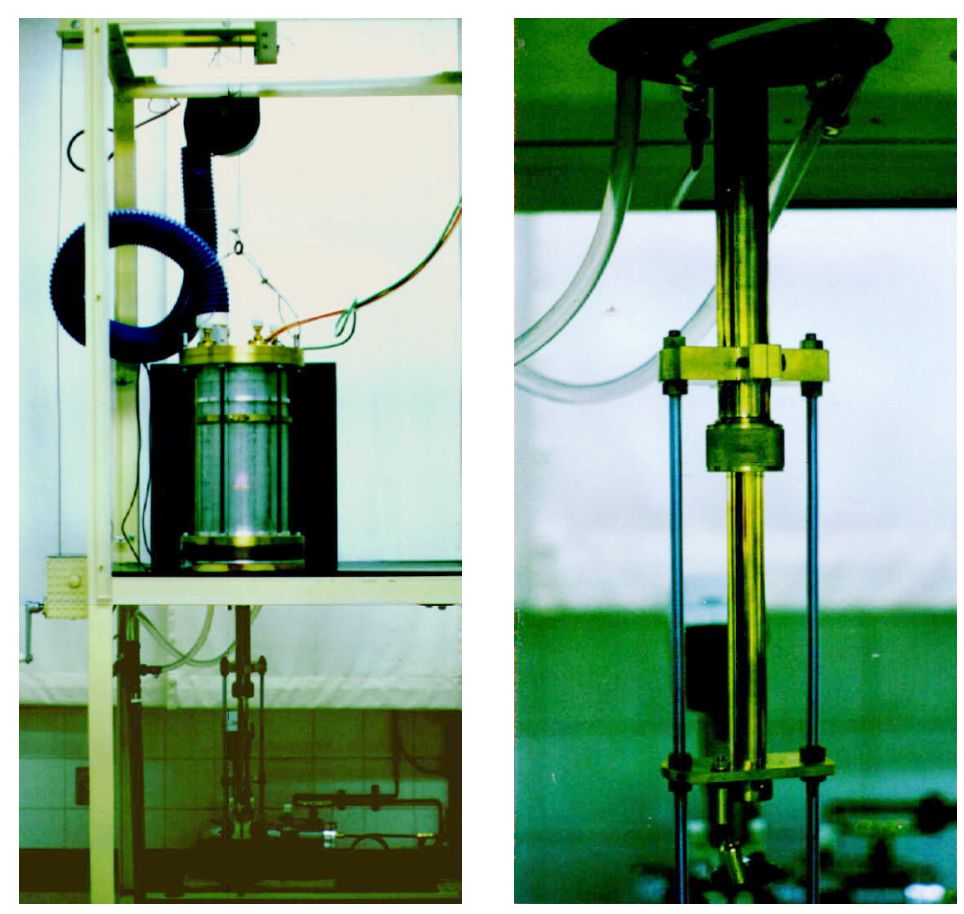

Figura 2.2: A foto da esquerda mostra o reator CVD completo, sendo que na porção de baixo se encontra o porta amostras. A foto da direita apresenta o ajuste de altura do porta amostras em detalhe.

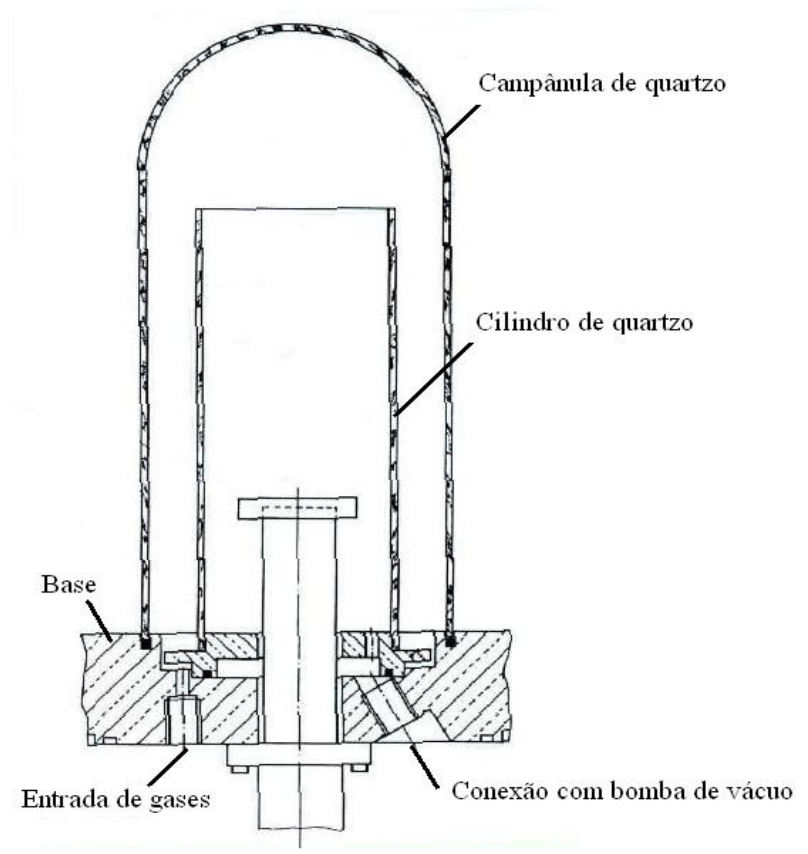

Figura 2.3: Câmara de reação formada por uma campânula de quartzo apoiada sobre a base da cavidade, um cilindro de quartzo que guia os gases reagentes até o topo da amostra, e o porta objeto ajustável, também de quartzo. 
Assim, a radiação de microondas entra na cavidade ressonante pela sua parte superior, formando um máximo de campo elétrico numa região interna à campânula, contendo os gases reagentes. A distribuição de campo pode ser ajustada com o equipamento em funcionamento através da variação da altura da cavidade ressonante. Os gases reagentes disponíveis no sistema são: hidrogênio, metano, argônio, nitrogênio e oxigênio. Os fluxos destes gases são controlados através de medidores de fluxo de massa (mass flow meters). A baixa pressão utilizada no sistema é obtida a partir de uma bomba mecânica e medida através de um sensor de membrana capacitiva. Utilizamos no processo de deposição a convencional mistura dos gases hidrogênio $\left(\mathrm{H}_{2}\right)$, metano $\left(\mathrm{CH}_{4}\right)$ e um porcentual de nitrogênio $\left(\mathrm{N}_{2}\right)$ com o intuito de obtermos diamante nano estruturado, como é mencionado na literatura $[14,15]$.

\subsection{Microscopia Eletrônica de Varredura (MEV) e o sistema de litografia.}

Na litografia por feixe de elétrons de média energia(entre 20 e $40 \mathrm{keV}$ ), utilizamos o Microscópio Eletrônico de Varredura Jeol 6460LV do Laboratório de Filmes Finos (ver especificações do equipamento Tabela 2.2). Ferramenta esta usada para a produção e caracterização do padrão a ser transferido para a amostra. O processo de litografia por feixe de elétrons depende de vários parâmetros e é composto de várias etapas, mas a priori, abordaremos o funcionamento do microscópio eletrônico de varredura, sendo este, de suma importância para que compreendamos o processo de litografia por feixe de elétrons.

Tabela 2.1: Principais características do Jeol 6460-LV e acessórios

\begin{tabular}{|c|c|}
\hline MEV Jeol 6460LV & Características \\
\hline Aumentos & $8 \mathrm{X}$ a $300.000 \mathrm{X}$ \\
\hline Corrente do feixe & $\sim 1 p A$ a $1 \mu A$ \\
\hline Resolução & $3 \mathrm{~nm}$ (alto vácuo) e $4 \mathrm{~nm}$ (baixo vácuo) \\
\hline Detectores & $\begin{array}{l}\text { Elétrons secundários e elétrons retroespalha- } \\
\text { dos }\end{array}$ \\
\hline Alto Vácuo (Máximo) & $0,1 \mathrm{mPa}\left(1 \times 10^{-6} \mathrm{mbar}\right)$ \\
\hline Baixo Vácuo (Ajustável) & 10 a $270 P a(0,1$ a 2,7 mbar $)$ \\
\hline \multicolumn{2}{|l|}{ Acessórios } \\
\hline $\begin{array}{l}\text { Microanálise química EDS } \\
\text { (Energy Dispersive X-ray } \\
\text { Spectroscopy) }\end{array}$ & $\begin{array}{l}\text { detecção de elementos a partir do boro } \\
\text { resolução de } 132 \mathrm{eV}\end{array}$ \\
\hline Sistema de Nanolitografia & $\begin{array}{l}\text { velocidade de escrita } 100 \mathrm{kHz} \\
\text { interruptor de feixe (acionamento em } 1 \mu \mathrm{s} \text { ) } \\
\text { campo máximo de transferência }(5 \mathrm{a} 10 \mathrm{~mm} \text { ) }\end{array}$ \\
\hline
\end{tabular}


Dentro de uma coluna em alto vácuo mostrada na Figura 2.4, os elétrons são gerados a partir de um catodo termiônico de tungstênio e acelerados em direção ao sistema óptico-eletrônico, por uma diferença de potencial entre catodo e ânodo de $0,3 \mathrm{kV}$ a $30 \mathrm{kV}$. O feixe gerado pelo canhão de elétrons passa por bobinas alinhadoras e posteriormente por lentes condensadoras que colimam o feixe e reduzem seu diâmetro. Bobinas de deslocamento corrigem o posicionamento do feixe de elétrons em $(x, y)$ e bobinas específicas corrigem o astigmatismo. As lentes objetivas focalizam o feixe sobre a superfície da amostra, que é montada em um estágio motorizado. Acima da lente objetiva existem dois estágios de bobinas eletromagnéticas, um é responsável pela varredura do feixe sobre a amostra e o outro é utilizado para deslocamentos finos.

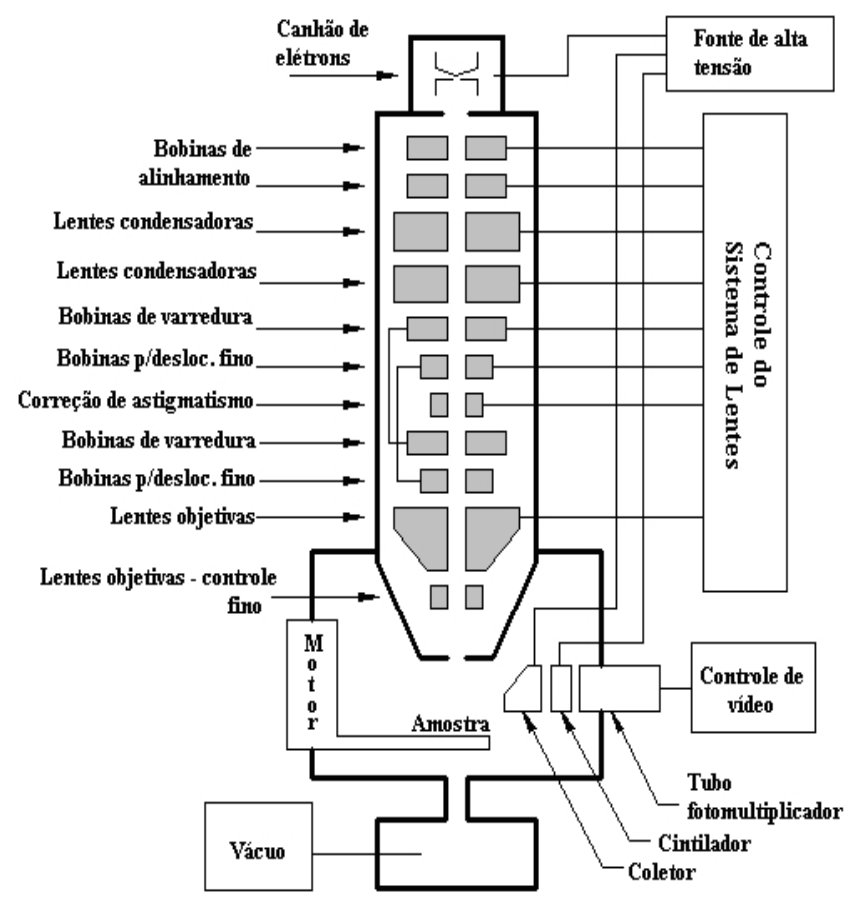

Figura 2.4: Coluna óptico-eletrônica de um Microcópio Eletrônico de Varredura.

\subsubsection{Espalhamento dos Elétrons em sólidos.}

Dependendo do material e da energia do feixe de elétrons, quando focalizado em uma pequena área da amostra, o feixe irá interagir numa profundidade de um a poucos micrômetros, criando o chamado volume de interação (ver Figura 2.5). Nessa interação uma série de sinais são gerados e podem ser utilizados para caracterizar propriedades, tais como; imagem topográfica, composição e informações cristalográficas.

Os elétrons retro espalhados e elétrons secundários são responsáveis pelos sinais que serão convertidos em imagem. Os elétrons do feixe que sofrem colisão elástica com os átomos da 


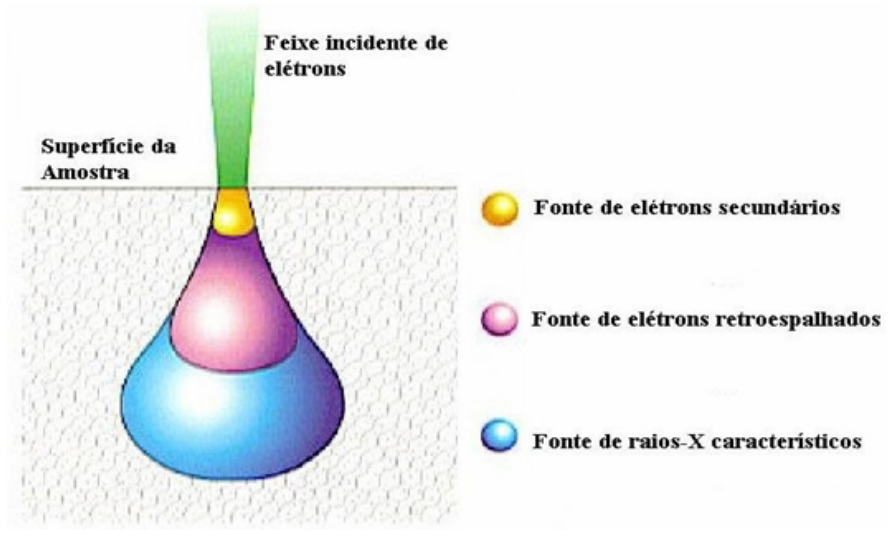

Figura 2.5: Volume de interação na amostra atingida pelo feixe de elétrons

amostra, sem alteração significativa da sua energia, são os elétrons retroespalhados. Interações inelásticas do feixe com a estrutura de banda do material geram uma série de sinail, sendo um deles o de elétrons secudários. Outros sinais gerados são raios-X contínuos, raios-X característicos e elétrons de Auger.

Para formação da imagem, o fluxo de informação do microscópio para o computador de controle consiste na localização dos pontos da varredura no plano $(x, y)$ com o conjunto de intensidades correspondentes, originadas pelo detector de elétrons retroespalhados ou pelo detector de elétrons secundários. O detector de elétrons retroespalhados é montado junto às lentes objetivas, Ele possui dois elementos semicondutores, os quais detectam os elétrons separadamente, de maneira que os sinais sejam processados e adicionados ou subtraídos para formar três tipos de imagens diferentes: sólida, topográfica e composicional. O detector de elétrons secundários utiliza um conjunto composto por coletor, cintilador, guia de luz e tubo fotomultiplicador para transformar os elétrons secundários em sinais elétricos [16]. Enquanto a amostra é varrida a uma determinada velocidade, a tela do display é varrida simultaneamente com correspondência de posições, utilizando as intensidades dos detectores para cada ponto, como esquematizado (ver Figura 2.6). Dependendo do sinal utilizado para formar a imagem, o contraste pode fornecer tanto a topografia quanto a distribuição de número atômico dos átomos na amostra. 


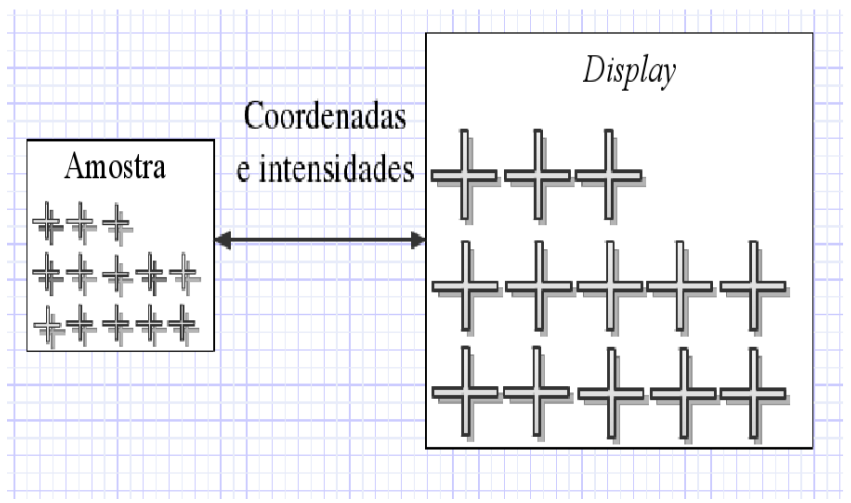

Figura 2.6: Ilustração esquemática da formação de imagem em um MEV.

\subsubsection{Sistema de Geração de Padrões Litográficos}

Acoplado ao MEV temos um sistema gerador de padrões o NPGS (Nanometer Pattern Generation System) que controla as bobinas de varredura através de computador e software dedicados. Esta ferramenta permite reproduzir desenhos de padrões pré-definidos sobre a superfície lisa de uma amostra, em escala micro ou nanométrica, utilizando o feixe de elétrons de MEV. As estruturas, que serão marcadas pelo feixe, são definidas utilizando-se, por exemplo, um software CAD (Computer Assisted Design). As coordenadas $(x, y)$ do desenho são transformadas em comandos que controlam o interruptor do feixe (beam blanking) e as bobinas de varredura do microscópio, manipulando-os de forma que o feixe de elétrons reproduza as coordenadas $(x, y)$ do desenho sobre a superfície da amostra para a geração do padrão. Temos um diagrama do sistema na Figura 2.7.

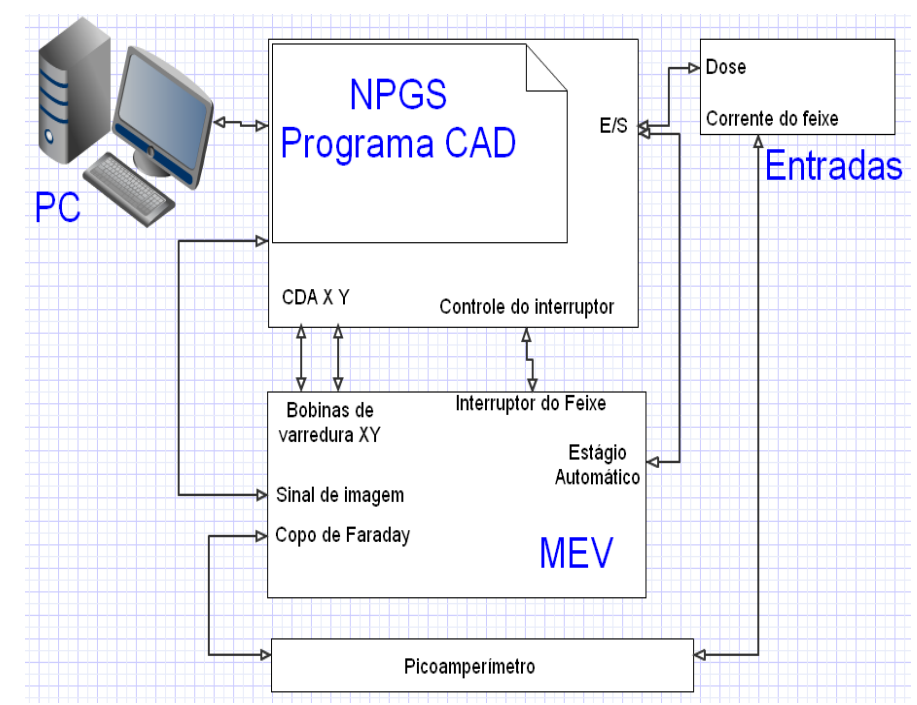

Figura 2.7: Ciclo de Controle do Sistema NPGS acoplado ao MEV. 


\subsection{Litografia por feixe de elétrons.}

A litografia, que vem do grego lithos (pedra) e graphein (escrever), é uma técnica antiga, contudo, com o seu desenvolvimento, devido à necessidade em micro eletrônica, ela é atualmente uma das ferramentas mais importantes nos processos de micro e nanofabricação [17]. Dentre os vários processos de litografia existentes, iremos abordar a litografia por feixes de elétrons [18]. A litografia por feixe de elétrons é uma técnica de transferência de padrões de alta resolução em que elétrons, com energia entre $10 \mathrm{keV}$ a $100 \mathrm{keV}$, são focalizados em um feixe bastante fino e usados para exposição em resistes sensíveis ao feixe de elétrons (elétronresistes) $[17,19]$.

\subsubsection{Elétrons-Resistes.}

A princinpal matéria-prima utilizada na litografia por feixe de elétrons são os elétronresistes, que são quase sempre polímeros orgânicos de alta massa molar. Quando um polímero orgânico é exposto à radiação eletrônica, a energia absorvida induz a mudanças químicas no polímero que afetam as suas propriedades físicas e químicas. Os elétrons-resistes são geralmente classificados como positivos ou negativos.

Quando são usados elétron-resistes positivos, as áreas expostas ao feixe tornam-se muito mais solúveis a uma solução química reveladora do que as áreas não expostas, de forma que essas regiões sensibilizadas devem ser completamente dissolvidas, e portanto retiradas, enquanto as outras permanecem praticamente intactas no tempo de revelação (ver Figura 2.8). O elétron-resiste positivo mais utilizado para litografia por feixe de elétrons, principalmente para alta-resolução, é o PMMA (Poli(metacrilato de metila)).

Quando a interação do feixe de elétrons com o polímero faz com que as cadeias adjacentes juntem-se para formar cadeias cruzadas, criando estruturas complexas, que têm um massa molar médio maior do que aquele original, o resiste é dito negativo. Quando a dose de irradiação é adequada, ocorrerem ligações cruzadas suficientes para que o material irradiado não seja dissolvido em solventes usados para remover o material não irradiado. Assim, as áreas irradiadas permanecem após a revelação com o solvente, enquanto que as áreas não irradiadas são removidas. Tais resistes negativos, como o SU-8, são muito utilizados quando se deseja obter estruturas com alta razão de aspecto (ver Figura 2.8). 


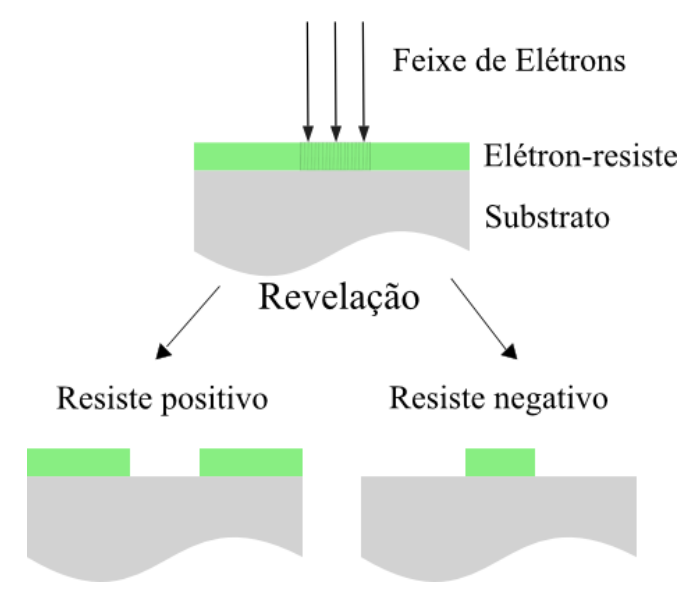

Figura 2.8: Ilustração mostrando a diferença entre elétron-resistes positivos e negativos.

Para um mesmo polímero teremos ligações cruzadas e a quebra das cadeias em diferentes graus. Se ambos ocorrem em quantidades aproximadamente iguais, o resiste terá características muito pobres. Os seguintes requisitos, para materiais elétron-resistes, são essenciais:

1 Alta resolução e contraste resultando em imagens menores que $100 \mathrm{~nm}$

2 Sensibilidade, medida pela carga incidente por unidade de área.

3 Facilidade de aplicar, dando filmes livres de ondulações e com boa adesão ao substrato desejado.

Os parâmetros acima descritos e os atributos do próprio MEV influenciam na resolução da litografia por feixe de elétrons, mas neste trabalho não abordaremos tais parâmetros, pois os padrões utilizados nas litografias foram da ordem de dezenas de micrômetro, com isso, não necessitamos de alta resolução para os mesmos, como será descrito adiante na seção 2.4.5.

\subsection{Preparação de amostras.}

\subsubsection{Polimento do Substrato}

Os substratos utilizados, foram lâminas de silicio (100) do tipo n com dimensões de $17 x 17 \mathrm{~cm}^{2}$ e espessura de 0,3-0,35 $\mathrm{mm}$. Estes substratos foram submetidos a um tratamento anterior à deposição para promover o chamado "seeding", que tem objetivo de produzir centros nucleadores através de polimento da superfície com pó de diamante [20,21]. As lâminas foram então, aderidas a um porta amostra com cera de abelha para que fossem polidas na politriz MINIMET 
BUEHLER® por 20 minutos em suspensão ${ }^{1}$ de diamante de $9 \mu \mathrm{m}$ e posteriormente por 10 minutos em suspensão ${ }^{2}$ de diamante de $1 \mu \mathrm{m}$. Estes tempos foram divididos em intervalos iguais de 2 minutos e 30 segundos para que fosse removido o material desbastado da superfície do substrato, lavando o mesmo em água corrente.

\subsubsection{Limpeza dos Substratos}

Para remoção de resíduos impurezas e desengorduramento das superfícies todos os substratos utilizados neste trabalho passaram pelo seguinte processo de limpeza, seguindo as seguintes etapas:

1 Xileno por 5 minutos em agitação ultra-sônica.

2 Tricloroetileno por 5 minutos em agitação ultra-sônica.

3 Acetona por 5 minutos em agitação ultra-sônica.

4 Álcool isopropílico por 5 minutos em agitação ultra-sônica.

Após a limpeza acima mencionada cada amostra foi levada ao equipamento CVD para deposição do filme de diamante.

\subsubsection{Recobrimento do Substrato com o Elétron-Resiste}

Estando a lâmina com diamante depositado faz-se o recobrimento da mesma com resiste, utilizando o spin coater (ver Figura 2.9). A lâmina é colocada no porta amostra desse equipamento, presa por vácuo, e um programa é rodado, o qual comanda o equipamento para executar determinada velocidade angular durante um tempo necessário. Assim a solução é espalhada de maneira uniforme na superfície do substrato. Neste trabalho foi utilizado o PMMA ARP671.06, de peso molar $950 \mathrm{~kg} / \mathrm{mol}$ e concentração 6, do fabricante Allresist e o SU-8 2002 do fabricante Micro Chem. Para PMMA, por exemplo, uma quantidade de cerca de $0,5 \mathrm{~cm}^{3}$ do polímero é pingada sobre a superfície, e a amostra é colocada pra girar durante $30 \mathrm{~s}$ a $4000 \mathrm{rpm}$, para gerar uma espessura de cerca de $200 \mathrm{~nm}$.

\footnotetext{
${ }^{1}$ Buehler $\AA$ METADI $囚$ Diamond Suspension $9 \mu m N^{\circ} 40-6533$

${ }^{2} 150 \mathrm{mg}$ de pó de diamante de 1 $\mu \mathrm{m}$ Man Made Insdustrial Diamand, $10 \mathrm{ml}$ de etanol
} 


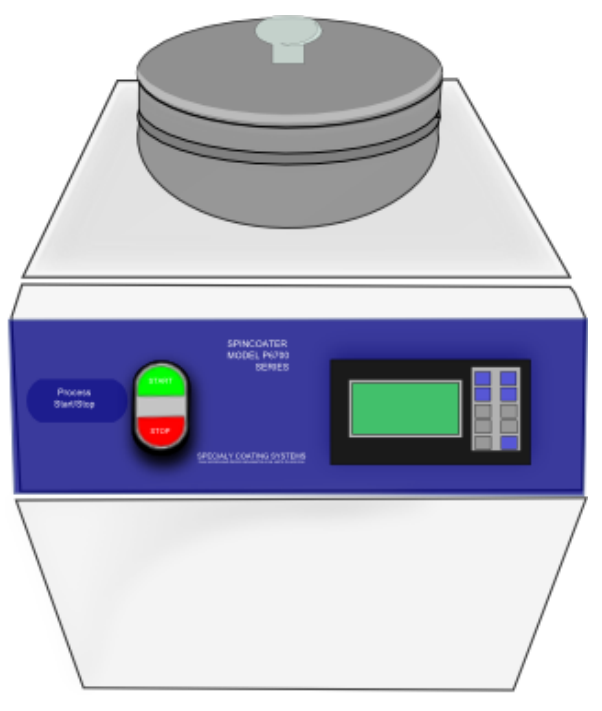

Figura 2.9: spin coater modelo P6700 da empresa Specialty Coating Sistems INC

\subsubsection{Secagem}

Após o recobrimento com PMMA a amostra foi seca durante 20 minutos utilizando uma placa quente a $180^{\circ} \mathrm{C}$, processo esse necessário para evaporação do solvente. Utilizou-se placa da Eletronic MicroSystems-Modelo 1000-1 que alcança temperatura máxima de 200, $0^{\circ} \mathrm{C}$ com precisão de $\pm 0,1^{\circ}$ instalada num ambiente de fluxo laminar.

No caso do SU-8 após o recobrimento devemos colocar a lâmina na placa quente a 65, $0 \pm$ $0,1^{\circ} \mathrm{C}$ durante 1 minuto, e em seguida colocar a lâmina numa outra placa quente a $95,0 \pm 0,1^{\circ} \mathrm{C}$ durante 2 minutos para pré-secagem do solvente.

\subsubsection{Geração de Padrões}

Os padrões são gerados em um software tipo CAD. O formato e dimensões do padrão dependerão da estrutura que se pretende fabricar. Como etapa seguinte, uma amostra de calibração deve ser desenhada e transferida sobre silício recoberto com o resiste para a determinação correta dos parâmetros. O padrão transferido para as superfícies (ver Figura 2.10), têm as seguintes dimensões, faixas de $50 \mu m \times 5 m m$ espaçadas de $465 \mu m$ no centro temos um array $7 \times 7$ de linha espaçadas de $45 \mu \mathrm{m}$. O segundo padrão utilizado foram faixas de $50 \mu \mathrm{m} \times 3 \mathrm{~mm}$ espaçadas de $150 \mu m$. 

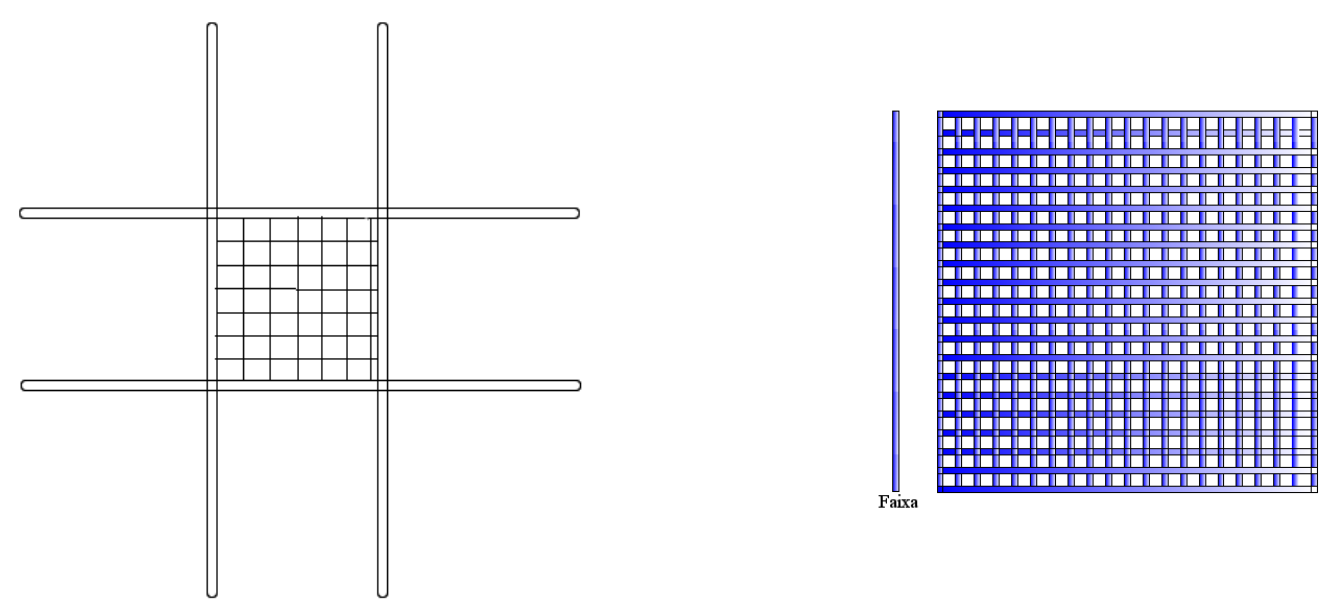

Figura 2.10: Na esquerda padrão utilizado na litografia por feixe de elétrons com $5 \times 5 \mathrm{~cm}^{2}$, $\mathrm{Na}$ direita padrão utilizado na litografia por feixe de elétrons com $3 \times 3 \mathrm{~cm}^{2}$

\subsubsection{Transferência de padrões}

A amostra foi levada a um microscópio eletrônico de varredura, com acessório para nanolitografia, e um padrão pré-estabelecido foi transferido para a superfície da amostra através de sensibilização por feixe de elétrons. Para isso precisamos conhecer alguns parâmetros de litografia como:

Dose em $\mu \mathrm{C} / \mathrm{cm}^{2}$,

Distância centro a centro de cada ponto do feixe,

Distância entre centro de linhas adjacentes,

Aumento do microscópio,

Corrente do feixe.

Antes de todo padrão ser transferido para a amostra, a corrente do feixe incidente deve ser medida. Para essa finalidade é utilizado um copo de Faraday (Faraday Cup). Um Faraday Cup consiste em um recipiente completamente fechado, com medidas conforme a Figura 2.11-a , exceto por um furo em uma lâmina de cobre, colada sobre o furo maior do cilindro de latão (ver Figura 2.11-b), com diâmetro de cerca de $75 \mu \mathrm{m}$ ( ver Figura 2.12). O Faraday cup portanto não permite que elétrons retroespalhados e secundários gerados pelo feixe incidente escapem. A corrente que escoa para o aterramento é, portanto exatamente igual à corrente de feixe incidente e é medida através de um picoamperímetro. É interessante perceber que a definição das 
estruturas muitas vezes será limitada pelo diâmetro do feixe, diretamente proporcional ao valor da corrente.
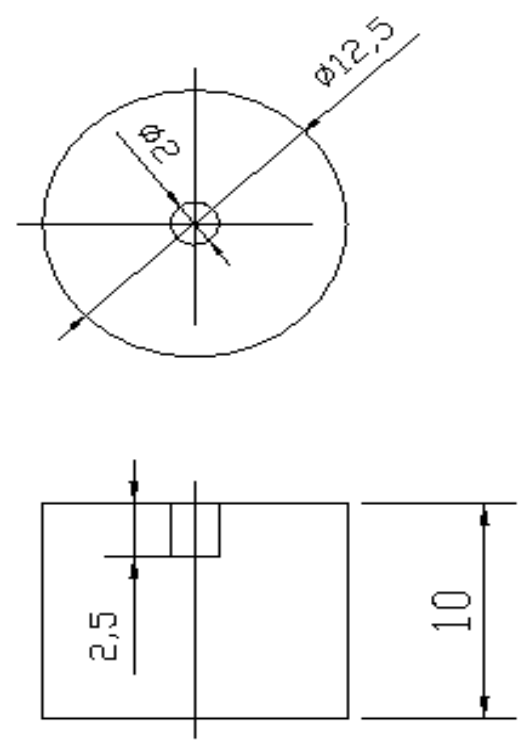

Figura 2.11: A figura da esquerda mostra as dimensões (em mm) de fabricação do Faraday Cup. A figura da direita apresenta o corte transversal do arranjo.

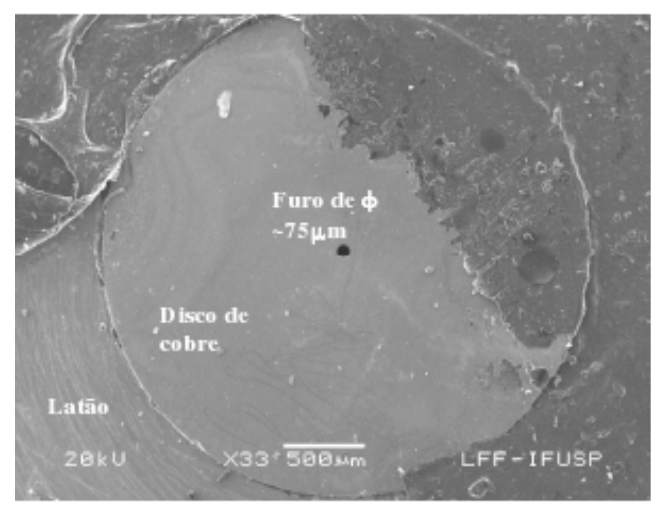

Figura 2.12: Micrografia do Faraday Cup em detalhes.

O campo de transferência é dependente do aumento do microscópio e também de uma constante C de calibração obtida com o NPGS que determina além do tamanho do campo, também a correta razão de aspecto, segundo expressão abaixo:

$$
\text { campo de transferência }(\mu m)=\frac{C}{\text { aumento }}
$$

Portanto, quanto maior o campo de transferência, menor deve ser o aumento do microscópio, que por sua vez depende da distância entre o final da lente objetiva e a superfície da amostra (distância de trabalho). Para as exposições, o aumento necessário foi de 18X, conseguido com 
uma distância de trabalho de $27 \mathrm{~mm}$ Os parâmetros de litografia utilizados para expor ao feixe de elétrons as amostras foram os seguintes:

Para o $1 \underline{0}$ padrão utilizado:

Corrente: $200 p A$

Dose de área: $100 \mu \mathrm{C} / \mathrm{cm}^{2}$

Distância centro a centro: $558,15 \mathrm{~nm}$

Distância entre centros de linhas adjacentes :558,15 $\mathrm{nm}$

e para o $2 \underline{\underline{Q}}$ padrão utilizado:

Corrente: $850 p A$

Dose de área: $100 \mu \mathrm{C} / \mathrm{cm}^{2}$

Distância centro a centro: 558, $15 \mathrm{~nm}$

Distância entre centros de linhas adjacentes :558,15 nm

\subsubsection{Revelação do Elétron-Resiste}

\section{Revelação do PMMA}

Terminada a transferência do padrão para a superfície, a amostra é retirada e deve ser revelada. Para isso, ela é mergulhada e agitada com moderação em uma solução reveladora. $\mathrm{O}$ revelador utilizado foi diluição de 1 parte de metilisobutilcetona em três partes de álcool isopropílico, seguido de enxague em álcool isopopílico por 30 segundos para cessar o processo de revelação. e é então seca com um jato de gás nitrogênio. Após terminada a revelação teremos a superfície dos filmes de diamante com regiões expostas que ainda permanecem hidrogenadas .

\section{Revelação do SU-8}

Terminada a transferência do padrão para a superfície, a amostra é retirada do MEV e levada para a placa quente a $65,0 \pm 0,1^{\circ} \mathrm{C}$ durante 2 minutos, seguindo é colocada na placa quente a $95,0 \pm 0,1{ }^{\circ} \mathrm{C}$ durante 2 minutos para pós-secagem do solvente. Para a revelação utilizou-se o revelador do SU-8 durante 2 minutos, agitando um pouco o béquer e mexendo a lâmina com a pinça, seguindo de enxague em álcool isopropílico durante $30 \mathrm{~s}$, agitando o béquer. E por fim a lâmina é seca no spinner. 


\subsection{Modificação da Superfície de Diamante}

Para que pudéssemos ter áreas adjacentes com diferentes terminações química de superfície, os filmes de diamante com regiões hidrogenadas foram litografados e submetidos a descarga de plasma. Para essa finalidade foi utilizado um canhão de plasma do Laboratório de Filmes Finos do tipo hollow-cathode e porta amostra dentro da câmara de vácuo [22]. O sistema possui duas bombas de vácuo sendo uma mecânica e uma de aprisionamento.A câmara de vácuo feita de aço inox tem as seguintes dimensões $90 \times 90 \times 45 \mathrm{~cm}^{3}$. Após pré-vácuo $\left(\sim 10^{-2}\right.$ Torr $)$ obtido com bomba mecânica seguido da bomba de aprisionamento obtêm-se o vácuo necessário para a modificação da superfície do diamante. O canhão de plasma é formado por um catodo, um eletrodo de partida, e uma malha de tungstênio como ânodo, a descarga ocorrendo entre catodo e ânodo. Os gases são conduzidos até o canhão de plasma através de um pequeno tubo plástico na parte anterior do canhão. Uma válvula agulha é utilizada para controlar a injeção de gás (ver Figura 2.13). A pressão é mantida dinamicamente, com entrada e saída contínuas do gás reagente, de forma a se manter de $10^{-4}$ a $10^{-5}$ Torr.

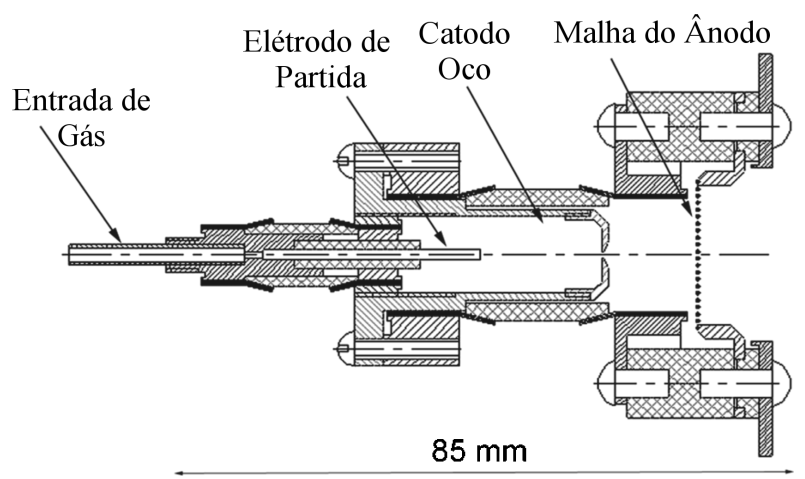

Figura 2.13: Ilustração esquemática do canhão de plasma.

\subsubsection{Modificação da Superfície de Diamante com tratamento de plasma de $\mathrm{O}_{2}$.}

A exposição ao plasma para modificação da superfície de diamante foi realizada com o canhão de plasma alimentado com $O_{2}$ operando a tensão DC de 750 a $800 \mathrm{~V}$, pressão de base de 2,0 $\times 10^{-4}$ Torr amostra litografada foi posicionada a $120 \mathrm{~mm}$ a frente do canhão de plasma e o tempo de exposição foi variado. Retirando a amostra do equipamento, após o tratamento, o remanescente do elétron-resiste foi removido com a amostra mergulhada por 2 minutos em acetona por agitação ultra-sônica e a superfície de diamante com áreas seletivas oxidadas foi concluída. 


\subsubsection{Modificação da Superfície de Diamante com tratamento de plasma de $S F_{6}$.}

As superfícies de diamante com terminações adjacentes de hidrogênio e flúor foram produzidas utilizando o mesmo canhão de plasma mencionado acima. A exposição ao plasma foi realizada com o canhão de plasma alimentado com hexafluoreto de enxofre $S F_{6}$, operando a tensão de 800 a $850 \mathrm{~V}$ DC e pressão de base de 7,5 $\times 10^{-3}$ Torr. A amostra litografada foi posicionada a $15 \mathrm{~mm}$ a frente do canhão e o tempo de exposição foi variado. Retirando a amostra do equipamento, após o tratamento, o remanescente do elétron-resiste foi removido com a amostra mergulhada por 2 minutos em acetona por agitação ultra-sônica e a superfície de diamante com áreas seletivas fluoradas foi concluída.

\subsection{Preparação das amostras contendo regiões adjacentes de flúor e oxigênio.}

Para produzirmos superfícies de diamante com terminações de flúor e oxigênio em regiões adjacentes, uma amostra de silício coberto com filme de diamante de $17 \times 17 \mathrm{~cm}^{2}$, logo após ser retirada do equipamento CVD, foi tradada com plasma de $S F_{6}$. Esse tratamento foi realizado utilizando o canhão de plasma e com os parâmetros descritos na seção 2.5.2. O tempo de exposição foi de 5 minutos, tempo este determinado a partir dos dados obtidos na seção 4.5. Seguindo, esta amostra foi então, recoberta com elétron-resiste e passa pelo processo de litografia descrito na seção 2.4 e 4 padrões de $3 \times 3 \mathrm{~mm}^{2}$ foram litografados no centro de cada quadrante (ver Figura 2.14).

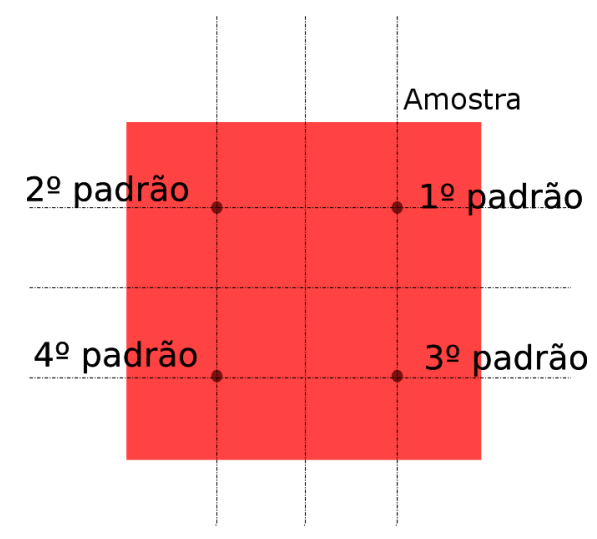

Figura 2.14: Esquema ilustrando a divisão da superfície para litografar vários padrões.

Terminado a litografia, a amostra foi clivada em 4 novas amostras de $8,5 \times 8,5 \mathrm{~cm}^{2}$ ainda recoberta com o remanescente do elétron-resiste. Essas amostras foram então tratadas em plasma 
de $\mathrm{O}_{2}$ utilizando novamente o canhão de plasma e os parâmetros descritos na seção 2.5.1. Foram usados diferentes tempos de exposição para as amostras. O remanescente do elétron-resiste foi removido com a amostra mergulhada por 2 minutos em acetona por agitação ultra-sônica e assim a superfície de diamante com áreas seletivas oxidadas a partir de superfícies fluoradas foi preparada. Apresentaremos os resultados obtidos para estas amostras na seção 4.6. 


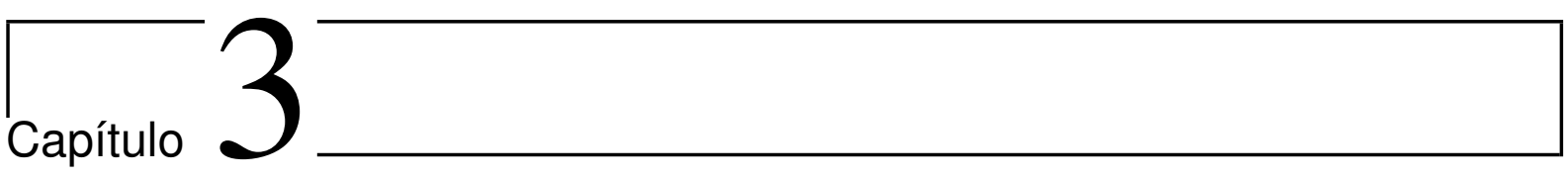

\section{TÉCNICAS DE CARACTERIZAÇÕES}

Apresentamos resumidamente as técnicas utilizadas neste trabalho para caracterização das superfícies produzidas a partir dos métodos descritos no capítulo 2. A priori utilizamos microscopia eletrônica de varredura convencional. Como mencionado anteriormente, as propriedades elétricas das superfícies de diamante oxidadas e hidrogenadas são consideravelmente distintas gerando assim, um contraste em imagens utilizando sinal de elétrons secundários (seção 2.2 na página 7). Inicialmente dar-se-á uma sucinta descrição da espectroscopia Raman e da difração de raios-X. Seguindo, será apresentada uma visão geral da técnica de Microscopia de Força Atômica, bem como, do Kelvin Force Microscopy . Por fim, são apresentados os modelos utilizados para calcular as energias livre de superfície para as diferentes terminações, onde, este é mensurado através da técnica de ângulo de contato, e a partir destas determinar as propriedades de molhabilidade das amostras.

\subsection{Espectroscopia de espalhamento Raman.}

A espectroscopia de espalhamento Raman é baseada no efeito Raman. O efeito Raman consiste no espalhamento da luz incidente, que após o processo de interação com os átomos do meio espalhador, apresenta frequências ligeiramente diferente da radiação incidente. Classicamente e de forma simplificada pode-se visualizar o espalhamento Raman como a interação de um campo elétrico da radiação incidente com os átomos de um meio espalhador, gerando um momento de dípolo induzido nestes átomos. $\mathrm{O}$ momento de dípolo induzido oscila com frequências $v_{0}$, $v_{0}+v_{k}$ e $v_{0}-v_{k}$, onde $v_{0}$ é a frequência da radiação incidente e $v_{k}$ é a frequência de vibração do átomo. As diferenças de frequência entre a radiação incidente e a espalhada constituem o espectro Raman. Essas diferenças correspondem às frequências de vibração dos átomos do 
material da amostra. A espectroscopia Raman oferece a vantagem de ser sensível não somente a um material cristalino, mas também às varias fases possíveis não cristalinas de um mesmo elemento químico. No caso do carbono, a eficiência do espalhamento Raman é cerca de quase duas ordens de grandeza maior par o grafite em relação ao diamante. Devido a isto, a espectroscopia Raman é um meio efetivo de detectar carbono grafítico como impureza, bem como outras formas de carbono amorfo em filmes de diamante. Espectroscopia Raman tem sido uma técnica muito usada para caracterizar filmes de diamante, pela sua sensibilidade e especificidade. $O$ diamante apresenta um pico Raman estreito e bem definido em torno de $1332 \mathrm{~cm}^{-1}$.

Os espectros Raman foram obtidos em um instrumento Renishaw Raman System 3000, equipado com um microscópio Olympus (BTH2) que por sua vez, possui um detector CCD acoplado, com uma capacidade de aumento de até 50x, levando a uma resolução espacial de cerca de 1 a $2 \mu m$ (técnica de micro-Raman). As amostras foram irradiadas com a linha de $632,8 \mathrm{~nm}$ de um laser He-Ne (Spectra Physics), e a potência do laser foi mantida em cerca de $0,7 \mathrm{~mW}$ na amostra. Os experimentos foram realizados em condições ambientes utilizando geometria de retroespalhamento.

\subsection{Difração de Raios-X.}

A estrutura dos monocristais é composta por um conjunto básico de átomos que se repetem com periodicidade tridimensional. A lei de Bragg estabelece que, no caso de se ter um feixe incidente monocromático, há direções para as quais o espalhamento produzido por todos os conjuntos básicos de átomos estão "em fase" e produzem picos estreitos de "difração". Para que isso aconteça, a diferença de caminho ótico entre os raios associados ao feixe espalhado deve ser igual a um número inteiro de comprimentos de onda da radiação incidente. Essa condição é satisfeita quando se verifica a lei de Bragg, a qual envolve duas relações:

$$
\begin{gathered}
\theta=\theta_{i}=\theta_{r} \\
2 d \sin \theta=n \lambda
\end{gathered}
$$

onde $\theta_{i}$ é o ângulo de incidência, $\theta_{r}$ o ângulo de reflexão, $\lambda$ é o comprimento de onda da radiação incidente e $d$ a distância interplanar associada às diversas "famílias" de planos cristalográficos [23-25]. 
As medidas de $X$-ray-diffraction (XRD) foram feitas na geometria $\theta-2 \theta$, em um difratômetro Rigakuß, potência dada por $I=20 \mathrm{mAe} V=40 \mathrm{KV}$, usando uma radiação monocromática de $C u K_{\alpha}(\lambda=0,15418 \mathrm{~nm})$, com passo de varredura de $\Delta 2 \theta=0,05^{\circ}$ e tempo de contagem de $30 \mathrm{~s}$.

\subsection{Microscopia de Força Atômica.}

Todos os dias de nossas vidas obtemos informações dos objetos tocando suas superfícies com nossos dedos. Além da rugosidade da superfície podemos sentir também propriedades tais como elasticidade, atrito, dureza, temperatura e granularidade. Estas propriedades podem ser analisadas em uma escala milhões de vezes menor, por meio do Scanning Probe Microscopy (SPM). No SPM uma sonda com dimensões apropriadas varre a superfície da amostra, registrando ponto a ponto interação entre a ponta e a superfície da amostra (ver Figura 3.1)[26]. SPM é frequentemente usado para estudar a topografia das superfícies por meio de um feedback que mantém a força entre a ponta e a superfície da amostra constante. Nos últimos anos a família de métodos do SPM tem sido expandida e vários modos e princípios de operação têm sido obtidos para caracterização de diferentes propriedades dos mais diversos tipos de materiais. As técnicas de AFM (Atomic Force Microcopy) e KFM (Kelvin Force Microscopy) fazem parte da família do SPM.

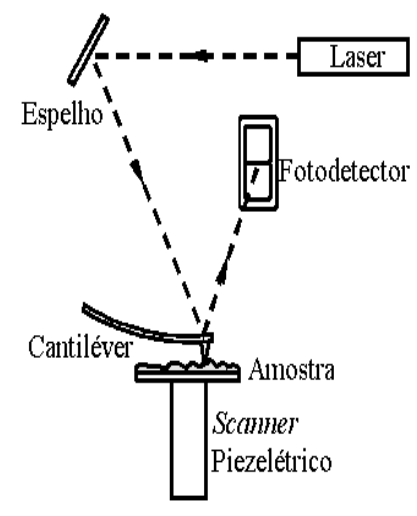

Figura 3.1: Esquema ilustrativo do funcionamento do AFM.

Os dois modos básicos de operação do SPM são:

Microscopia de Tunelamento (STM Scanning Tunneling Microscopy) e

Microscopia de Força Atômica (AFM - Atomic Force Microscopy).

Atualmente existe uma infinidade de modos de operação para um SPM, sendo alguns deles: 
Magnetic Force Microscopy (MFM),

Electric Force Microscopy (EFM),

Kelvin Force microscopy (KFM) etc.

A caracterização por AFM Atomic Force Microcopy KFM [27] foi realizada num Scanning Probe Microscope NanoScope $\AA$ III MultiMode ${ }^{T M}$ comercial com Extender ${ }^{T M}$ Eletronics Module da Digital Instruments. Na técnica de AFM teremos informações morfológicas da superfície, enquanto que a KFM viabiliza mapear a superfície medindo a diferença de potencial entre diferentes regiões. A literatura apresenta variações de potencial medidas por KFM em superfície de diamante parcialmente oxidada [6], o que identifica essa técnica como de grande importância neste trabalho. A seguir serão descritos os princípios de funcionamento dos modos que serão utilizados neste trabalho.

\subsubsection{Descrição dos Modos AFM}

O AFM se subdivide em três modos:

AFM de contato

AFM de contato intermitente

AFM de não-contato

Mais especificamente serão utilizados os dois primeiros modos.

\subsubsection{Descrição do Modo AFM de Contato}

Neste modo de operação, a sonda consiste em uma ponta presa a um cantiléver, que se mantém em contato com a superfície da amostra durante toda a varredura [28], como indica a Figura 3.2. Quando a ponta varre a superfície da amostra, passa por pontos de diferentes alturas, gerando variações na deflexão do cantiléver. Estas deflexões são medidas através de um feixe de laser refletido na ponta do cantiléver, chegando até um fotodetector. Através de um feedback com um computador, a deflexão do cantiléver é mantida constante durante a varredura, movendo o cantiléver verticalmente, a cada ponto. A posição vertical do cantiléver, juntamente com a posição $(x, y)$ correspondente, é armazenada em computador formando, ao final da varredura, a imagem topográfica da superfície da amostra. 


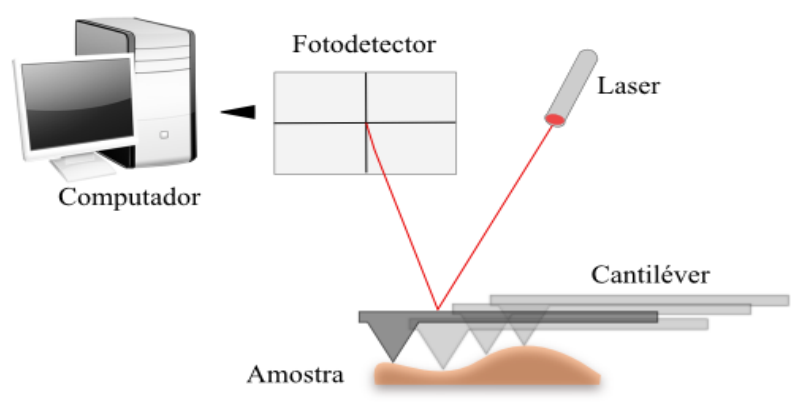

Figura 3.2: Esquema apresentando o princípio básico de funcionamento de um AFM de contato.

Note que, mantendo a deflexão do cantiléver constante, a força entre ponta e amostra também se mantém constante e dada por: $F=-k \cdot x$ (lei de Hooke), onde $F$ é o módulo da força que a ponta exerce sobre a amostra, $k$ é a constante de mola associada à deformação do cantiléver, e $x$ é a deflexão do cantiléver. Sendo $k$ entre 0,01 e $1,0 \mathrm{~N} / \mathrm{m}$ a força resultante está entre $n N$ e $\mu N$.

\section{Descrição do AFM de Contato Intermitente}

Nesse modo de operação a sonda consiste em uma ponta presa a um cantiléver oscilante que, durante a varredura, toca a superfície da amostra no ponto de máxima amplitude de oscilação. O cantiléver oscila em sua frequência de ressonância, ou próximo dela, com uma amplitude típica entre $20 \mathrm{~nm}$ e $100 \mathrm{~nm}$. Durante a varredura, a ponta oscilante passa por diferentes alturas da amostra, gerando variações na amplitude de oscilação da ponta. A amplitude de oscilação da ponta é definida, na verdade, pelo seu RMS (root mean square), que é obtido através do sinal gerado no fotodetector pelo feixe de laser refletido no cantiléver. Através de um feedback com um computador, o RMS da amplitude de oscilação da ponta é mantido constante durante a varredura, movendo o cantiléver verticalmente, a cada ponto. Assim, a posição vertical do cantiléver, juntamente com a posição $(x, y)$ correspondente, é armazenada em computador formando, ao final da varredura, a imagem topográfica da superfície da amostra. Note que neste caso, o contato entre ponta e amostra é bastante delicado, sendo um modo de operação indicado para amostras frágeis [28].

\subsubsection{Kelvin Force Microscopy (KFM)}

O modo KFM teve origem na técnica de Kelvin Probe, nome em alusão a William Thomson, também conhecido como Lord Kelvin, que foi o primeiro a introduzí-la em 1898, para explicar a formação de uma diferença potencial de contato nos metais [29]. A diferença de potencial 
de contato (Contact Potencial Difference-CPD) ocorre quando duas superfícies são colocas em contato elétrico e o equilíbrio termodinâmico é obtido [30]. No Kelvin Force Microscopy é registrado a interação eletrostática entre a superfície da amostra em estudo e a sonda, uma ponta piramidal presa a um cantiléver [29].

Para entender o que ocorre em uma superfície que apresente diferença de potencial em regiões adjacentes, vamos tomar como exemplo duas placas de metal separadas por uma pequena distância no vácuo. É conhecido que os elétrons livres de um metal são confinados por forças elétricas, o que dá origem a uma barreira de potencial de superfície. A função de trabalho $\phi$ é definida como a energia necessária para remover um elétron do metal, ou seja, é a diferença entre a energia do nível de Fermi de um metal e a energia de um elétron livre no vácuo $\left(E_{v a c}\right)$. Na Figura 3.3-a é apresentado o diagrama de energia para as placas M1 e M2. No diagrama estão indicadas as energias de Fermi $\left(E_{F 1} e E_{F 2}\right)$ e as funções de trabalho $\left(\phi_{1} e \phi_{2}\right)$ das placas metálicas, quando estão eletricamente desconectadas.

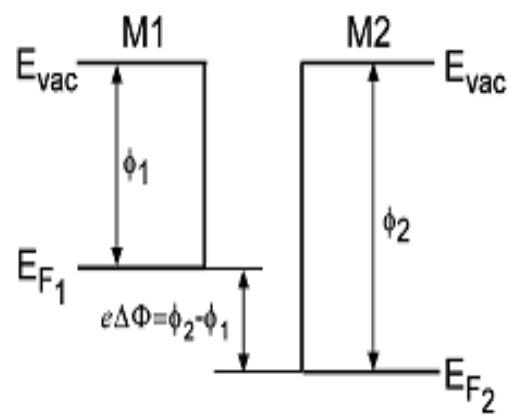

(a)

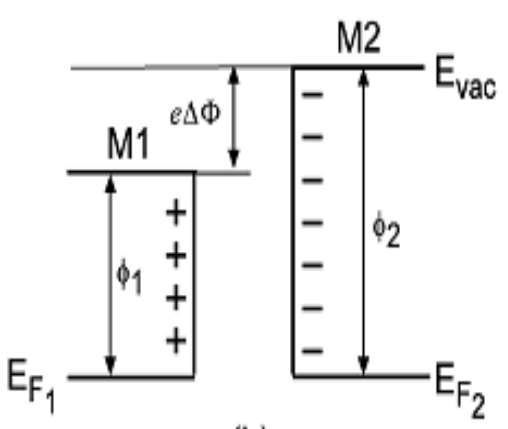

(b)

Figura 3.3: Diagrama de Energia dos elétrons de duas placas de metal (M1 e M2) (a) eletricamente desconectadas (b) eletricamente conectadas.

Conectando eletricamente as duas placas, após o equilíbrio termodinâmico ser obtido, as energias dos níveis de Fermi dos dois metais serão alinhadas (ver Figura 3.3-b). Este alinhamento entre os níveis de Fermi é obtido pelo fluxo de elétrons da placa com a função de trabalho mais baixa (M1) para a placa com função trabalho mais elevada (M2). Notamos que neste processo a superfície de M1 é positivamente carregada, enquanto que a superfície de M2 ficará negativamente carregada. Assim uma diferença de potencial entre a duas placas é criada, sendo dada por $\Delta \Phi=\left(\phi_{1}-\phi_{2}\right) / e[30]$.

Passaremos agora a descrição do modo de operação do KFM. Para a aquisição de imagens no modo KFM, é utilizado um recurso denominado interleave, que consiste na obtenção de duas modalidades diferentes de imagens simultaneamente, numa mesma área de varredura. Como 
podemos ver na figura 3.4-a, quando o modo interleave está desabilitado, a ponta varre uma linha de traço (ida) e retraço (volta) na direção de varredura rápida obtendo o mesmo tipo de informação, tanto na ida como na volta, e realiza a varredura lenta na direção perpendicular, efetuando passos cujo avanço corresponde ao tamanho de pixel da imagem. Quando o modo interleave é habilitado figura 3.4-b, inicialmente o sistema realiza uma varredura de ida e volta, como o padrão, mas avançando apenas metade do tamanho de pixel na direção da varredura lenta; em seguida realiza outra varredura de ida e de volta, mas agora obtendo informações diferentes da varredura ida e volta anterior. Dessa forma é possível se obter duas imagens, em modos diferentes, mas precisamente na mesma região. No modo KFM, durante a primeira varredura obtém-se uma imagem de AFM de contato intermitente, e na varredura de interleave obtém-se a imagem de KFM. Note que, na segunda varredura, o modo interleave utiliza o lift mode com lift height de $25 \mathrm{~nm}$, onde a ponta realiza uma varredura mantendo uma distância fixa da superfície, da ordem de algumas dezenas de nanômetros, acompanhando o perfil da amostra, desde que esse perfil já foi obtido na varredura padrão anterior. Para a obtenção do KFM durante a varredura de interleave, o transdutor que coloca o cantiléver para vibrar é desligado e um potencial oscilante $V_{A C}=\operatorname{sen}(\omega \cdot t)$ é aplicado à ponta, com a frequência de ressonância mecânica $\omega$ do cantiléver. Note que a ponta deve estar eletricamente isolada da amostra e irá varrer a superfície da amostra sem tocá-la. Com esse procedimento, quando a ponta passa próximo de regiões da amostra que apresentem potencial elétrico estático, a ponta oscilará devido a uma força elétrica oscilante criada entre ponta e amostra na frequência de ressonância do cantiléver. Considere ainda que, superposto a esse potencial oscilante, uma tensão contínua (DC) seja também aplicada à ponta de forma a levá-la ao mesmo potencial local da amostra. Então a força oscilante não mais estará presente entre ponta e amostra, cessando o movimento oscilatório da ponta. Assim, ponto a ponto da varredura, a ponta fica sujeita ao potencial oscilante $V_{A C}=\operatorname{sen}(\omega \cdot t)$ até que a ponta seja colocada para oscilar, então o microscópio aplica uma tensão DC até que essa oscilação cesse, obtendo assim o potencial local da amostra. Esse potencial é registrado em memória juntamente com a posição $(x, y)$ da medida e, ao final da varredura, teremos duas imagens: uma correspondente à morfologia da amostra e outra, precisamente no mesmo local, mapeando o potencial elétrico da superfície.

\subsection{Montagem para realizar medidas de AFM/KFM em at- mosfera controlada}

Como já descrito anteriormente, os modos AFM e KFM são utilizados simultaneamente. Para as medidas de KFM foi necessário o uso de um acessório que permite atmosfera contro- 


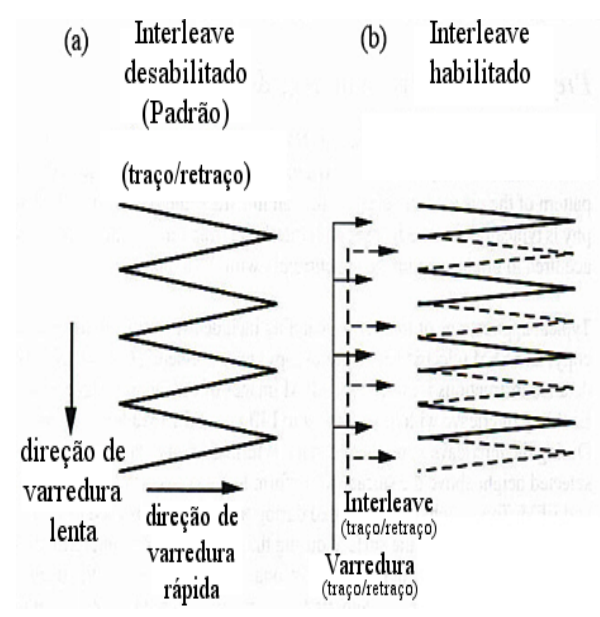

Figura 3.4: Descrição do recurso interleave que permite a obtenção de duas modalidades diferentes de imagem simultaneamente, numa mesma área de varredura. (a) Interleave desabilitado e (b)interleave habilitado.

lada. Esse acessório consiste basicamente de uma campânula de acrílico que reveste todo o conjunto: scanner, cabeça, cantiléver e amostra. Essa campânula, em nosso caso, foi usada para controlar a umidade local na região onde a amostra está localizada. Isso foi feito através da purga com um gás inerte de umidade controlada passando pelas conexões fornecidas pelo acessório. A pressão a que a amostra está sujeita é a atmosférica, desde que o gás é inserido na campânula em uma das conexões e extravasa em outra, aberta à atmosfera. O fluxo de gás adequado depende de sua aplicação específica, mas em geral um fluxo de cerca de $2 \mathrm{~L} / \mathrm{min}$ pode ser usado para purga inicialmente e depois baixa-se para menos de $1 \mathrm{~L} / \mathrm{min}$, uma vez que o equilíbrio termodinâmico é obtido, para um melhor desempenho em termos de ruído. Na figura 3.5-a é possível ver o equipamento sem o acessório e na figura 3.5-b com o acessório instalado. Na figura 3.5-b é possível ver também a entrada do gás mostrado em vermelho com o número 1 e a saída mostrado em vermelho com o número 2. Controlou-se o fluxo de entrada através de um rotâmetro para que houvesse uma vazão de $1 \mathrm{~L} / \mathrm{min}$. Com o intuito de se eliminar a umidade adsorvida à superfície dos filmes de diamante, as medidas de KFM foram realizadas em atmosfera de hélio. A primeira varredura da sonda sobre a superfície foi realizada sob condições ambiente. Seguindo, a campânula era colocada sobre todo conjunto; scanner, cabeça, cantiléver e amostra. Os parâmetros relacionados à oscilação da sonda são ajustados novamente, o que é imposto pela mudança do gás em que ela está imersa. O equipamento foi então configurado para armazenar continuamente cada varredura da sonda, sob tais condições, até que o sistema estabilizasse. A partir destes dados conseguimos gerar gráficos das diferenças de potencial existentes entre as regiões de diferentes terminações, a medida que a amostra era purgada com gás hélio. 

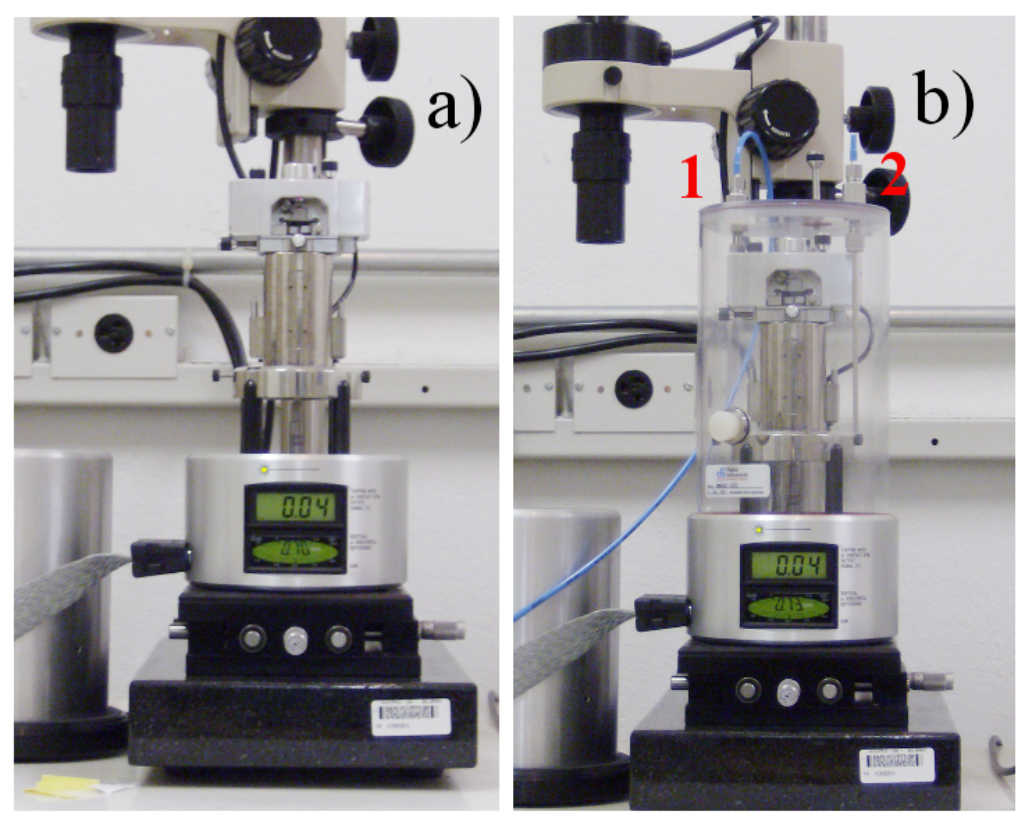

Figura 3.5: Imagem ilustrando a câmpanula de controle atmosférico do equipamento AFM.

\section{5 Ângulo de Contato e Energia Livre de Superfície}

A molhabilidade de uma superfície depende do equilíbrio termodinâmico entre um sistema de três interfaces: sólido, líquido e vapor. Assim, para se estudar a molhabilidade de uma superfície coloca-se uma gota de um líquido de interesse sobre a mesma e determina-se o ângulo de contato. $\mathrm{O}$ ângulo de contato representa uma medida quantitativa do processo de molhabilidade. Este é definido como o ângulo entre um plano tangente a uma base da gota do líquido e um plano contendo a superfície onde o líquido se encontra depositado, conforme esquematizado na figura 3.6.

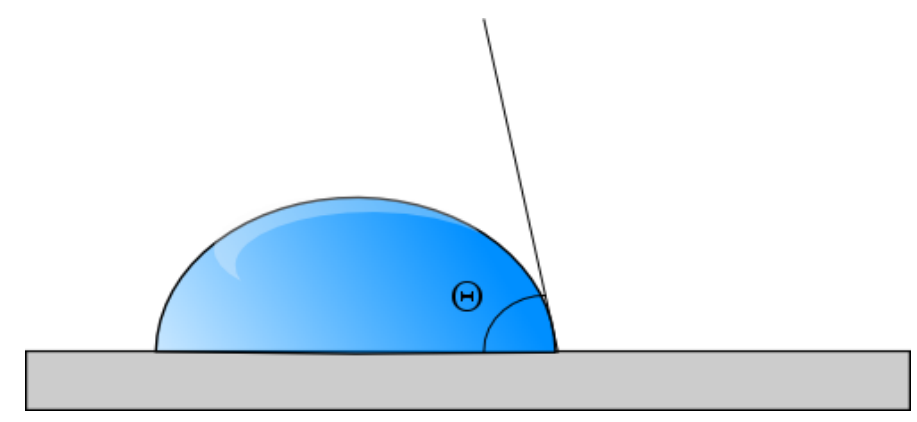

Figura 3.6: Esquema ilustrando as interfaces sólido/líquido, sólido/vapor e líquido/vapor e indicando a formação do ângulo de contato 
A equação de Young [31-37]:

$$
\gamma_{S L}=\gamma_{S V}-\gamma_{L V} \cdot \cos (\Theta)
$$

relaciona o ângulo de contato definido anteriormente com as energias livres de superfície das interfaces sólido/líquido $\gamma_{S L}$, sólido/vapor $\gamma_{S V}$ e líquido/vapor $\gamma_{L V}$. As grandezas $\gamma_{L V}$ e $\Theta$ podem ser obtidas experimentalmente e $\gamma_{S L}$ pode ser obtido a partir dessas medidas, através da equação 3.3. Para essa finalidade, muitos métodos têm sido desenvolvido baseados na consideração de forças intermoleculares [32].

Uma suposição básica é considerar que $\gamma_{S L}$ é um parâmetro que depende das propriedades do sólido e do líquido sonda. Assim teremos a chamada equação de estado:

$$
F\left(\gamma_{S V}, \gamma_{L V}, \gamma_{S L}\right)=0
$$

ou

$$
\gamma_{S L}=f\left(\gamma_{S V}, \gamma_{L V}\right)
$$

que são temas de numerosos estudos.

No fim do século 19 Berthelot $^{1}$ iniciou seus estudos assumindo que o trabalho de adesão interfacial $W_{S L}$ era igual à média geométrica do trabalho de coesão do sólido $W_{S S}$ e o trabalho de coesão do líquido sonda $W_{L L}$ :

$$
W_{S L}=\sqrt{W_{S S} \cdot W_{L L}}
$$

O trabalho de coesão, $W_{S S}$ por exemplo, é definido como o trabalho necessário para separar 2 superfícies de área unitária de um dado material mediante uma tensão superficial $\gamma$ aplicada [39]. Considerando $W_{S S}=2 \cdot \gamma_{S V}$ e $W_{L L}=2 \cdot \gamma_{L V}$ [40] e ainda que [34, 40]:

$$
W_{S L}=\gamma_{S V}+\gamma_{L V}-\gamma_{S L}
$$

\footnotetext{
${ }^{1}$ Pierre-Eugène-Marcellin Berthelot, foi um químico e político francês. Ficou conhecido pelo principio de termo-química Thomsen-Berthelot. Sintetizou vários compostos orgânicos de substâncias inorgânicas e refutou a teoria do vitalismo. Ele é considerado como um dos grandes químicos de todos os tempos [38]
} 
onde $W_{S L}$ é o trabalho de adesão. O trabalho de adesão é definido de forma similar ao trabalho de coesão, que é o trabalho necessário para separar uma área unitária de interface entre dois materiais [39]. Substituindo as expressões para os trabalhos de coesão na equação 3.7 temos;

$$
\gamma_{S L}=\gamma_{S V}+\gamma_{L V}-2 \sqrt{\left(\gamma_{S V} \cdot \gamma_{L V}\right)}
$$

a equação 3.8 é um ponto essencial de partida para dedução das relações que permitem deter$\operatorname{minar} \gamma_{S L}$.

Em 1964, Fowkes sugeriu que a componente de energia livre de superfície de um sólido $\gamma_{S V}$ (e do líquido sonda $\gamma_{L V}$ ) fosse dividida na soma de componentes independentes. Assim para cada componente será associada com uma interação específica:

$$
\gamma_{S V}=\gamma_{S V}^{d}+\gamma_{S V}^{p}+\gamma_{S V}^{h}+\gamma_{S V}^{i}+\gamma_{S V}^{a b}+\gamma_{S V}^{o}
$$

onde $\gamma_{S V}^{d}, \gamma_{S V}^{p}, \gamma_{S V}^{h}, \gamma_{S V}^{i}, \gamma_{S V}^{a b}$ são as componentes de dispersão, polar, hidrogênio (relacionado as ligações de hidrogênio), indução, ácido-base, respectivamente e $\gamma_{S V}^{o}$ se refere a todas as demais interações. De acordo com Fowkes a componente dispesiva $\gamma_{S V}^{d}$ está relacionada com interações do tipo London, decorrente de flutuações eletrônicas. Estas interações são do tipo dipolo-dipolo e ocorrem comumente nos materiais sendo resultado da atração entre os átomos e moléculas adjacentes. As forças de London dependem do tipo de elementos que se atraem mutuamente nos materiais e são independentes de outros tipos de interações [40, 41]. As demais componentes são interações do tipo Van der Waals. As principais investigações de Fowkes foram em sistemas em que aparecem apenas interações dispersivas. Considerando tais sistemas Fowkes determinou a energia livre de superfície da interface sólido/líquido como sendo:

$$
\gamma_{S L}=\gamma_{S V}+\gamma_{L V}-2 \sqrt{\left(\gamma_{S V}^{d} \cdot \gamma_{L V}^{d}\right)}
$$

Owens e Wendt extenderam a aproximação de Fowkes e assumiram que a soma de todas as componentes da equação 3.9, exceto $\gamma_{S V}^{d}$, podem ser consideradas como interações do tipo polar $\gamma_{S V}^{p}$. Consequentemente a equação 3.10 é modificada e obtendo-se [40, 41]:

$$
\gamma_{S L}=\gamma_{S V}+\gamma_{L V}-2\left(\sqrt{\gamma_{S V}^{d} \cdot \gamma_{L V}^{d}}+\sqrt{\gamma_{S V}^{p} \cdot \gamma_{L V}^{p}}\right)
$$


Substituindo a equação 3.3 em 3.11 teremos:

$$
1+\cos (\Theta)=2 \sqrt{\gamma_{S V}^{d}}\left(\frac{\sqrt{\gamma_{L V}^{d}}}{\gamma_{L V}}\right)+2 \sqrt{\gamma_{S V}^{p}}\left(\frac{\sqrt{\gamma_{L V}^{p}}}{\gamma_{L V}}\right)
$$

um gráfico de $\left(\frac{1}{2} \frac{\gamma_{L V}}{\gamma_{L V}^{d}}\right)\left(1+\cos (\Theta)\right.$ em função de $\left(\frac{\sqrt{\gamma_{L V}^{p}}}{\sqrt{\gamma_{L V}^{d}}}\right)$ deverá produzir uma reta, de onde pode-se obter as componentes dispersiva $\gamma_{S V}^{d}$ e não dispersiva $\gamma_{S V}^{p}$ do sólido em estudo [41].

Wu aceitou a idéia de Owens e Wendt que dividia a energia livre de superfície em duas componentes, mas ao invés de média geométrica ele usou média harmônica das interações interfaciais. Wu chegou então a seguinte equação:

$$
\gamma_{S L}=\gamma_{S V}+\gamma_{L V}-4\left(\frac{\gamma_{S V}^{d} \cdot \gamma_{L V}^{d}}{\gamma_{S V}^{d}+\gamma_{L V}^{d}}+\frac{\gamma_{S V}^{p} \cdot \gamma_{L V}^{p}}{\gamma_{S V}^{p}+\gamma_{L V}^{p}}\right)
$$

As equações 3.11 e 3.13 são conhecidas como média geométrica e média harmônica da energia livre de superfície, respectivamente. Estas equações serão usadas na seção 4.8 para cálculo das energias livre das superfícies de diamante com diferentes terminações.

Realizamos as medidas de ângulo de contato no sistema automatizado Contact angle goniometer CAM200 da KSV (processo FAPESP número 06/07306-4) que permite posicionamento controlado de uma gota, de volume definido por software, sobre a superfície em estudo. A imagem da gota sobre a superfície pode ser gravada a 1 quadro/segundo ou 62 quadros/segundo. Desta forma, pode-se também observar a cinética da gota em um processo de evaporação, por exemplo, ou quando a gota está sendo depositada sobre a superfície. Utilizando as imagens gravadas, o software determina o ângulo de contato ajustando uma expressão matemática ao formato da gota (Young-Laplace) e calculando a inclinação da tangente à gota na interface líquido-sólido-vapor (ver Figura 3.7).

O método utilizado para estudo do ângulo de contato foi o de gota séssil, onde foi realizada inclinação dinâmica pelo equipamento a uma taxa de $1 \%$. No método da gota séssil, uma gota de um líquido puro é depositada sobre a superfície de um sólido por meio de uma seringa. Registos de imagem são realizados através de uma câmera CCD, que são armazenadas para posterior ajuste. Este tipo de medida é chamado de estático. O valor do ângulo de contato formado por uma gota do líquido sonda depende da energia de superfície do sólido $\gamma_{S V}$ e da tensão superficial do líquido $\gamma_{L V}$ como visto na equação 3.10. Se a gota se espalhar por toda superfície do material seu ângulo de contato será de aproximadamente zero, mas se o espalhamento for parcial o ângulo de contato variará de $0^{\circ}$ a $180^{\circ}$. O líquido selecionado determina o grau de 


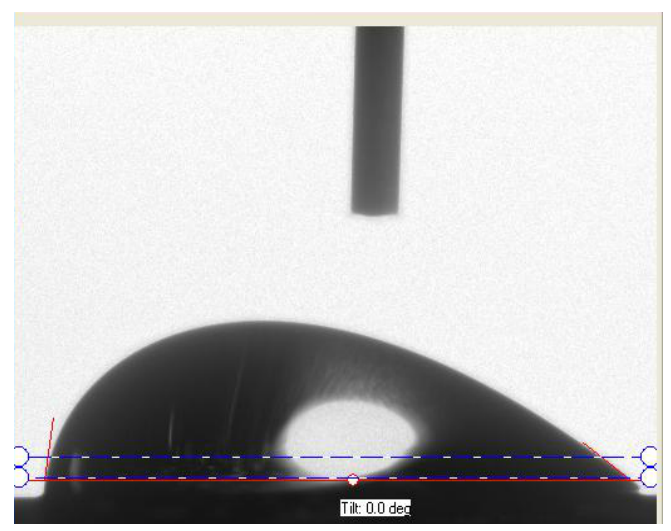

Figura 3.7: Imagem do ajuste do ângulo de contato calculado pelo software de controle do equipamento CAM200. Nessa imagem a amostra está inclinação de aproximadamente $50^{\circ}$ com inclinação realizado pelo equipamento.

molhabilidade e de interação com a superfície do substrato. Este líquido deve reunir as seguintes propriedades: baixa volatilidade, baixa viscosidade, ser estável e não atacar ou reagir com a superfície do substrato, diz-se que um líquido molha um substrato quando o ângulo de contato formado entre o líquido e o sólido é menor que $90^{\circ}$. Quando água é utilizada como líquido sonda tem se que para $\Theta>90^{\circ}$ a superfície é dita ser hidrofóbica e para valores de $\Theta<90^{\circ}$ a superfície é dita ser hidrofóbica (ver Figura 3.8). O líquido sonda mais adequado para o estudo, levando em consideração a molhabilidade e a não polaridade da superfície do substrato, foi a água.

Superfície Hidrofóbica

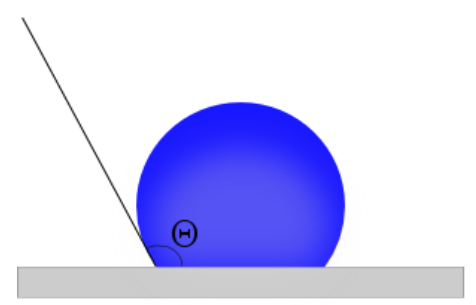

Superfície Hidrofilica

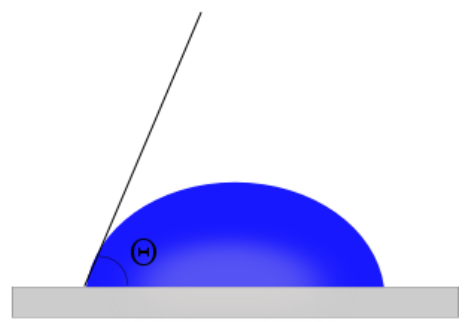

Figura 3.8: Ângulo de contato para superfícies hidrofílicas e superfícies hidrofóbicas.

Para utilização do método de Fowkes e do método de Wu é recomendado utilizar dois líquidos sonda, água e diiodometano. A água é considerada como líquido sonda que possui componente polar dominante $\left(\gamma_{L V}^{d}=21,8 \mathrm{~mJ} / \mathrm{m}^{2}\right.$ and $\left.\gamma_{L V}^{p}=51,0 \mathrm{~mJ} / \mathrm{m}^{2}\right)$ e diiodomentano como líquido sonda dispersivo sendo $\gamma_{L V}^{d}=48,5 \mathrm{~mJ} / \mathrm{m}^{2}$ e $\gamma_{L V}^{p}=2,3 \mathrm{~mJ} / \mathrm{m}^{2}$ [40]. Água deionizada e diiodometano foram utilizados para obtenção das energias livre de superfície neste trabalho. 


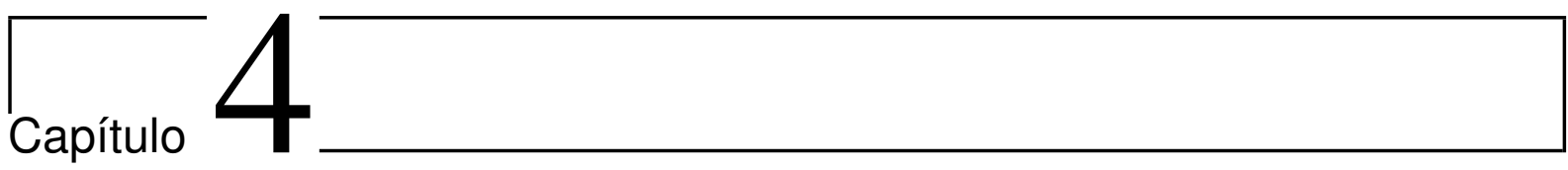

\section{RESULTADOS EXPERIMENTAIS E DISCUSSÃO.}

Neste capítulo iremos apresentar os resultados obtidos para a modificação das superfícies dos filmes de diamante. Como já mencionado, os filmes de diamante foram obtidos no equipamento CVD após uma série de ajuste de parâmetros. Inicialmente esses filmes foram caracterizados por espectroscopia Raman, difração de raios-X e microscopia eletrônica de varredura. Seguindo, esses filmes foram recobertos com elétron-resiste e passaram por um processo de litografia para que se pudessem ter áreas adjacentes com diferentes terminações químicas de superfície. Após a modificação de superfície descrita na seção 2.5 estes filmes foram caracterizados por Kelvin Force Microscopy-KFM por Microscopia eletrônica de varredura, por fim apresentamos medidas de ângulo de contato e os resultados obtidos para energia livre de superfície.

\subsection{Espectroscopia Raman dos Filmes de Diamante deposi- tados no Equipamento CVD.}

Uma otimização de parâmetros foi realizada para a deposição dos filmes policristalinos de diamante no equipamento CVD. Para isto, adicionamos gás nitrogênio a mistura convencional dos gases metano $\left(\mathrm{CH}_{4}\right)$ e hidrogênio $\left(\mathrm{H}_{2}\right)$. A adição de nitrogênio à mistura $\mathrm{H}_{2} / \mathrm{CH}_{4}$ teve como intuito a obtenção de filme de diamante com estrutura nano cristalina, onde, segundo a literatura o diamante nano cristalino apresenta um ganho em suas propriendades elétricas e mecânicas comparado ao diamante microcristalino [42, 43]. Mantivemos constante a quantidade de 3,00 sccm de metano $\left(\mathrm{CH}_{4}\right)$ e $300 \mathrm{sccm}$ de hidrogênio $\left(\mathrm{H}_{2}\right)$ e variamos o fluxo de 
nitrogênio de $0 ; 1 ; 2 ; 3 ; 4 ; 10 ; 12 ; 30$ e 68,9 sscm. Para as amostras depositadas com 10;12;30 e 68,9 sscm de nitrogênio não obtivemos filme contínuo sobre o substrato. As demais amostras que apresentaram uma deposição contínua sobre o substrato foram analisadas por espectroscopia Raman.

Pode-se observar na figura 4.1) no espectro Raman da amostra depositada sem a presença de nitrogênio obtivemos dois picos: o de diamante próximo de $1332 \mathrm{~cm}^{-1}$ e de carbono amorfo proximo a $1580 \mathrm{~cm}^{-1}$. À medida que aumentamos a quantidade de nitrogênio podemos observar claramente a presenças dos picos característicos devido ao diamante e ao carbono amorfo ficarem mais intensos e podemos ver também o aparecimento de um terceiro pico por volta de $1150 \mathrm{~cm}^{-1}$ referente ao trans-poliacetileno $\left(\left[\mathrm{C}_{2} \mathrm{H}_{2}\right]_{n}\right)$ [44]. Pfeiffer et al mostrou que pequenos segmentos de trans $-(\mathrm{CH})_{x}$ são formados entre os grãos de diamante na deposição de filmes nano estruturados.

As amostras que foram depositadas com 3 e $4 \mathrm{sccm}$ de $N_{2}$ apresentam o pico característico do diamante por volta de $1332 \mathrm{~cm}^{-1}$ bem mais definido. Para a amostra depositada com $3 \mathrm{sccm}$ de $\mathrm{N}_{2}$ a intensidade deste pico é ligeiramente maior. Os picos Raman em 1150, $1332 \mathrm{e}$ $1580 \mathrm{~cm}^{-1}$ são visto como característico de diamante nanocristalino [45-47].

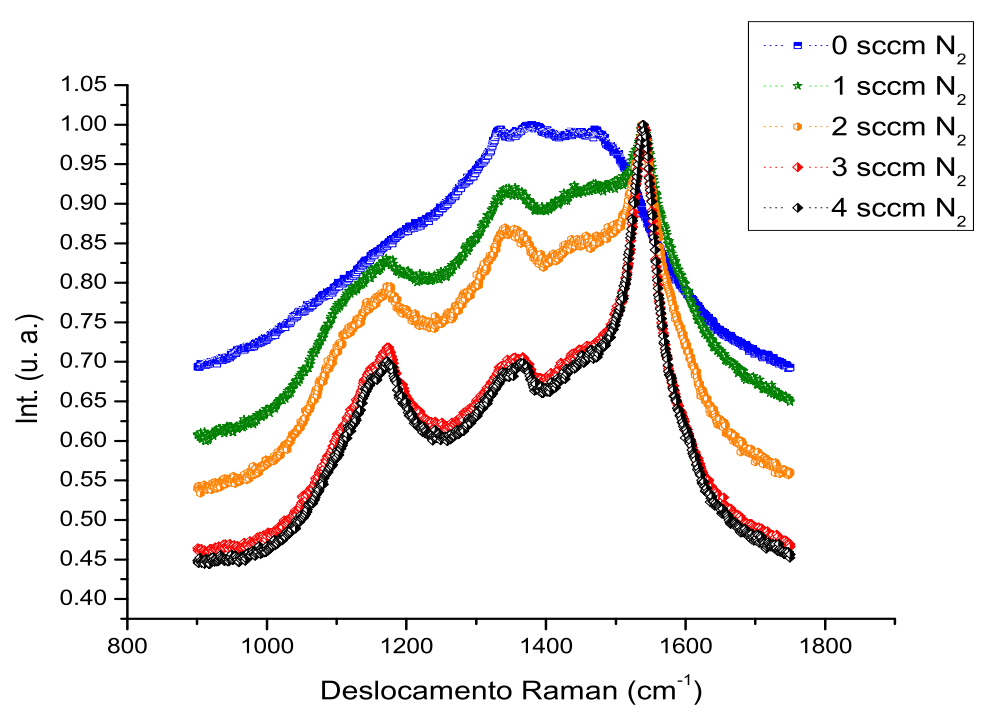

Figura 4.1: Espectros Raman normalizado com relação ao pico mais intenso $\left(1580 \mathrm{~cm}^{-1}\right)$ das amostras de filme de diamante obtidos variando-se a quantidade de nitrogênio $N_{2}$ adicionado à mistura de hidrogênio $\mathrm{H}_{2}$ e metano $\mathrm{CH}_{4}$.

Imediatamente depois de remover a amostra do equipamento CVD teremos um filme de diamante com terminação química de superfície consistindo de hidrogênio. Note que na deposição temos uma alta concentração de hidrogênio (94\%) com (3\%) de nitrogênio visto como "contaminação 
de superfície" e o restante é composto de Metano sendo este fomento de carbono para a formação do filme de diamante. Dessa forma, as amostras depositadas com 3 sccm de nitrogênio adicionados a mistura convencional de hidrogênio/metano $\left(\mathrm{H}_{2} / \mathrm{CH}_{4}\right)$ foram escolhidas por apresentar o pico Raman por volta de $1332 \mathrm{~cm}^{-1}$ ligeiramente mais intenso.

\subsection{Difratometria de raios-X e Microscopia Eletrônica de Var- redura dos Filmes de Diamante depositados no Equipa- mento CVD.}

Para as amostras depositadas com 3,00 $\pm 0,03 \mathrm{sccm}$ de nitrogênio adicionada a mistura $\mathrm{H}_{2} / \mathrm{CH}_{4}$ analisada através do XRD (ver Figura 4.2) podemos observar que se trata de um filme de diamante nanocristalino, onde, o espectro apresenta os picos característicos do diamante. Usando a equação de Debye-Scherrer obtivemos um tamanho de grão cristalográfico médio de $19,2 \mathrm{~nm}[14,15,48]$.

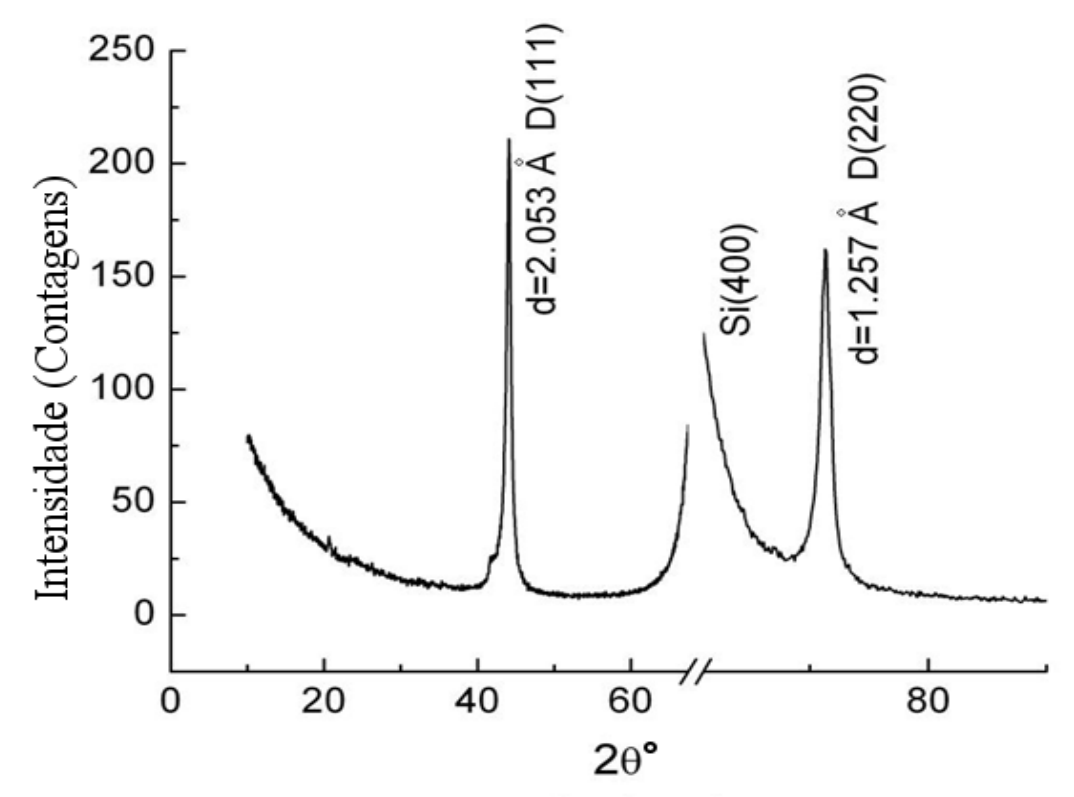

Figura 4.2: Espectro de difração de raios-X típico das amostras de filme de diamante obtidos com $300 \mathrm{sccm}$ de hidrogênio 3,00 sccm de metano e 3,00 sccm de nitrogênio

Todas as amostras utilizadas neste trabalho foram produzidas com os seguintes parâmetros; fluxo de hidrogênio de $300( \pm 1) \mathrm{sccm}$, fluxo de metano e nitrogênio de 3,00 $( \pm 0,03) \mathrm{sccm}$, temperatura de $850^{\circ} \mathrm{C}( \pm 5)$, pressão da câmara de 50,0 $( \pm 0,3)$ Torr e tempo de deposição de 24 h. Na figura 4.3 é mostrada uma micrografia típica dos filmes de diamante depositados com tais parâmetros. Nesta micrografia é possível observar estruturas com tamanhos de cerca de $3 \mu \mathrm{m}$, o que correspondem a aglomerados dos nano cristais da ordem de $20 \mathrm{~nm}$, como observado 
por difração de raios-X. Os filmes possuem aproximadamente $10 \mu \mathrm{m}$ de espessura e rugosidade da ordem de $91 \pm 4 n m$.

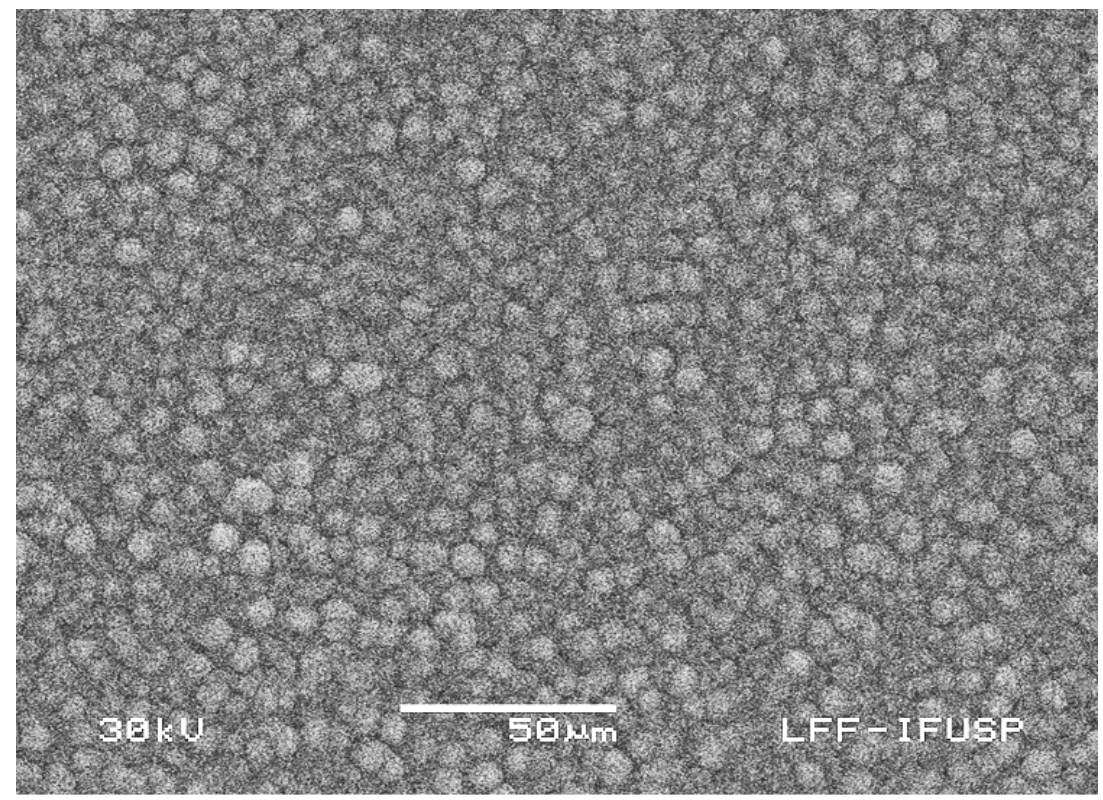

Figura 4.3: Imagem MEV típica dos filmes de diamante usados neste trabalho.

\subsection{Resultados para litografia por feixe de elétrons.}

Para a realização da litografia por feixe de elétrons sobre os filmes de diamante, estes foram recobertos com elétron-resiste logo após serem removidos do reator CVD. Então um padrão foi transferido através do processo de litografia descrito na seção 2.4. Para os parâmetros descritos obtivemos a amostra apresentada na micrografia ótica da Figura 4.4. Nessa imagem, as regiões cobertas pelo elétron-resiste, no caso PMMA, são mais claras e as demais áreas, que foram expostas pelo feixe de elétrons e o PMMA foi removido, estão em um tom mais escuro.

As amostras assim preparadas foram expostas a tratamento por plasma, como descrito na seção 2.5, substituindo as terminações de hidrogênio por terminações de oxigênio ou flúor, conforme o gás utilizado. Os apêndices A.1, A.2 e A.3 apresentam um estudo preliminar com diferentes tempos de exposição aos tratamentos por plasma. Foi observado que a partir de 3 minutos de tratamento com plasma de oxigênio, o mascaramento de PMMA foi completamente removido, passando a expor toda a superfície da amostra ao plasma. O mesmo efeito é observado para o caso do tratamento com plasma de $S F_{6}$, onde o tempo para corrosão do mascaramento de PMMA foi de 7 minutos. O recurso que foi usado para se prolongar os tempos de exposição ao plasma foi a deposição do polímero SU-8, cuja espessura é da ordem de $1 \mu \mathrm{m}$. No 


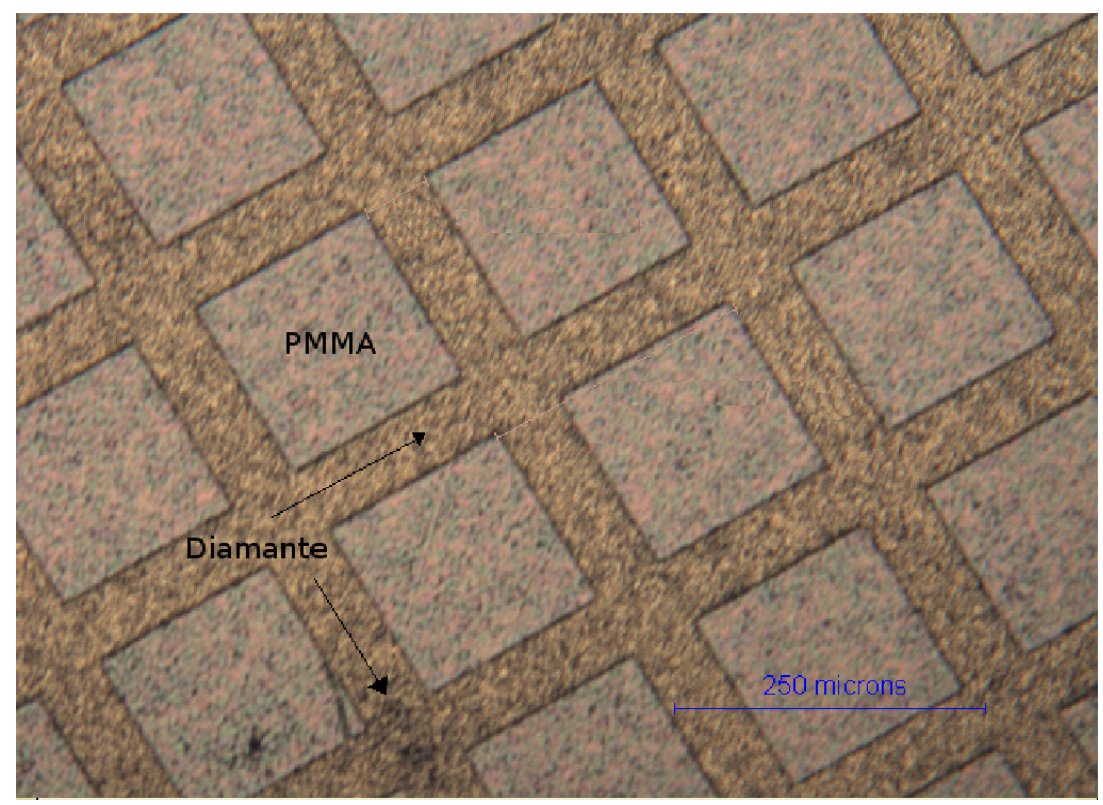

Figura 4.4: Micrografia ótica panorâmica de uma amostra de diamante policristalino com padrão litografado cobrindo uma área total de $3 \times 3 \mathrm{~mm}^{2}$.

entanto, esse polímero não pode ser removido do substrato com facilidade (como é o caso do PMMA). Então um filme de PMMA foi inicialmente depositado sobre o substrato de diamante e posteriormente o filme de SU-8. A finalidade do uso do PMMA abaixo do SU-8 consiste em utilizá-lo como camada sacrificial no final do processo. Em seguida a litografia por feixe de elétrons foi realizado sobre o SU-8. Como resultado, temos um mascaramento com SU-8, mas, nas regiões onde o SU-8 foi removido, ainda permanecia o PMMA. Assim, os tempos escolhidos para o tratamento por plasma partiram de valores superiores aos conhecidos para a remoção do PMMA pelos plasmas. Após o tratamento por plasma, o PMMA (posicionado abaixo do mascaramento de SU-8) foi removido utilizando acetona como solvente, desprendendo o SU-8 remanescente da superfície do substrato. 


\subsection{Resultados da modificação de superfície utilizando gás de $\mathrm{O}_{2}$.}

Para a modificação da superfície do diamante utilizou-se o canhão de plasma trabalhando com gás $\mathrm{O}_{2}$ puro. Os parâmetros do processo foram os mesmos descritos na seção 2.5.1, página 18. Para tais amostras serão apresentados os resultados obtidos, onde temos como grandeza variada o parâmetro tempo de exposição ao plasma de $\mathrm{O}_{2}$, sendo que os demais foram mantidos constantes.

Apresentamos na Figura 4.5 uma micrografia MEV obtida por sinal de elétrons secundários para a amostra contendo regiões adjacentes com terminações de hidrogênio, nas regiões claras, e oxigênio nas regiões escuras. O contraste é devido a diferentes propriedades elétricas das regiões com diferentes terminações.

Na Figura 4.6 temos micrografias obtidas simultaneamente por AFM e KFM. A imagem da esquerda mostra a topografia da amostra de filme de diamante policristalino obtida por AFM no modo tapping mode. Na imagem da direita temos o mapeamento do potencial da mesma superfície obtida por KFM com o recurso interleave habilitado. As regiões claras correspondem a terminação de oxigênio e as regiões mais escuras correspondem a terminação de hidrogênio. Para cada amostra obtivemos o perfil de potencial no software de processamento de imagens do equipamento AFM, através da ferramenta de cross-section (ver Figura 4.7) e em seguida exportamos estes dados para o ORIGIN@ Versão 8.0 para que pudéssemos trabalhar com valores médios de potencial em cada região (ver Figura 4.8).

A primeira varredura da sonda sobre a superfície foi realizada sob condições ambiente. Seguindo, a campânula era colocada sobre todo conjunto: scanner, cabeça do AFM, cantiléver e amostra. Os parâmetros relacionados à oscilação da sonda são ajustados novamente, o que é imposto pela mudança do gás em que ela está imersa. O equipamento foi então configurado para capturar e armazenar continuamente cada varredura da sonda sobre a superfície registrando uma micrografia AFM/KFM, sob tais condições, até que o sistema estabilizasse. Para cada micrografia capturada obtivemos o perfil de potencial médio. A partir destes dados conseguimos gerar gráficos das diferenças de potencial existentes entre as regiões com terminações de oxigênio e hidrogênio $\left(V_{O}-V_{H}\right)$, à medida que a amostra era banhada com gás hélio.

Na Figura 4.9 é apresentado um gráfico das diferenças de potencial entre as regiões com terminação de hidrogênio e oxigênio em função do tempo permanência em atmosfera de hélio, para amostras expostas a diversos tempos de tratamento em plasma de oxigênio. Os tempos de exposição foram 3, 5, 7 e 9 minutos. Podemos observar no gráfico que para os tempos de 7 e 
9 minutos de exposição ao plasma de oxigênio a diferença de potencial entre as regiões com diferentes terminações de superfície das amostras foi atenuado. Este fato pode ser devido ao ataque, com remoção de parte do polímero do mascaramento, e sua possível redeposição nas regiões expostas ao plasma.

$\mathrm{Na}$ amostra exposta ao plasma de oxigênio por 3 minutos observa-se que este tempo não foi suficiente para modificar a superfície. Ou seja, com este tempo não conseguimos uma substituição quantitativa das ligações $-C-H$ de superfície por ligações $-C-O$ a ponto de gerar uma diferença de potencial $\left(V_{O}-V_{H}\right)$ significativa.

A superfície de diamante exposta ao plasma de oxigênio pelo tempo de 5 minutos apresenta o maior potencial entre as regiões com terminações de oxigênio e de hidrogênio comparado às amostras expostas ao plasma pelos tempos de 3, 7, e 9 minutos. Podemos observar que essa amostra apresenta uma diferença de potencial entre regiões de oxigênio e de hidrogênio $\left(V_{O}-V_{H}\right)$ do valor inicial de $153 \pm 2 m V$. Após $4 \mathrm{~h}$ de varredura em atmosfera controlada de hélio gasoso a diferença de potencial entre oxigênio e hidrogênio $\left(V_{O}-V_{H}\right)$ passa para o valor de $161 \pm 7 \mathrm{mV}$. Assim, 5 minutos é o tempo que mais se aproxima da situação ideal. Para esse tempo as ligações $-C-H$ de superfície são prioritariamente substituídas por ligações $-C-O$, gerando uma diferença de potencial entre as terminações de oxigênio e hidrogênio $\left(V_{O}-V_{H}\right)$ de maior valor, quando comparado aos demais tempos de exposição ao plasma de oxigênio.

Para todas as amostras podemos observar da tabela 4.1 que as medidas de KFM realizadas em ambiente gasoso de hélio apresentam um ganho no valor da medida de diferença de potencial entre as terminações de oxigênio e hidrogênio. Com isso acredita-se que o uso do ambiente gasoso de hélio promove um arraste da humidade adsorvida à superfície aumentando assim, a diferença de potencial entre as regiões de diferentes terminações.

Tabela 4.1: Diferença de potencial medido para as superfícies de diamante em atmosfera controlada de hélio gasoso para diversos tempos de exposição ao plasma de $\mathrm{O}_{2}$.

Diferença de potencial entre regiões contendo terminações de hidrogênio e de oxigênio

\begin{tabular}{|c|c|c|}
\hline \hline Tempo de exposição & Diferença de Potencial inicial & Diferença de Potencial final \\
\hline 3 minutos & $95 \pm 2 \mathrm{mV}$ & $117 \pm 2 \mathrm{mV}$ \\
\hline 5 minutos & $153 \pm 2 \mathrm{mV}$ & $161 \pm 7 \mathrm{mV}$ \\
\hline 7 minutos & $86 \pm 2 \mathrm{mV}$ & $108 \pm 4 \mathrm{mV}$ \\
\hline 9 minutos & $17 \pm 1 \mathrm{mV}$ & $59 \pm 1 \mathrm{mV}$ \\
\hline
\end{tabular}




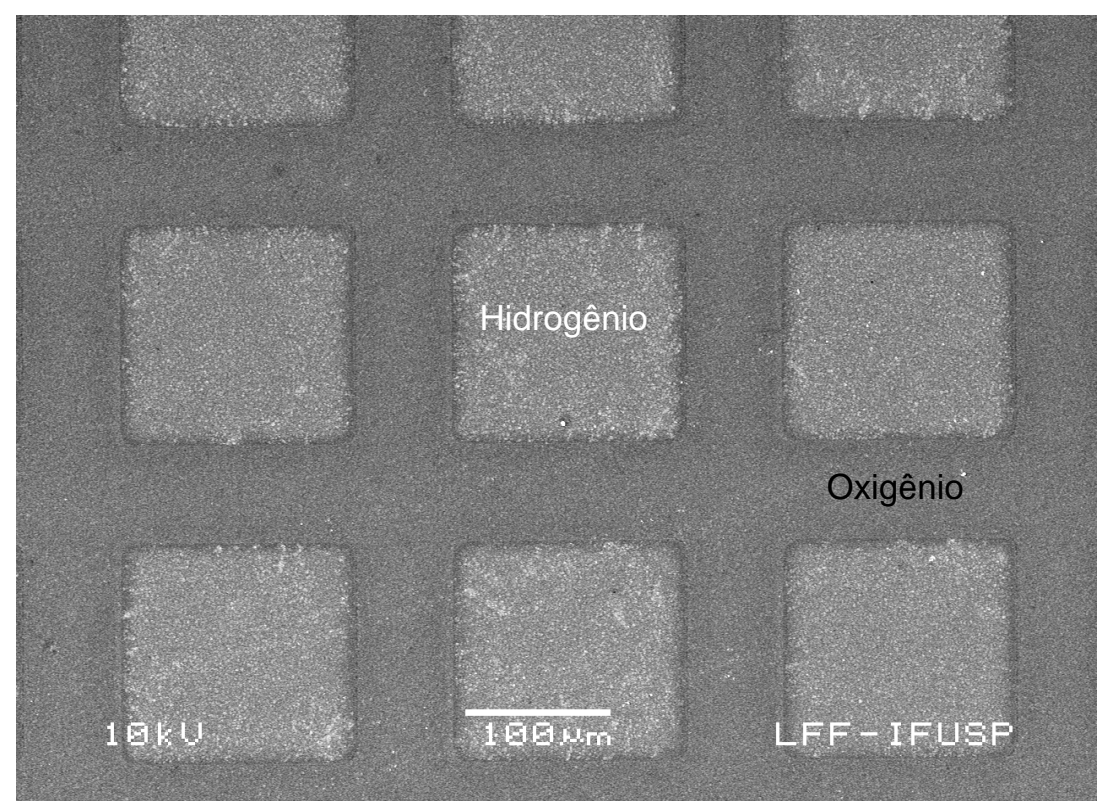

Figura 4.5: Imagem MEV da superfície do filme de diamante exposta ao plasma de oxigênio por 5 minutos com regiões adjacentes com terminações de hidrogênio, nas regiões claras, e de oxigênio nas regiões escuras.

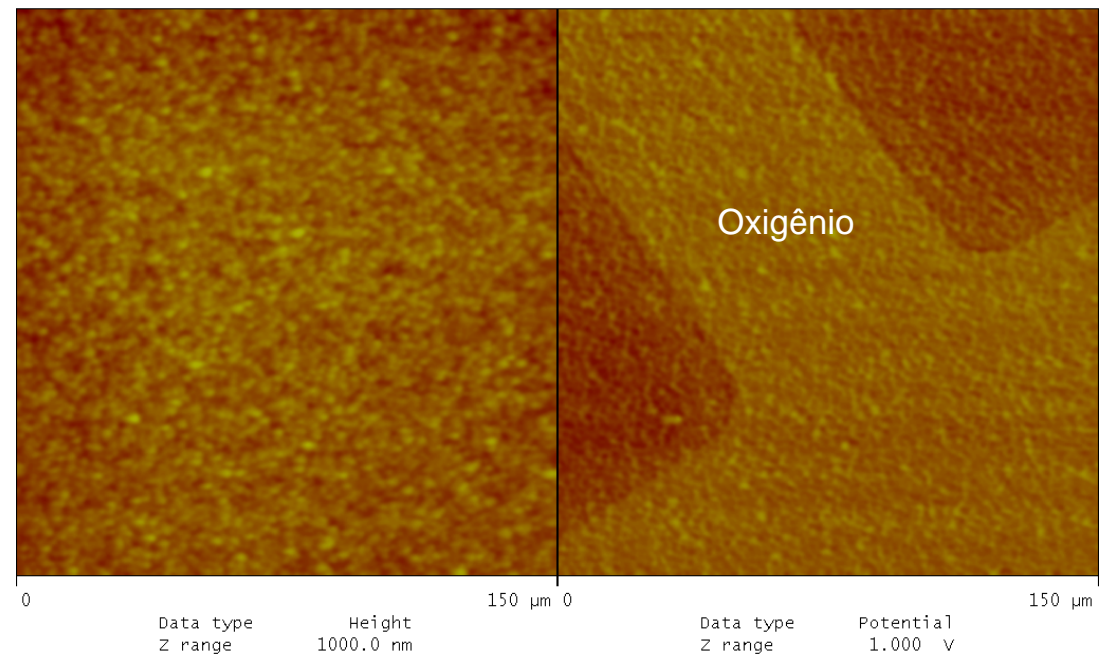

Figura 4.6: Micrografia de AFM (à esquerda) e de KFM (à direita) da amostra do filme de diamante exposto ao plasma de oxigênio por 5 minutos. Na figura da esquerda temos a morfologia do filme de diamante e na direita temos o respectivo mapeamento do potencial de superfície para a mesma região onde, as regiões claras correspondem a terminações de oxigênio e as regiões escuras correspondem a terminações de hidrogênio. 


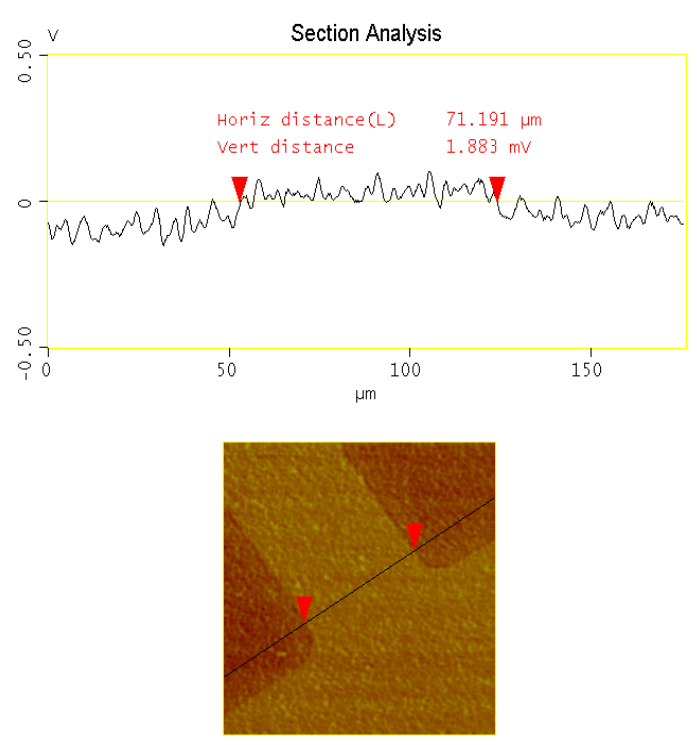

Figura 4.7: Tela do NanoScope III a apresentando a medida da diferença de potencial entre as regiões adjacentes de hidrogênio e oxigênio através da ferramenta cross section

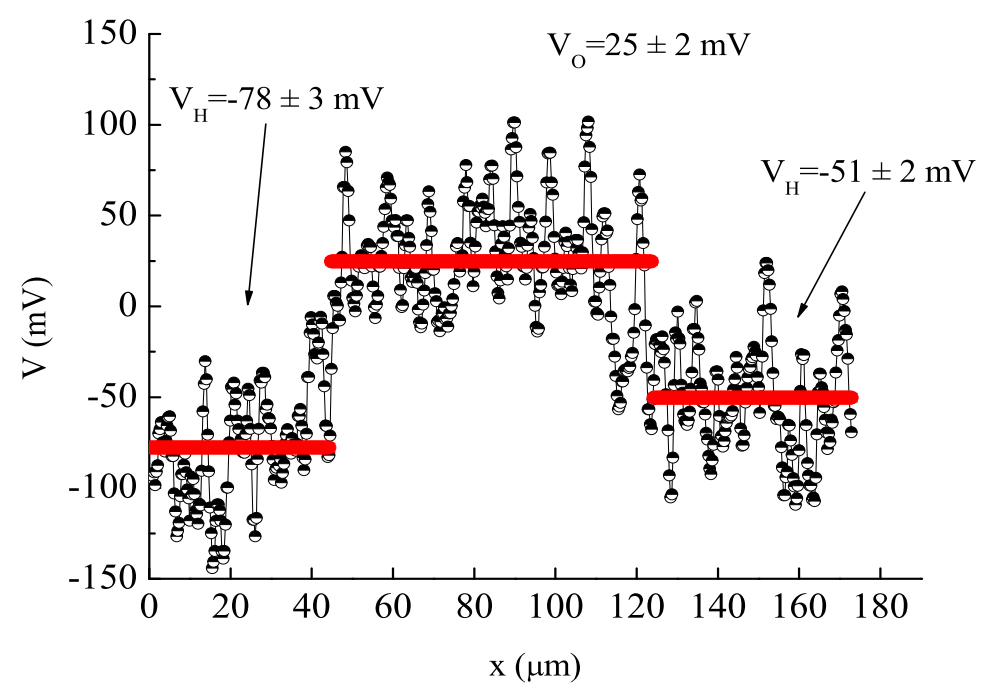

Figura 4.8: Perfil médio de potencial calculado a partir do dados obtidos na primeira imagem KFM capturada. 


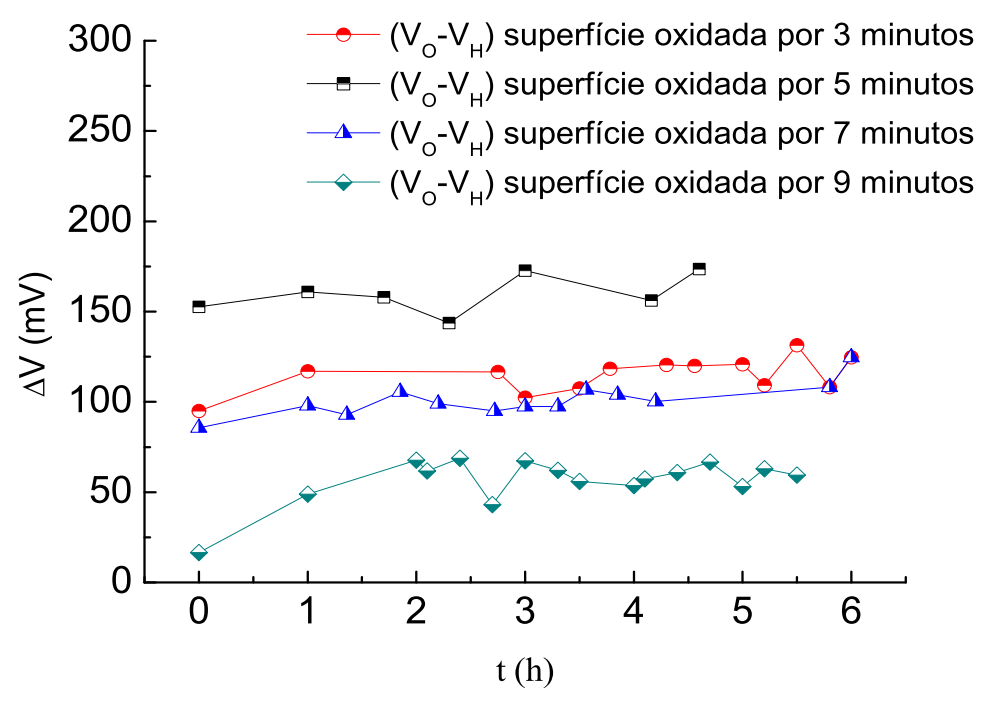

Figura 4.9: Gráfico da diferença de potencial entre regiões com terminações de oxigênio e de hidrogênio calculado a partir das imagens KFM ao longo do tempo $t$ no qual a superfície era banhada com hélio gasoso. As várias curvas correspondem a diferentes tempos de exposição ao plasma de oxigênio. 


\subsection{Resultados da modificação de superfície utilizando gás de $S F_{6}$.}

Para a modificação da superfície do diamante utilizamos o canhão de plasma trabalhando com gás $S F_{6}$. Os parâmetros do processo foram os mesmos descritos na seção 2.5.2, página 19. Para tais amostras serão apresentados os resultados obtidos, onde temos como grandeza variada o parâmetro tempo de exposição ao plasma de $S F_{6}$, sendo que os demais foram mantidos constantes.

Na figura 4.10 é apresentada a micrografia MEV obtida por sinal de elétrons secundários onde é possível identificar as regiões adjacentes contendo terminações de hidrogênio, nas regiões escuras, e flúor nas regiões claras. O contraste é devido a diferentes propriedades elétricas existente entre as regiões com terminações de flúor e hidrogênio. Na figura 4.11 é apresentada uma micrografia de AFM e KFM obtidas simultaneamente onde na imagem da esquerda é mostrado a topografia da superfície do filme de diamante policristalino e na imagem da direita temos o mapeamento do potencial da mesma superfície. Na imagem de KFM, podemos identificar regiões adjacentes com terminações de hidrogênio (regiões mais claras) e de flúor.

Para cada amostra obtivemos o perfil de potencial no software de processamento de imagens do equipamento AFM, através da ferramenta de cross-section (ver Figura 4.12). Seguindo estes dados são exportados para o software ORIGINß Versão 8.0 para que pudéssemos trabalhar com valores médios de potencial em cada região (ver Figura 4.13).

A cada varredura da sonda sobre a superfície da amostra, enquanto a mesma era banhada com gás hélio, uma micrografia AFM/KFM foi capturada e armazenada. Para cada micrografia capturada obtivemos o perfil de potencial médio. Uma vez obtido os perfis de potencial da superfície do diamante foi possível calcular as diferenças de potencial existentes entre as regiões com terminações de flúor e hidrogênio $\left(V_{F}-V_{H}\right)$ e assim gráficar os resultados obtidos (ver Figura 4.14).

Assim, na Figura 4.14 é apresentado um gráfico das diferenças de potencial entre as regiões com terminações de hidrogênio e flúor $\left(V_{F}-V_{H}\right)$ em função do tempo de permanência em atmosfera de hélio, para amostras expostas a diversos tempos de tratamento em plasma de $S F_{6}$. Da Figura 4.14 temos que para o tempo de 5 e 7 minutos de exposição ao plasma de $S F_{6}$ a diferença de potencial existente entre as regiões com terminações de flúor e hidrogênio $\left(V_{F}-\right.$ $V_{H}$ ) na superfície do diamante foi não atingiu seu valor máximo. Acredita-se que estes tempos de exposição ao plasma de $S F_{6}$ não foram suficientes para uma substituição significativa das 
ligações $-C-H$ de superfície por ligações $-C-F$ a ponto de gerar a diferença de potencial $\left(V_{F}-V_{H}\right)$ máxima.

Observa-se na Figura 4.14 que a superfície do diamante exposta ao plasma de $S F_{6}$ pelo tempo de 9 minutos apresenta o maior valor de diferença de potencial $V_{F}-V_{H}$ comparado às amostras expostas ao plasma de $S F_{6}$ pelos tempos de 5,7 , e 11 minutos. O potencial da superfície de diamante para esta amostra apresenta um uma diferença de potencial entre flúor e hidrogênio de valor inicial $142 \pm 1 \mathrm{mV}$. Por volta de $3 \mathrm{~h}$ de varredura em atmosfera controlada de hélio gasoso é possível ver que o potencial da superfície de diamante estabiliza e passa para o valor médio de $279 \pm 3 m V$. Assim, tem-se que mantendo as condições de deposição, 9 minutos é o tempo que mais se aproxima da situação ideal. Condições estas que vão desde a deposição do polímero até a exposição ao plasma de $S F_{6}$. Para esse tempo as ligações $-C-H$ de superfície são substituídas prioritareamente por ligações $-C-F$, gerando a maior diferença de potencial entre as terminações de flúor e hidrogênio $\left(V_{F}-V_{H}\right)$.

Para a amostra exposta ao plasma de $S F_{6}$ pelo tempo de 11 minutos, a diferença de potencial foi atenuada. Este fato pode ser devido ao ataque, com remoção de parte do polímero do mascaramento, e sua possível redeposição nas regiões expostas ao plasma.

Na tabela 4.2 pode se observar que o uso da atmosfera controlada de hélio mostra um aumento na diferença de potencial existente entre terminações de flúor e hidrogênio na superfície do diamante. Como já mencionado, acredita-se que com o uso da atmosfera de hélio haja um arraste da humidade adsorvida à superfície, aumentando assim a diferença de potencial entre as regiões de diferentes terminações [27]. Para a amostra exposta ao plasma de $S F_{6}$ pelo tempo de 9 minutos mais especificamente, é possível observar que a diferença de potencial obteve um ganho em torno de $137 \mathrm{mV}$.

Tabela 4.2: Diferença de potencial medido para as superfícies de diamante em atmosfera controlada de hélio gasoso para diversos tempos de exposição ao plasma $S F_{6}$.

\begin{tabular}{|c|c|c|}
\hline \multicolumn{2}{|c|}{ Diferença de potencial entre as regiões contendo terminações de hidrogênio e de flúor. } \\
\hline \hline Tempo de exposição & Diferença de Potencial inicial & Diferença de Potencial final \\
\hline 5 minutos & $42 \pm 1 \mathrm{mV}$ & $22 \pm 6 \mathrm{mV}$ \\
\hline 7 minutos & $85 \pm 1 \mathrm{mV}$ & $210 \pm 1 \mathrm{mV}$ \\
\hline 9 minutos & $142 \pm 1 \mathrm{mV}$ & $279 \pm 3 \mathrm{mV}$ \\
\hline 11 minutos & $76 \pm 1 \mathrm{mV}$ & $154 \pm 1 \mathrm{mV}$ \\
\hline
\end{tabular}




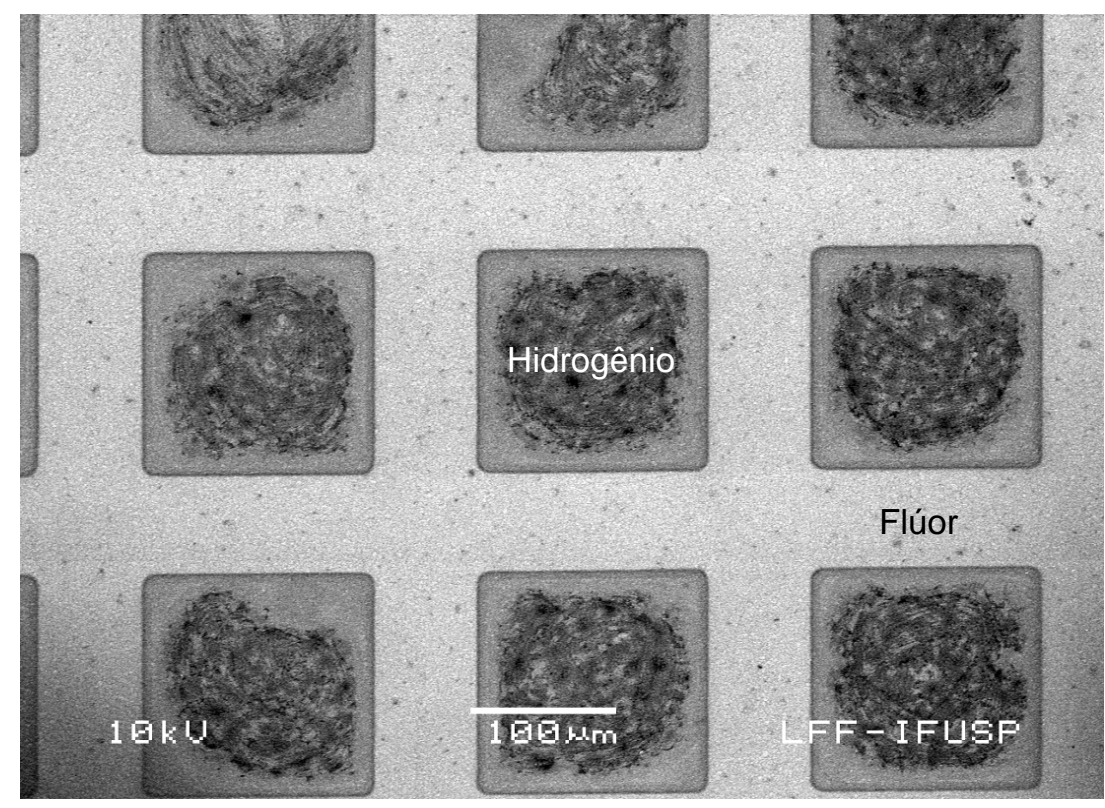

Figura 4.10: Micrografia MEV da superfície de diamante exposta ao plasma de $S F_{6}$ por 9 minutos. Apresentando regiões adjacentes com terminações de hidrogênio(regiões escuras) e flúor nas regiões claras.

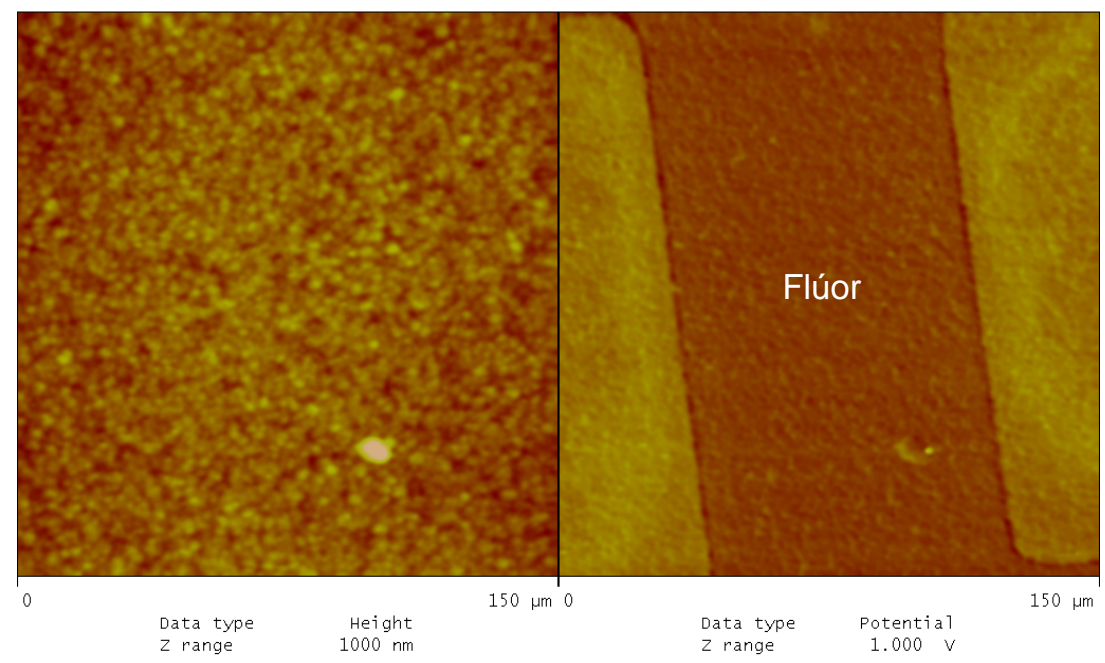

Figura 4.11: Micrografia de AFM (à esquerda) e de KFM (a direita) da amostra do filme de diamante exposto ao plasma de $S F_{6}$ por 9 minutos. Na figura da esquerda temos a morfologia do filme de diamante e na direita temos o respectivo mapeamento do potencial de superfície para a mesma região onde, as regiões claras correspondem a terminações de hidrogênio e as regiões escuras correspondem a terminações de flúor. 

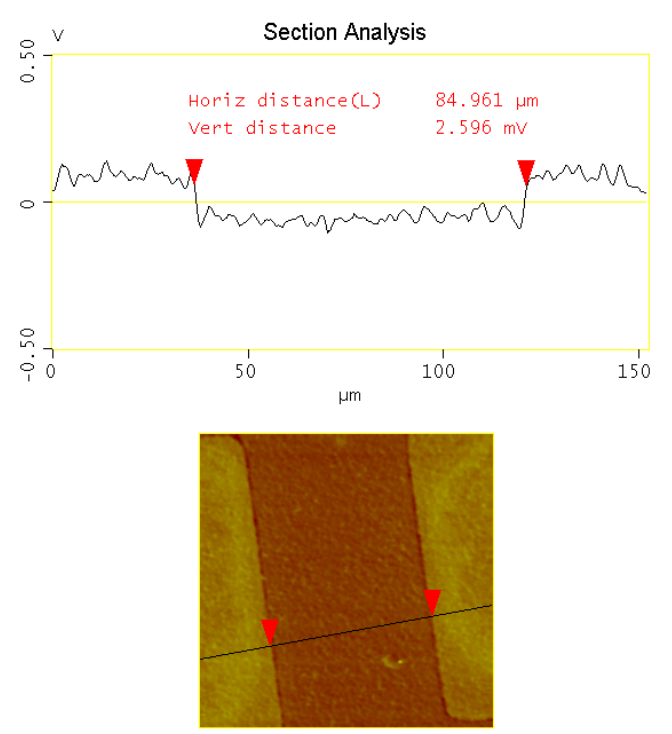

Figura 4.12: Tela do NanoScope IIIa apresentando a medida do perfil de potencial entre as regiões adjacentes de hidrogênio e flúor através da ferramenta cross section.

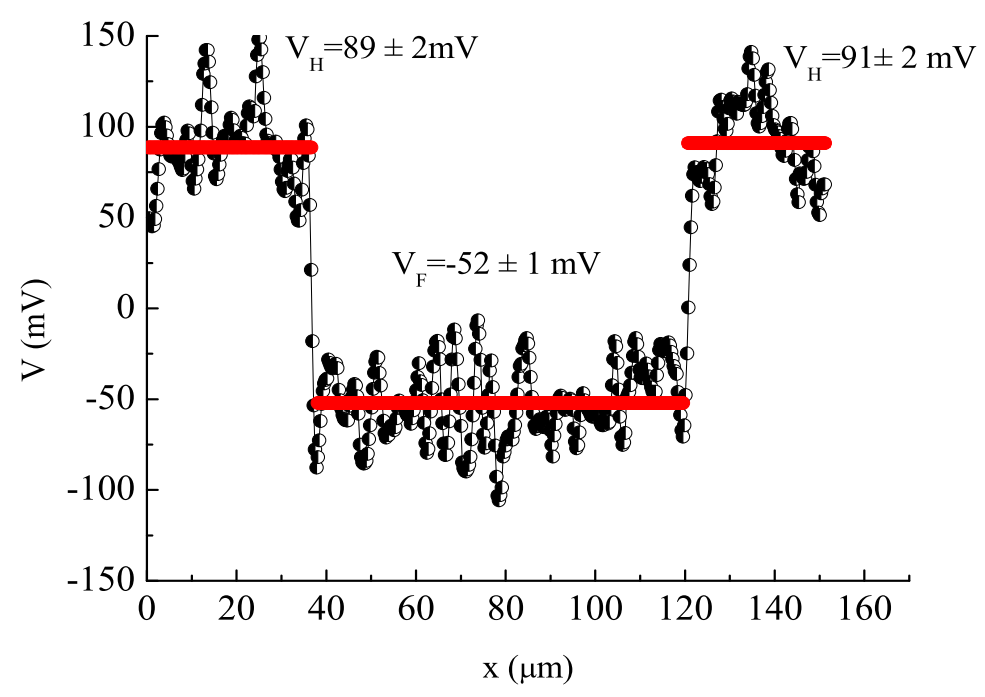

Figura 4.13: Perfil médio de potencial calculado a partir do dados obtidos na primeira imagem KFM capturada. 


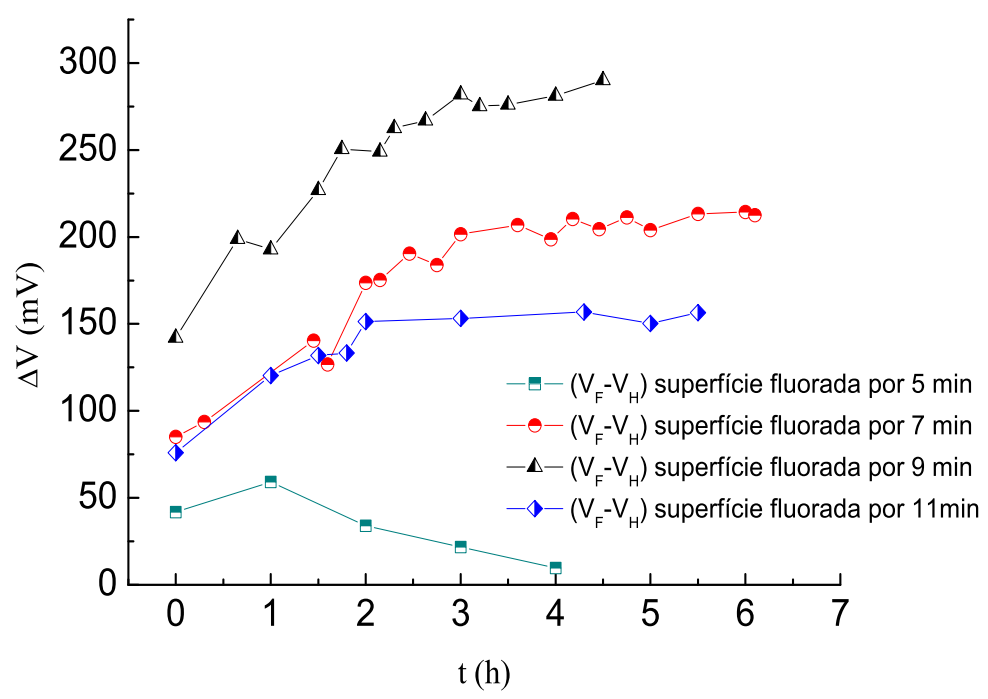

Figura 4.14: Gráfico da diferença de potencial entre as regiões com terminações de flúor e de hidrogênio obtidos a partir das imagens KFM ao longo do tempo $t$ no qual a superfície era banhada com hélio gasoso. As várias curvas correspondem a diferentes tempos de exposição ao plasma de $S F_{6}$. 


\subsection{Resultados da modificação de superfície com plasma de $\mathrm{O}_{2}$ para amostra com terminação de Flúor.}

As amostras de diamante com terminações de superfície de flúor e oxigênio foram produzidas a partir dos procedimentos descritos na seção 2.6. Na figura 4.15 é apresentada uma micrografia MEV como resultado da produção destas amostras (ver Figura 4.15). Novamente, o contraste é devido a diferentes propriedades elétricas existente entre as regiões com terminações de flúor e oxigênio.

Na figura 4.16 pode ser visto uma micrografia de AFM e KFM obtidas simultaneamente onde na imagem da esquerda é mostrado a topografia da superfície do filme de diamante policristalino e na imagem da direita temos o mapeamento do potencial da mesma superfície. $\mathrm{Na}$ imagem de KFM, podemos identificar regiões adjacentes com terminações de oxigênio (regiões mais claras) e de flúor as regiões mais escuras.

Através da ferramenta de cross section (ver Figura 4.17), obtém-se o perfil médio de potencial (ver Figura 4.18) e através deste perfil medimos as diferenças de potencial para os diversos tempos de exposição ao plasma de gás $O_{2}$. A primeira varredura foi realizada em atmosfera ambiente. As demais varreduras foram realizadas em atmosfera controlada de hélio, e a cada varredura da sonda sobre a superfície da amostra uma micrografia AFM/KFM foi capturada e armazenada, como descrito na seção 3.4.

Na figura 4.19 é apresentando um gráfico das diferenças de potencial entre as regiões com terminações de $\left(V_{O}-V_{F}\right)$ em função do tempo de permanência em atmosfera de hélio, para as amostras expostas a diversos tempos de tratamento em plasma de $\mathrm{O}_{2}$. Para todas as amostras podemos observar na tabela 4.3 que as medidas de KFM realizadas em ambiente gasoso de hélio apresentam um ganho no valor da medida de diferença de potencial entre as regiões com terminações de flúor e de oxigênio. O valor máximo obtido para a diferença de potencial entre as regiões com terminações de flúor e regiões com terminações de oxigênio foi de $41 \pm 2 \mathrm{mV}$. Assim, tomaremos o tempo de 3 minutos como ideal para que as ligações $C-F$ sejam substituídas prioritariamente por $C-O$. 
Tabela 4.3: Diferença de potencial medido para as superfícies de diamante em atmosfera controlada de hélio gasoso para diversos tempos de exposição ao plasma $\mathrm{O}_{2}$ para superfície de diamante previamente exposta ao plasma de $S F_{6}$.

Diferença de Potencial entre regiões contendo terminações de flúor e de oxigênio.

\begin{tabular}{|c|c|c|}
\hline \hline Tempo de exposição & Diferença de Potencial inicial & Diferença de Potencial final \\
\hline 3 minutos & $34,9 \pm 0,7 \mathrm{mV}$ & $41 \pm 2 \mathrm{mV}$ \\
\hline 5 minutos & $35,9 \pm 0,6 \mathrm{mV}$ & $36 \pm 1 \mathrm{mV}$ \\
\hline 7 minutos & $19,0 \pm 0,5 \mathrm{mV}$ & $31 \pm 2 \mathrm{mV}$ \\
\hline 9 minutos & $9,3 \pm 0,5 \mathrm{mV}$ & $11 \pm 2 \mathrm{mV}$ \\
\hline
\end{tabular}

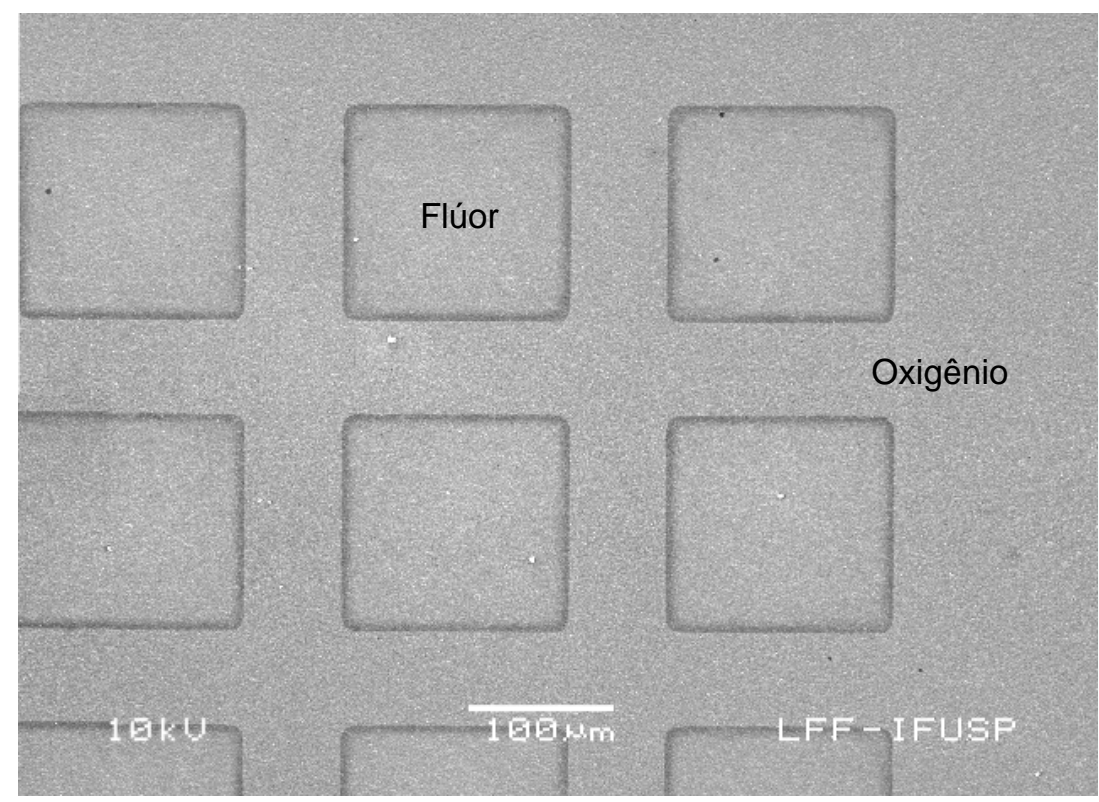

Figura 4.15: Micrografia MEV da amostra do filme de diamante exposto ao plasma de $S F_{6}$ por 5 minutos e em seguida, oxidado por 5 minutos. Apresentando regiões adjacentes com terminações de flúor (quadrados) e oxigênio nas demais regiões. 


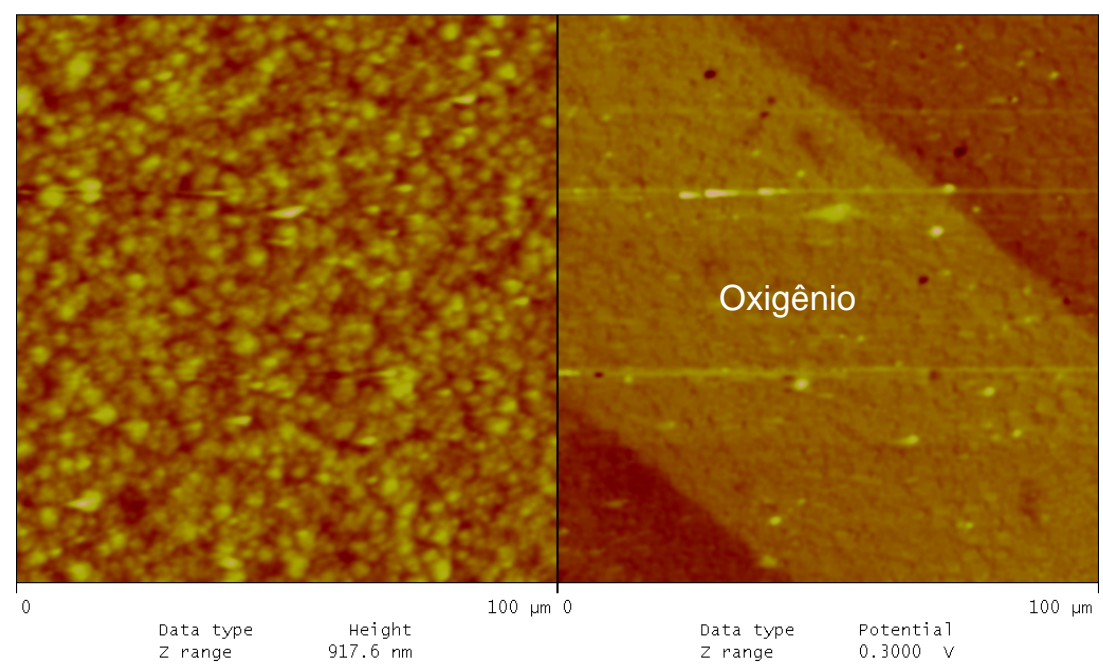

Figura 4.16: Imagens de AFM (à esquerda) e KFM (à direita) da amostra do filme de diamante exposto ao plasma de $S F_{6}$ por 5 minutos e em seguida, oxidado por 5 minutos. Na imagem de $\mathrm{KFM}$, as regiões escuras correspondem às terminações de flúor e as regiões claras correspondem às terminações de oxigênio.

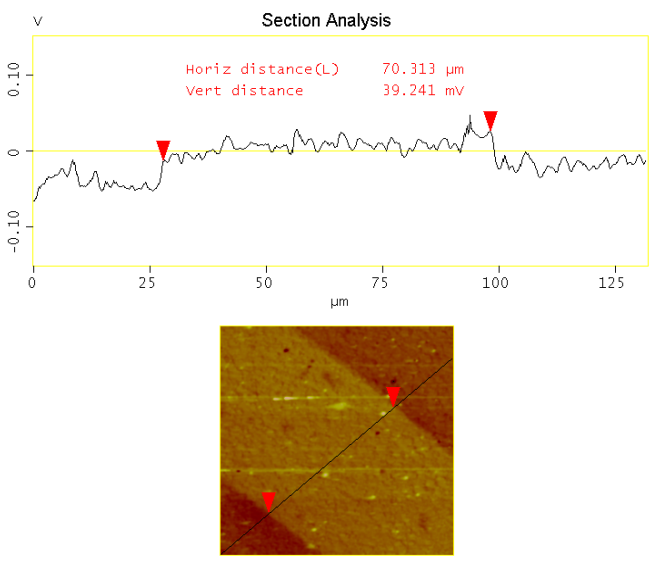

Figura 4.17: Tela do NanoScope IIIa apresentando a medida do perfil de potencial entre as regiões adjacentes de flúor e de oxigênio através da ferramenta cross section. 


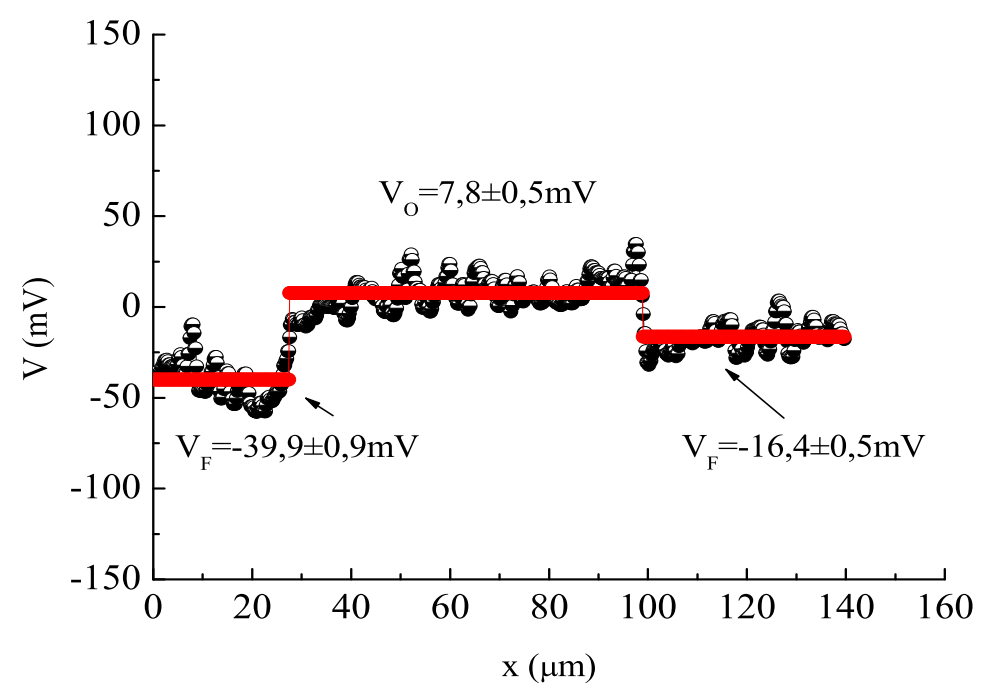

Figura 4.18: Perfil de médio potencial calculado a partir dos dados obtidos na primeira imagem KFM capturada.

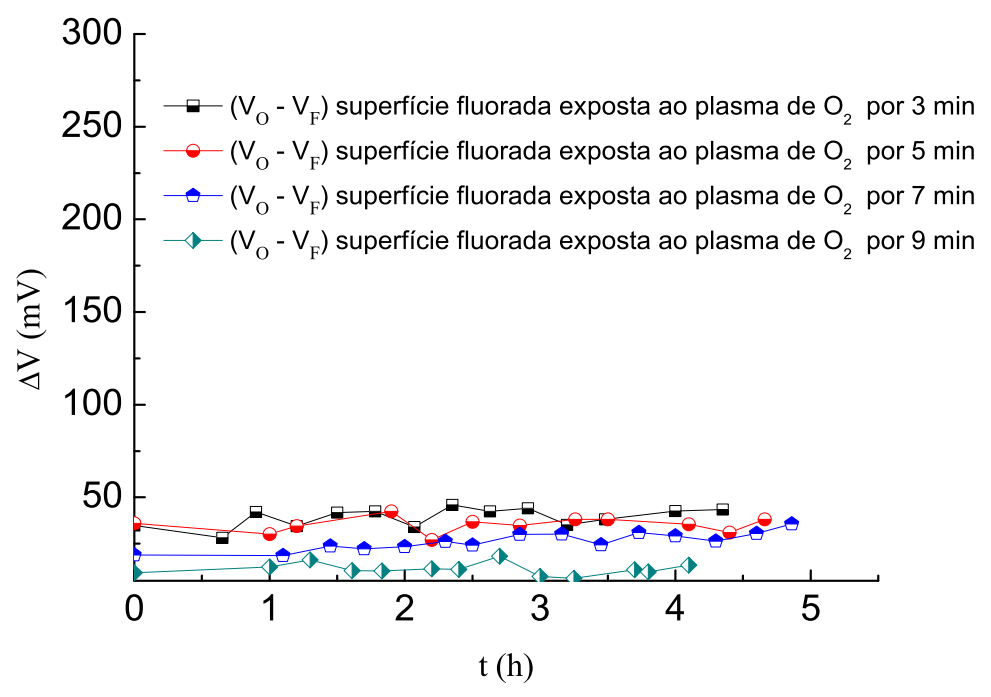

Figura 4.19: Gráfico da diferença de potencial entre as regiões com terminações de flúor e de oxigênio obtidos a partir das imagens KFM ao longo do tempo no qual a superfície era banhada com hélio gasoso. As várias curvas correspondem a diferentes tempos de exposição ao plasma de oxigênio. 


\subsection{Resultados para amostra contendo regiões com terminações de superfície de hidrogênio, de flúor e de oxigênio.}

Amostras com regiões adjacentes contendo hidrogênio, flúor e oxigênio foram produzidas seguindo uma metodologia similar a que foi usada na seção 2.6. Na figura 4.20 é mostrado uma micrografia obtida por sinal de elétrons secundários no MEV de uma amostra com regiões adjacentes contendo 3 diferentes terminações. O contraste se refere a diferentes propriedades elétricas entre as regiões com diferentes terminações, onde os círculos correspondem a terminações de oxigênio as faixas correspondem à terminações de flúor e as regiões quadradas, que apresentam tonalidades mais escuras, correspondem às terminações de hidrogênio. Foram preparadas 2 amostras com as 3 terminações mencionadas. Inicialmente uma litografia foi realizando mantendo as regiões em forma de quadrados protegidas com PMMA. Então a primeira amostra foi sujeita a um tratamento de plasma de $S F_{6}$ pelo tempo de 3 minutos e a segunda amostra pelo tempo de 5 minutos. Na sequência, os mascaramentos foram removidos e novas litografias foram realizadas expondo apenas as regiões circulares, onde a primeira amostra foi exposta ao plasma de oxigênio por 2 minutos e a segunda pelo tempo de 4 minutos. Após a remoção completa dos mascaramentos, a primeira amostra foi imageada por MEV, obtendo-se a figura 4.20. A primeira amostra será identificada no texto que segue pelo índice HF3O2 e a segunda será identificada pelo índice HF5O4, respectivamente. Uma análise qualitativa da figura 4.20 sugere que o tratamento utilizando plasma de oxigênio apresenta resultados diferentes para as regiões de superfície contendo originalmente hidrogênio e as regiões contendo originalmente flúor. 


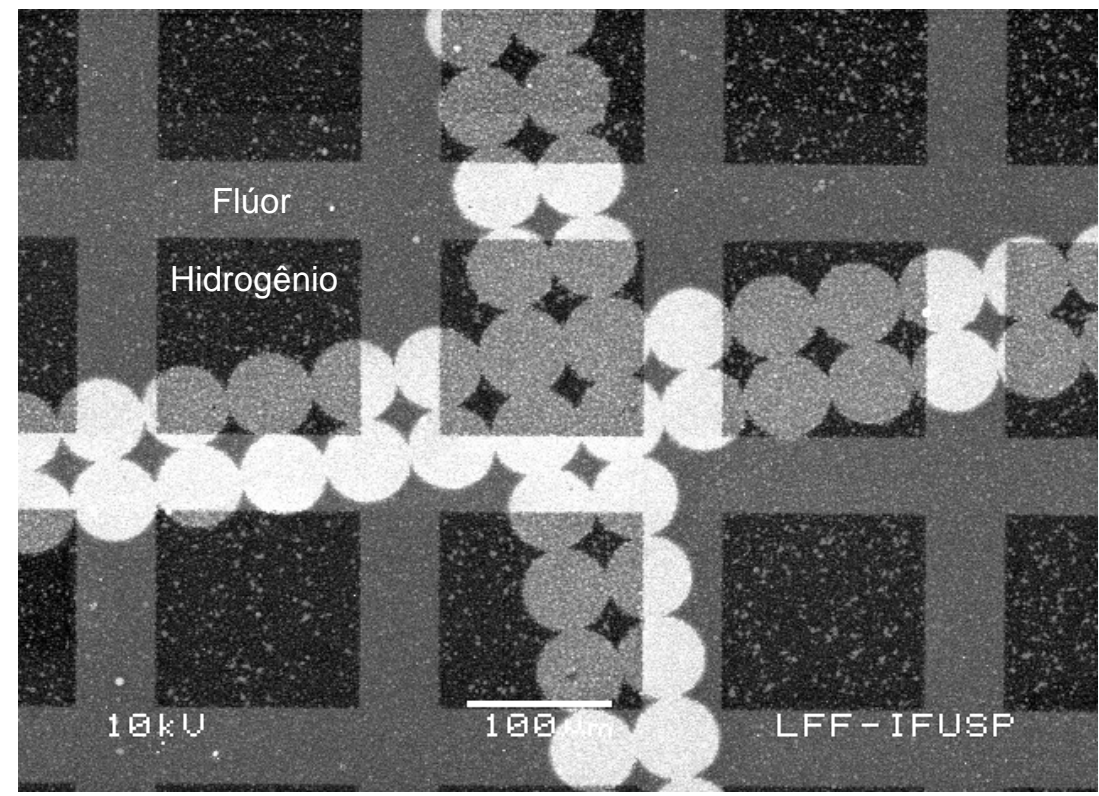

Figura 4.20: Micrografia MEV utilizada para identificar a intersecção entre as regiões com terminações de hidrogênio, de flúor e de oxigênio, para o caso da amostra tratada por 3 minutos com plasma de $\mathrm{SF}_{6}$ e 2 minutos com plasma de $\mathrm{O}_{2}$

Na figura 4.21 são mostradas as imagens de AFM e KFM da amostra HF3O2. Na imagem KFM é mostrado o mapeamento do potencial de superfície, onde podemos ver claramente o contraste devido as regiões com terminações de flúor, de oxigênio e de hidrogênio. Da mesma forma, que na imagem MEV (ver Figura 4.20)na micrografia KFM (ver Figura 4.21 a direita), podemos observar que são apresentados diferentes contrastes para as regiões tratadas com plasma de oxigênio, quando originalmente continham terminações de hidrogênio e quando continham terminações de flúor. Para medida do potencial de superfície nas regiões com diferentes terminações, utilizamos a ferramenta de cross section através das linhas pretas mostradas na figura 4.22, obtendo-se assim os perfis de potencial de superfície, como pode ser visto na figura 4.23 .

Nos gráficos mostrados nas figuras 4.24 e 4.25 podemos observar o potencial e a diferença de potencial, respectivamente, em função do tempo $t$ de imersão em hélio gasoso para cada região com terminações de hidrogênio, de flúor e de oxigênio. No caso desta ultima terminação, temos diferentes resultados para regiões originalmente hidrogenadas e regiões fluoradas. Para estas regiões iremos adotar as seguintes índices $O(H)$ e $O(F)$, respectivamente.

Nos gráficos mostrados nas figuras 4.26 e 4.27 podemos observar o potencial e a diferença de potencial, respectivamente, em função do tempo $t$ de imersão em hélio gasoso para cada região com terminações de hidrogênio, de flúor e de oxigênio. No caso desta ultima terminação, da mesma forma que para a amostra anterior, temos diferentes resultados para regiões original- 
mente hidrogenadas e regiões originalmente fluoradas. Para estas regiões também iremos adotar os seguintes índices $O(H)$ e $O(F)$, respectivamente.

Na tabela 4.4 são apresentados os valores médios dos potenciais, para cada região com diferente terminação. A média foi calculada a partir do tempo de $2 \mathrm{~h}$ de permanência em hélio gasoso para a amostra HF3O2. Para a amostra HF5O4 a média no potencial de cada terminação foi calculada a partir do tempo de $1,5 \mathrm{~h}$ de permanência em atmosfera de hélio gasoso. Para os valores de potencial médio da amostra HF5O4 foi subtraído $14 \mathrm{mV}$ de todos os valores para facilidade de comparação, o que não invalida o resultado desde que o KFM não fornece valores absolutos. Como pode ser observado na tabela 4.4 os potenciais das regiões com terminações de flúor $V_{F}$ e de hidrogênio $V_{H}$ apresentam os mesmos valores dentro das incertezas. Este indica que a terminações de superfície de flúor e de hidrogênio apresentam valores bem mais estáveis quando comparado aos valores de potencial referente ao oxigênio $O(H)$ e $O(F)$.

Na tabela 4.5 são apresentados as diferenças de potencial médias entre as regiões com diferentes terminações. $V_{F}-V_{H}$ apresenta os mesmos valores dentro de suas incertezas, o que mostra não haver variação no resultado no tratamento com plasma de $S F_{6}$ quando os tempos de exposição usados são de 3 ou 5 minutos. No entanto, comparando o valor aqui obtido para $V_{F}-V H \cong 96 \mathrm{mV}$ com o melhor resultado apresentado na seção 4.5, observamos uma variação considerável. Note que a amostra apresentada na seção 4.5 foi tratada em plasma de $S F_{6}$ por 6 minutos (3 minutos para remoção do PMMA e mais 6 minutos de real exposição ao plasma de $S F_{6}$ ). Uma possível justificativa para essa diferença nos resultados seria o fato das regiões com terminações de $\mathrm{H}$ e de $\mathrm{F}$ terem sido recobertas com PMMA para o $2^{\underline{O}}$ processo de litografia nas amostras $\mathrm{HF} 3 \mathrm{O} 2$ e HF5O4, o que pode ter levado à quebra de ligações de $\mathrm{H}$ e de $\mathrm{F}$ nas superfícies.

Ainda na tabela 4.4 é possível observar que $V_{O(F)}-V_{F}$ apresenta valor maior em módulo para a amostra HF5O4 quando comparado com a amostra $\mathrm{HF} 3 \mathrm{O} 2$ significando que, o maior tempo de exposição ao plasma de oxigênio aumenta a eficiência em remover as terminações de flúor por terminações de oxigênio. No entanto, esse aumento não é observado para o caso da diferença de potencial $V_{O(H)}-V_{H}$. Quanto a $V_{O(F)}-V_{O(H)}$ ocorreu sensível diminuição devido ao maior tempo de exposição ao plasma de oxigênio, viabilizando uma maior substituição de regiões originalmente fluoradas por regiões com terminações de oxigênio. 
Tabela 4.4: Potenciais em valores médios das regiões com terminações de hidrogênio, de flúor e de oxigênio. Para a amostra HF5O4 foi subtraído $14 \mathrm{mV}$ de todos os valores.

\begin{tabular}{|c|c|}
\hline \multicolumn{2}{|c|}{ Potenciais médios para cada terminação } \\
\hline \hline Amostra HF3O2 & Amostra HF5O4 \\
\hline$V_{F}=99 \pm 5 \mathrm{mV}$ & $V_{F}=94 \pm 6 \mathrm{mV}$ \\
\hline$V_{O(F)}=33 \pm 1 \mathrm{mV}$ & $V_{O(F)}=-14 \pm 1 \mathrm{mV}$ \\
\hline$V_{O(H)}=-50 \pm 3 \mathrm{mV}$ & $V_{O(H)}=-37 \pm 1 \mathrm{mV}$ \\
\hline$V_{H}=17 \pm 2 \mathrm{mV}$ & $V_{H}=17 \pm 1 \mathrm{mV}$ \\
\hline
\end{tabular}

Tabela 4.5: Diferença de potencial médio obtido entre as regiões com diferentes terminações de superfície.

\begin{tabular}{|c|c|}
\hline \multicolumn{2}{|c|}{ Diferença de potencial média. } \\
\hline \hline Valor final médio para HF3O2 & Valor final médio para HF5O4 \\
\hline$V_{F}-V_{H}=82 \pm 7 m V$ & $V_{F}-V_{H}=77 \pm 5 \mathrm{mV}$ \\
\hline$V_{O(H)}-V_{H}=-76 \pm 5 m V$ & $V_{O(H)}-V_{H}=-52 \pm 2 m V$ \\
\hline$V_{O(F)}-V_{F}=-66 \pm 5 m V$ & $V_{O(F)}-V_{F}=-109 \pm 6 m V$ \\
\hline$V_{O(F)}-V_{O(H)}=92 \pm 2 m V$ & $V_{O(F)}-V_{O(H)}=20 \pm 1 m V$ \\
\hline
\end{tabular}

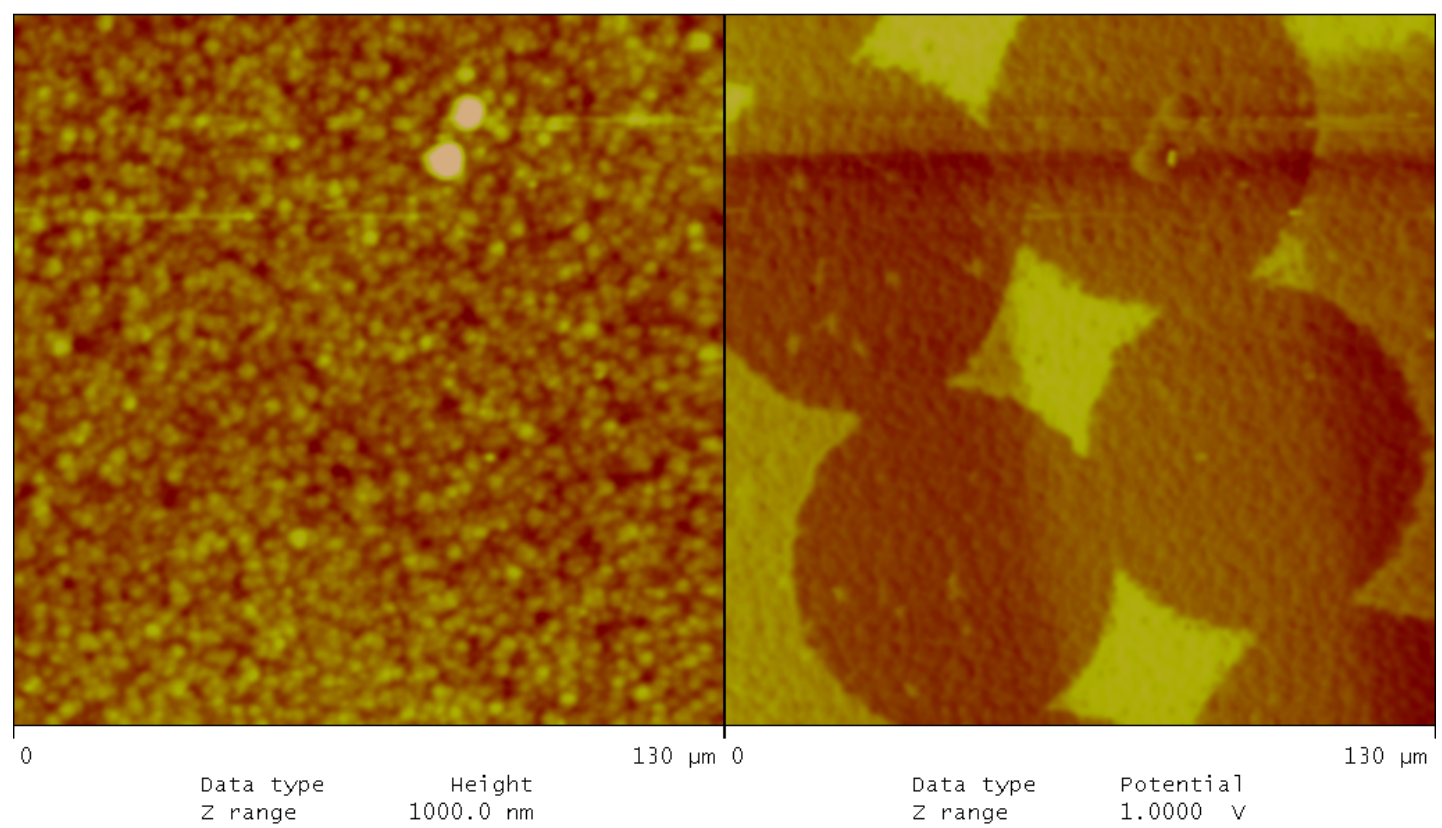

Figura 4.21: Micrografias de AFM e KFM, sendo a imagem da esquerda (AFM) referente a topografia da amostra e a imagem da direita (KFM) referente ao mapeamento do potencial de superfície. As regiões mais claras (faixas) correspondem a terminações de flúor, as regiões mais escuras (círculos) correspondem a terminação de oxigênio e as demais correspondem as terminações de hidrogênio. 

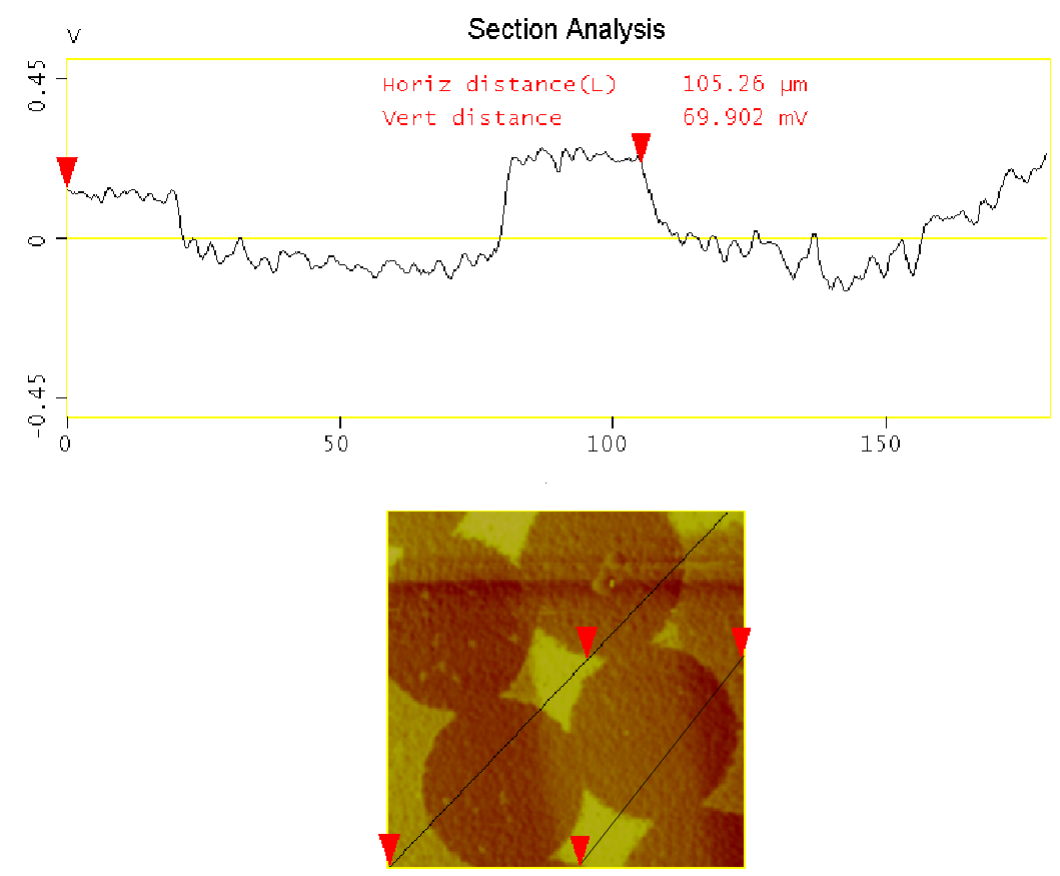

Figura 4.22: Tela no NanoScope IIIa apresentando o perfil de potencial de superfície medido para a amostra HF3O2, medido utilizando a ferramenta de cross-section.
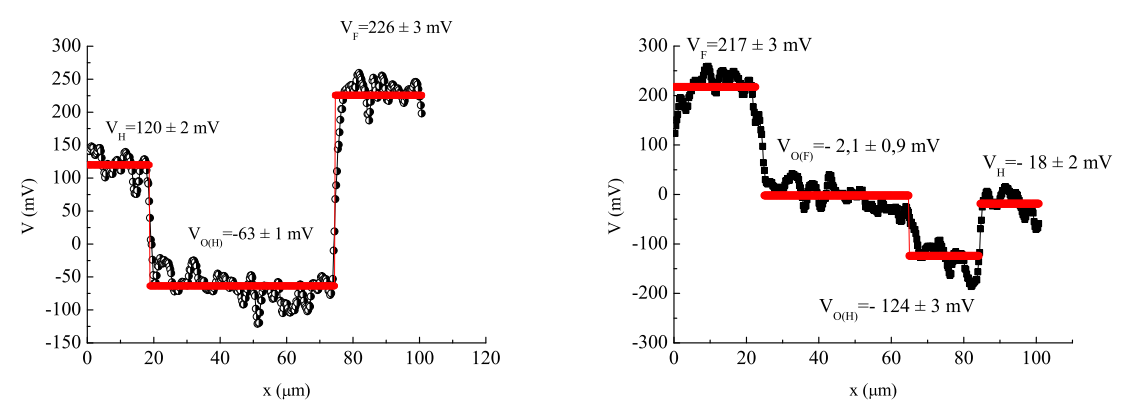

Figura 4.23: Perfil de Potencial de superfície referente às linhas traçadas na figura 4.22, na forma de gráfico do software ORIGIN. 


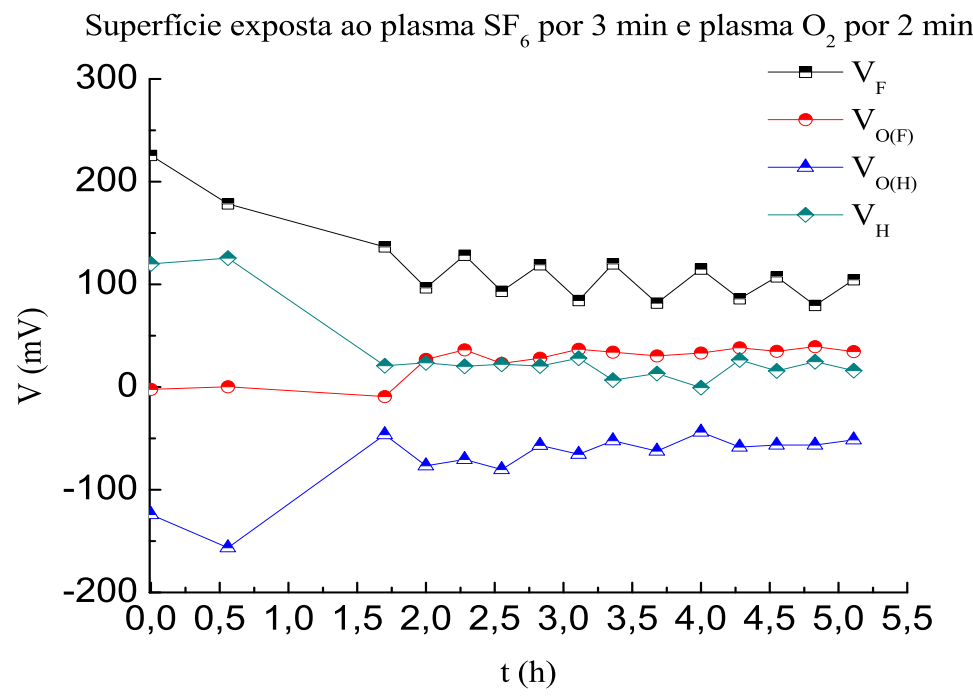

Figura 4.24: Potenciais das regiões com diferentes terminações da amostra HF3O2 obtidos a partir de imagens de KFM em função do tempo $t$ no qual a superfície era banhada com hélio gasoso. Os potenciais referentes as regiões com terminações de oxigênio estão designadas com índices $O_{(F)}$ para o caso onde havia anteriormente terminações de $\mathrm{F}$ e com índice $O_{(H)}$ quando as terminações eram de $\mathrm{H}$.

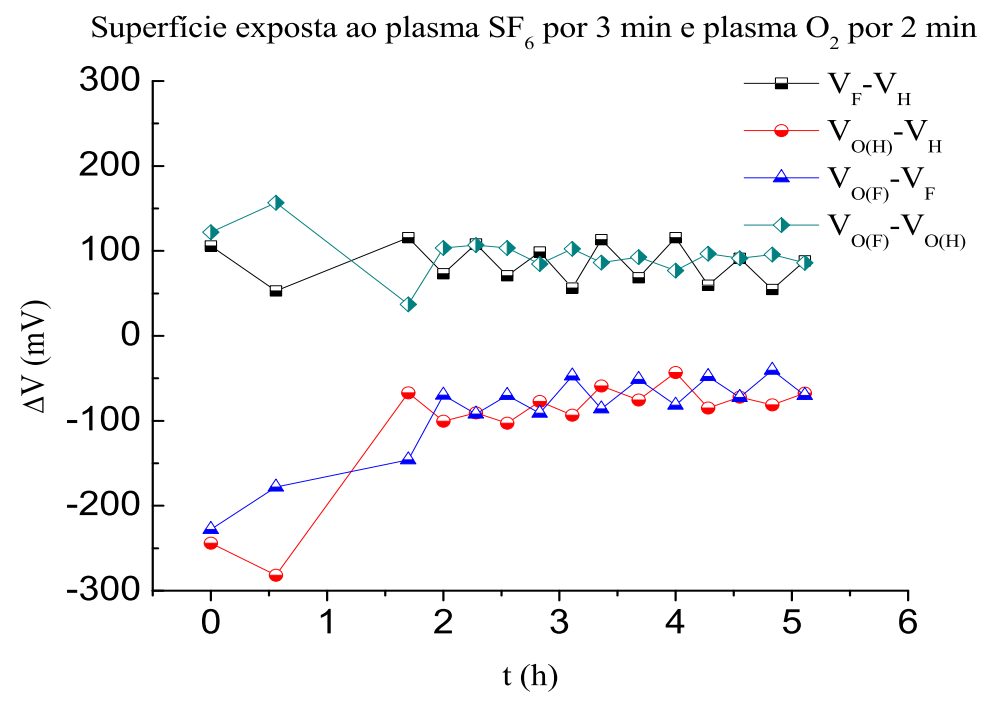

Figura 4.25: Diferenças de potencial entre as diferentes regiões especificas na figura 4.24 


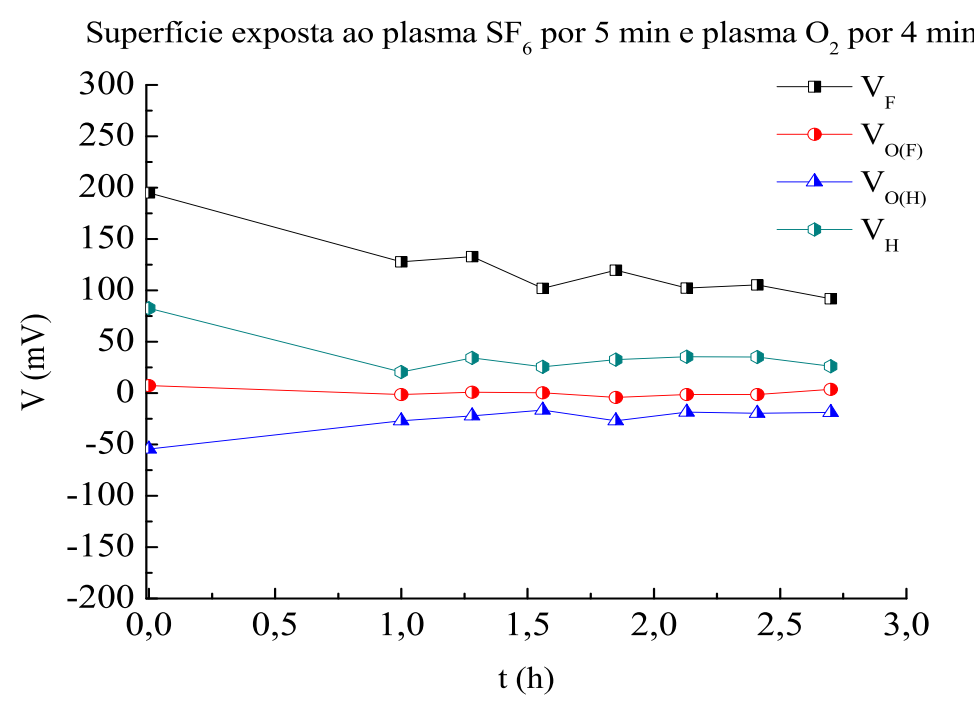

Figura 4.26: Potenciais das regiões com diferentes terminações da amostra HF5O4 obtido a partir de imagens de KFM em função do tempo $t$ no qual a superfície era banhada com hélio gasoso.

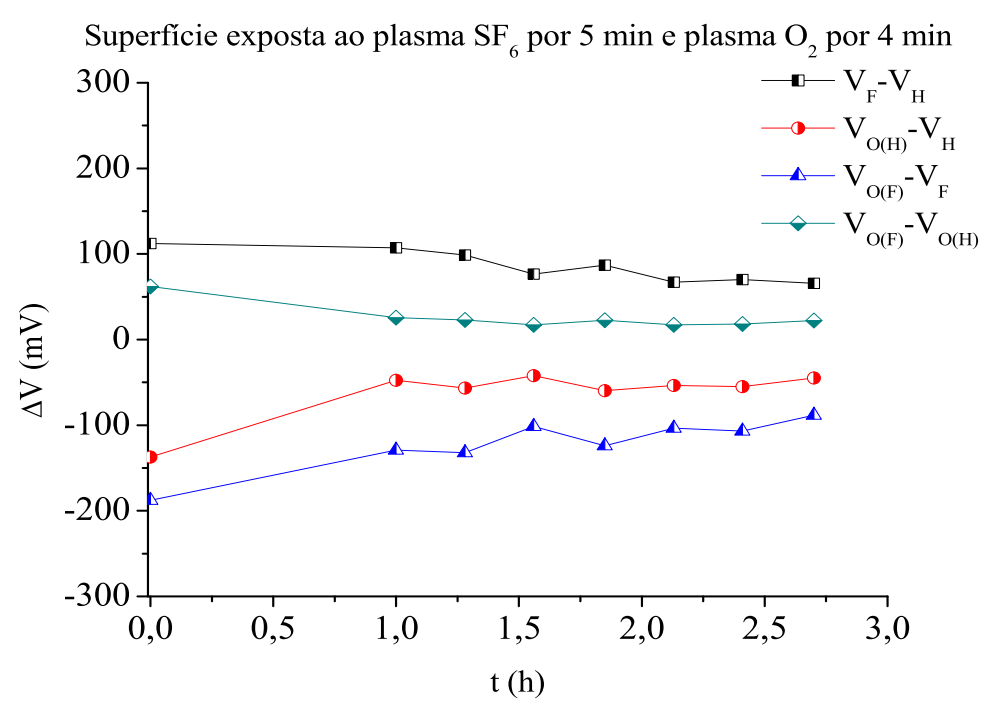

Figura 4.27: Diferença de potencial entre as diferentes regiões especificas na figura 4.26. 


\subsection{Resultados das Medidas de ângulo de Contato e energia livre de superfície.}

Para fazermos medidas de ângulo de contato 3 superfícies de diamante foram preparadas, cada uma delas superfícies contendo apenas uma espécie de terminação. Utilizando água destilada, a amostra com terminação de oxigênio, apresentou um ângulo de contato de $75^{\circ}$, sendo esta terminação a mais hidrofílica; a amostra com terminação de hidrogênio, teve um ângulo de contato de $83^{\circ}$; e a amostra, com terminação de flúor, $93^{\circ}$, esta sendo a mais hidrofóbica de todas. Fizemos microscopia ótica de superfície de diamante com regiões adjacentes com terminações de hidrogênio e oxigênio. A figura 4.28 mostra esta superfície quando seca, na figura 4.29 mostra a mesma superfície quando molhada com água deionizada. A imagem da superfície seca não apresenta contraste entre as regiões com diferentes terminações. No entanto, quando a superfície está molhada podemos ver claramente as regiões hidrofílicas, com terminação de oxigênio.

Para obtenção das energias interfaciais das três diferentes terminações, foi utilizado diiodometano $\left(\mathrm{CH}_{2} \mathrm{I}_{2}\right)$ cujos ângulos de avanço obtidos foram $38^{\circ}, 41^{\circ}$ e $51^{\circ}$ para superfícies com terminações de hidrogênio, oxigênio e flúor, respectivamente.

As tabelas 4.6 e 4.7 apresentam resultados obtidos através do método de Fowkes (média geométrica) e do método de Wu (média harmônica). Nessas tabelas são dadas as componentes dispersivas e polares para cada uma das regiões de diferentes terminações, apresentando também as respectivas energias livres de superfície.

O gráfico da Figura 4.30 apresenta as energias livres de superfície para as três amostras com diferentes terminações, calculadas através do método de Fowkes (média geométrica) e do método de $\mathrm{Wu}$ (média harmônica). Apesar dos resultados obtidos através dos dois diferentes métodos terem fornecido valores com discrepâncias entre 11 e 14\%, ambos apresentaram o menor valor de energia livre de superfície para a amostra mais hidrofóbica e o maior valor para a amostra mais hidrofílica.

O gráfico da Figura 4.31 apresenta as componentes polares e dispersivas das energias livres de superfície para as três amostras com diferentes terminações, calculadas através do método de Fowkes (média geométrica) e do método de Wu (média harmônica). É possível observar que, para ambos os métodos, as componentes dispersivas são praticamente iguais. Quanto às componentes polares, o método de $\mathrm{Wu}$ (média harmônica) apresenta valores superiores ao obtidos pelo método de Fowkes (média geométrica), sendo a componente responsável pela diferença observada na energia livre de superfícies. Note ainda que, para ambos os métodos, as 
componentes polares de menor valor correspondem à superfície mais hidrofóbica e os maiores valores à superfície mais hidrofílica, o que mostra coerência com a literatura [34, 49]. 


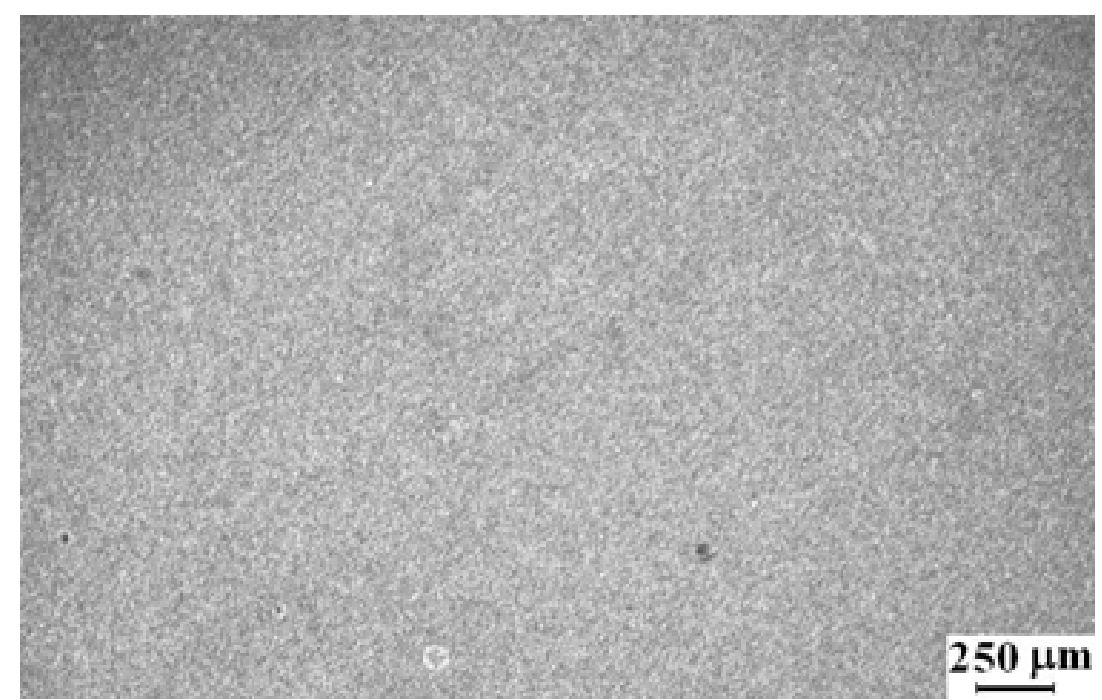

Figura 4.28: Micrografia óptica de superfície do filme de diamante contendo regiões adjacentes com terminações de superfície de hidrogênio e oxigênio.

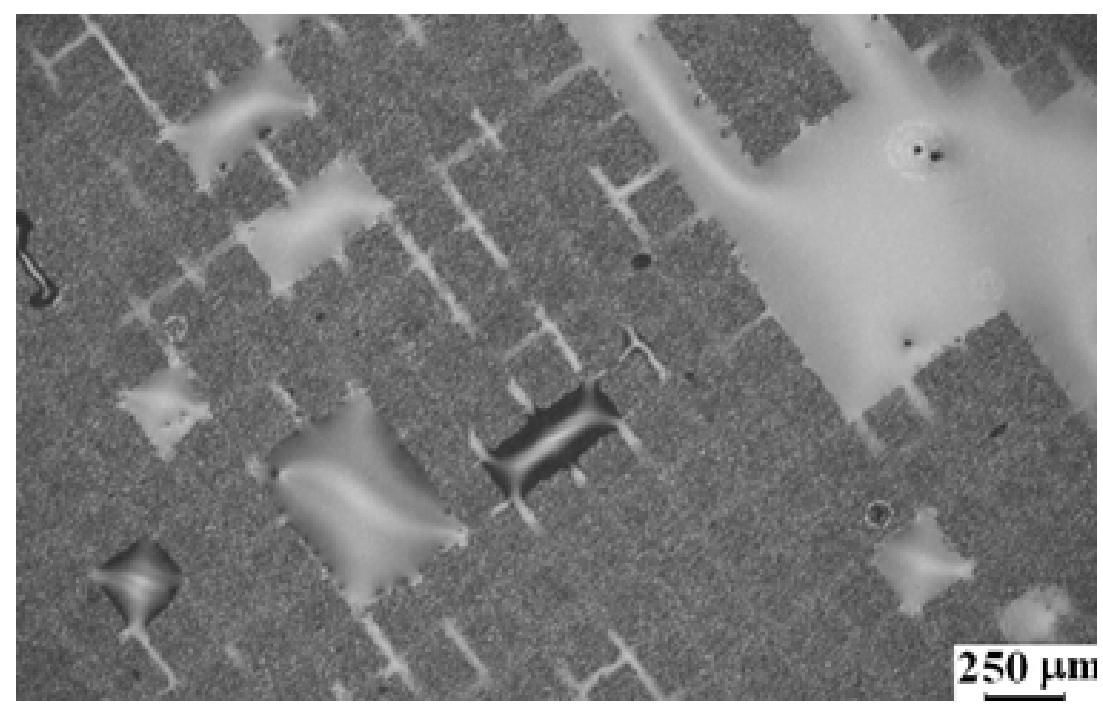

Figura 4.29: Micrografia óptica de superfície do filme de diamante contendo regiões adjacentes com terminações de superfície de hidrogênio e oxigênio, com a superfície molhada mostrando as regiões hidrofílicas com terminação de oxigênio. 
Tabela 4.6: Energias livres de superfície calculadas utilizando o método geométrico para as diferentes terminações de superfície

\begin{tabular}{|c|c|}
\hline \multicolumn{2}{|c|}{ Energia livre de superfície obtido para as terminações de hidrogênio, de flúor e de oxigênio. } \\
\hline Terminações & Média Geométria \\
\hline Flúor & $\gamma_{S V}^{d}=33,7 \pm 0,2 \mathrm{~mJ} / \mathrm{m}^{2} ; \quad \gamma_{S V}^{p}=2 \pm 1 \mathrm{~mJ} / \mathrm{m}^{2} ; \quad \gamma_{S V}=36 \pm 1 \mathrm{~mJ} / \mathrm{m}^{2}$ \\
\hline Hidrogênio & $\gamma_{S V}^{d}=40,4 \pm 0,3 \mathrm{~mJ} / \mathrm{m}^{2} ; \gamma_{S V}^{p}=7,0 \pm 0,6 \mathrm{~mJ} / \mathrm{m}^{2} ; \gamma_{S V}=47,4 \pm 0,4 \mathrm{~mJ} / \mathrm{m}^{2}$ \\
\hline Oxigênio & $\gamma_{S V}^{d}=39,0 \pm 0,5 \mathrm{~mJ} / \mathrm{m}^{2} ; \gamma_{S V}^{p}=10,1 \pm 0,6 \mathrm{~mJ} / \mathrm{m}^{2} ; \gamma_{S V}=49,2 \pm 0,2 \mathrm{~mJ} / \mathrm{m}^{2}$ \\
\hline \hline
\end{tabular}

Tabela 4.7: Energias livres de superfície calculadas utilizando o método harmônico para as diferentes terminações de superfície

\begin{tabular}{|c|c|}
\hline \multicolumn{3}{|c|}{ Energia livre de superfície obtido para as terminações de hidrogênio, de flúor e de oxigênio. } \\
\hline Terminações & \multicolumn{2}{|c|}{ Média Harmônica } \\
\hline Flúor & $\gamma_{S V}^{d}=34,9 \pm 0,1 \mathrm{~mJ} / \mathrm{m}^{2} ; \quad \gamma_{S V}^{p}=6 \pm 2 \mathrm{~mJ} / \mathrm{m}^{2} ; \quad \gamma_{S V}=41 \pm 2 \mathrm{~mJ} / \mathrm{m}^{2}$ \\
\hline Hidrogênio & $\gamma_{S V}^{d}=40,9 \pm 0,3 \mathrm{~mJ} / \mathrm{m}^{2} ; \gamma_{S V}^{p}=12,4 \pm 0,6 \mathrm{~mJ} / \mathrm{m}^{2} ; \gamma_{S V}=53,2 \pm 0,4 \mathrm{~mJ} / \mathrm{m}^{2}$ \\
\hline Oxigênio & $\gamma_{S V}^{d}=39,7 \pm 0,4 \mathrm{~mJ} / \mathrm{m}^{2} ; \gamma_{S V}^{p}=15,5 \pm 0,5 \mathrm{~mJ} / \mathrm{m}^{2} ; \gamma_{S V}=55,1 \pm 0,1 \mathrm{~mJ} / \mathrm{m}^{2}$ \\
\hline \hline
\end{tabular}

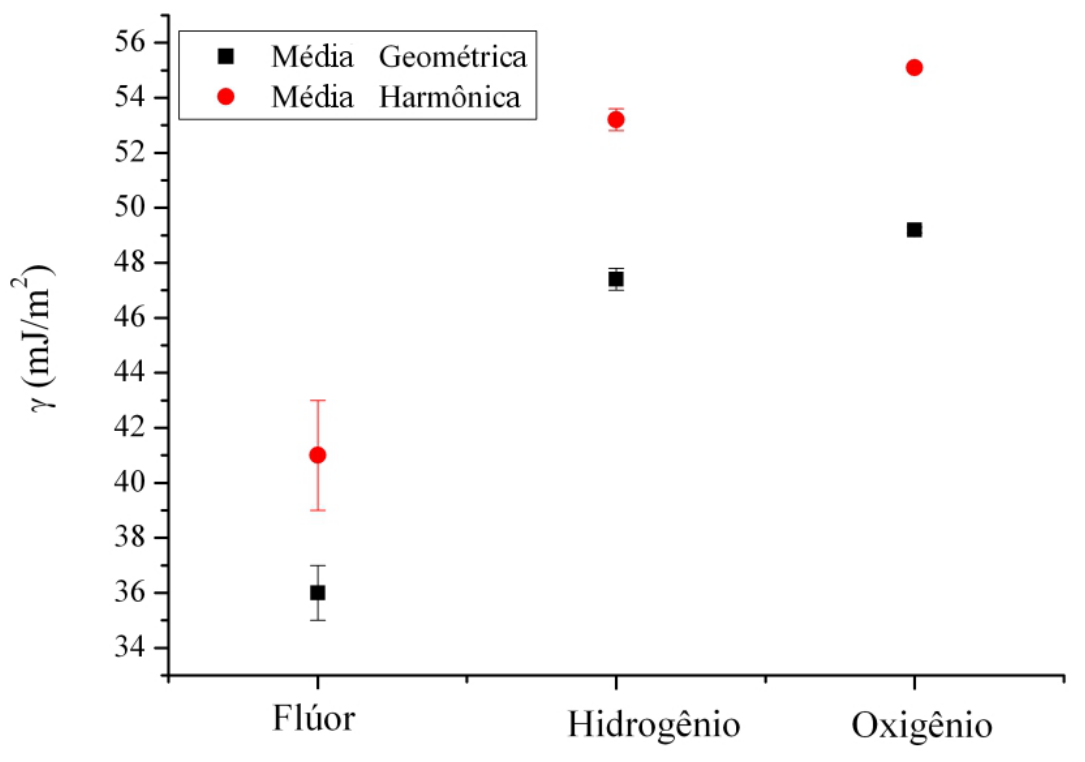

Figura 4.30: Gráfico das energias livres de superfície obtido pelo método de Fowkes (média geométrica) e pelo método de Wu (média harmônica) 


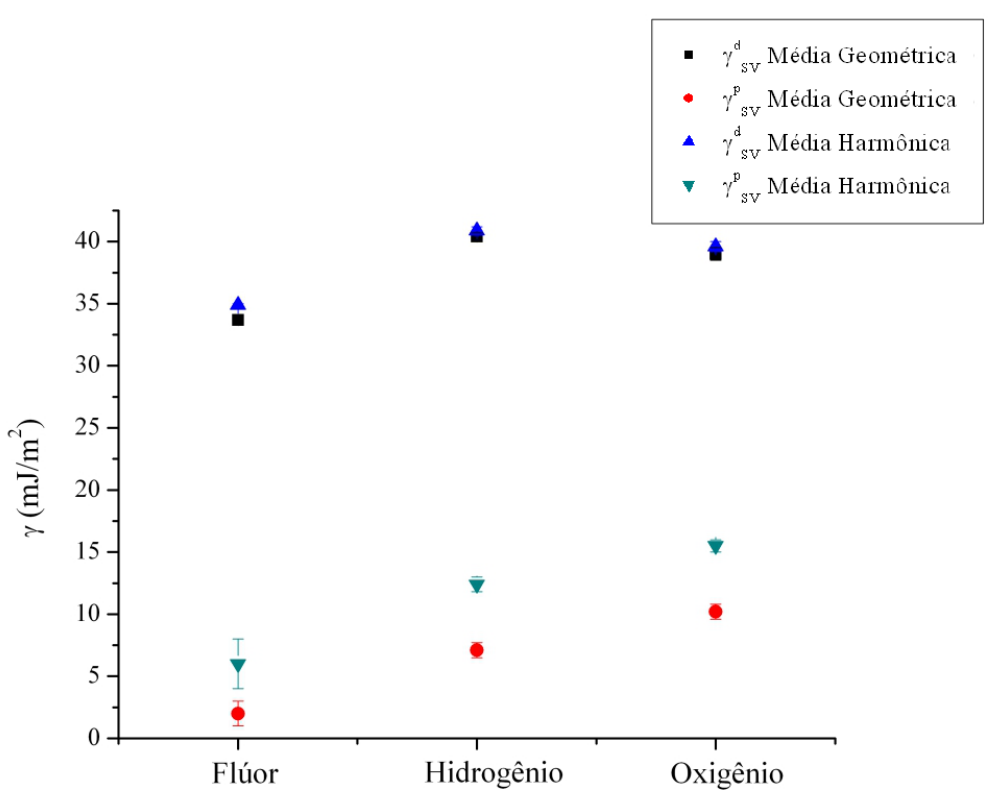

Figura 4.31: Gráfico das componentes dispersivas e polares obtidas pelo método de Fowkes (média geométrica) e pelo método de Wu (média harmônica) 


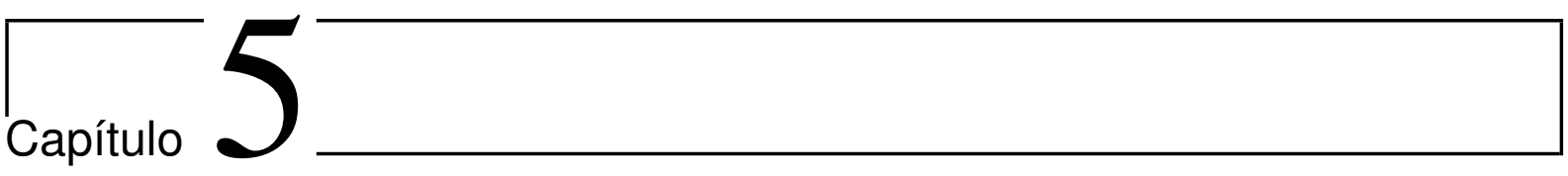

\section{SUMÁRIO E CONCLUSÕES}

Nesta Dissertação apresentamos os resultados obtidos para a modificação de superfícies de filmes de diamante depositados por CVD. Inicialmente foram ajustados parâmetros de deposição para a obtenção de filmes nanocristalinos de diamante, o que foi conseguido adicionando nitrogênio à mistura de gás em uma proporção $3: 3: 300$ em volume de metano, nitrogênio e hidrogênio, respectivamente. O critério para a escolha desses parâmetros foi a maior intensidade do pico característico de diamante em espectroscopia Raman. A comprovação de que os filmes de diamante eram nanocristalinos foi obtida através de difração de raios-X, mostrando um valor médio próximo a $20 \mathrm{~nm}$. O filme originalmente depositado possuia terminações de hidrogênio em sua superfície. A substituição dessas terminações por flúor ou oxigênio foi realizada através de exposição por plasma de hexafluoreto de enxofre e por plasma de oxigênio, respectivamente. Superfícies de diamante com regiões adjacentes com diferentes terminações foram obtidas através de mascaramentos realizados por litografia por feixe de elétrons. Microscopia eletrônica de varredura obtida por sinal de elétrons secundários apresentou contraste para essas amostras, desde que regiões com diferentes terminações apresentam diferentes propriedades elétricas. Essas mesmas superfícies foram também caracterizadas por microscopia de força atômica e Kelvin Force Microscopy em atmosfera de hélio. Para o caso de superfícies contendo regiões adjacentes com terminações de hidrogênio e oxigênio, a diferença de potencial obtida foi de $161 \pm 7 \mathrm{mV}$. Para o caso de terminações de hidrogênio e flúor, a diferença de potencial obtida foi de $279 \pm 3 \mathrm{mV}$. E, para o caso de terminações de flúor e oxigênio, a diferença de potencial obtida foi de $41 \pm 2 \mathrm{mV}$. Amostras com regiões adjacentes contendo hidrogênio, flúor e oxigênio foram produzidas utilizando dois diferentes tempos de exposição aos plasmas. Nestes casos observamos na micrografia KFM diferentes contrastes para as regiões tratadas com plasma de oxigênio, quando originalmente continham terminações de hidrogênio e quando continham terminações de flúor. As diferenças de potencial médias entre as regiões 
com terminações de flúor e de hidrogênio das duas amostras (contendo as três terminações) $V_{F}-V_{H}$ apresentam os mesmos valores, o que mostra não haver variação no resultado do tratamento com plasma de SF6 nos tempos de exposição usados de 3 e 5 minutos. As diferenças de potencial médias entre as regiões com terminações de oxigênio e de flúor das duas amostras (contendo as três terminações) $V_{O(F)}-V_{F}$ apresentaram o maior valor para o caso de maior tempo de exposição ao plasma de oxigênio, mostrando que nesse caso existe maior eficiência em remover as terminações de flúor por terminações de oxigênio. Quanto às diferenças de potencial entre as regiões contendo terminações de oxigênio, quando originalmente continham terminações de hidrogênio e quando continham terminações de flúor, $V_{O(F)}-V_{O(H)}$, ocorreu sensível diminuição devido ao maior tempo de exposição ao plasma de oxigênio, viabilizando uma maior substituição de regiões originalmente fluoradas por regiões com terminações de oxigênio. Para as medidas de ângulo de contato, foram preparadas três superfícies de diamante contendo apenas uma espécie de terminação. Foram medidos os ângulos de contato utilizando água destilada para as amostras com terminação de oxigênio, hidrogênio e flúor, obtendo-se os valores de $75^{\circ}, 83^{\circ}$ e $93^{\circ}$, respectivamente. Através dos métodos de Fowkes (média geométrica) e do método de Wu (média harmônica) foram determinadas as energias livres de superfície de cada uma dessas três amostras. Apesar dos resultados obtidos através dos dois diferentes métodos terem fornecido valores com discrepâncias entre 11 e 14\%, ambos apresentaram o menor valor de energia livre de superfície para a amostra mais hidrofóbica e o maior valor para a amostra mais hidrofílica. Também foram calculadas as componentes polares e dispersivas das energias livres de superfície das três amostras com diferentes terminações, utilizando os dois métodos mencionados. Foi possível observar que, para ambos os métodos, as componentes dispersivas são praticamente iguais. Quanto às componentes polares, o método de $\mathrm{Wu}$ apresenta valores superiores ao obtidos pelo método de Fowkes, sendo a componente responsável pela diferença observada na energia livre de superfícies. Foi ainda observado que, para ambos os métodos, as componentes polares de menor valor correspondem à superfície mais hidrofóbica e os maiores valores à superfície mais hidrofílica. 
$\prod_{\text {Apêndice }}$

\section{Resultados preliminares para modificação das superfícies de diamante.}

\section{A.1 Resultados da modificação de superfície utilizando gás de $\mathrm{O}_{2}$.}

Para a modificação da superfície do diamante com oxigênio, utilizamos os parâmetros descritos na seção 2.5.1 página 18. Para tais amostras serão apresentado os resultados obtidos, onde temos como grandeza variada o parâmetro tempo de exposição ao plasma de $O_{2}$ sendo que os demais foram mantidos constantes.

Na figura A.1)é apresentado a imagem de elétrons secundários para a amostra contendo regiões adjacentes com terminações de hidrogênio, nas regiões escuras, e oxigênio nas regiões claras. O contraste é devido à diferentes propriedades elétricas das regiões com diferentes terminações.

Na figura A.2 é apresentamos as micrografias de AFM e KFM. A imagem da esquerda mostra a topografia da amostra de filme de diamante policristalino obtida por AFM em tapping mode. Na imagem da direita temos o mapeamento do potencial da mesma superfície obtido por KFM. As regiões claras correspondem a terminações de oxigênio.

Na tabela A.1 são mostradas as diferenças de potencial medidas entre áreas adjacentes com terminações de hidrogênio e de oxigênio. Para obter essas medidas executamos a ferramenta de cross section (ver Figura A.3), obtendo-se assim o perfil de potencial médio. Através deste perfil de potencial é possível medir as diferenças de potencial existente entre as regiões com terminações de oxigênio e hidrogênio. 
Tabela A.1: Diferença de potencial obtido para diversos tempos de exposição ao plasma de $\mathrm{O}_{2}$.

\begin{tabular}{|c|c|}
\hline \multicolumn{2}{|c|}{ Diferença de potencial entre regiões com terminações de hidrogênio e de oxigênio } \\
\hline \hline Tempo de exposição & Diferença de Potencial \\
\hline 1 minuto & $\cong 22 \mathrm{mV}$ \\
\hline 2 minutos & $\cong 47 \mathrm{mV}$ \\
\hline 3 minutos & $\cong 8,5 \mathrm{mV}$ \\
\hline 4 minutos & $\cong 7,7 \mathrm{mV}$ \\
\hline
\end{tabular}

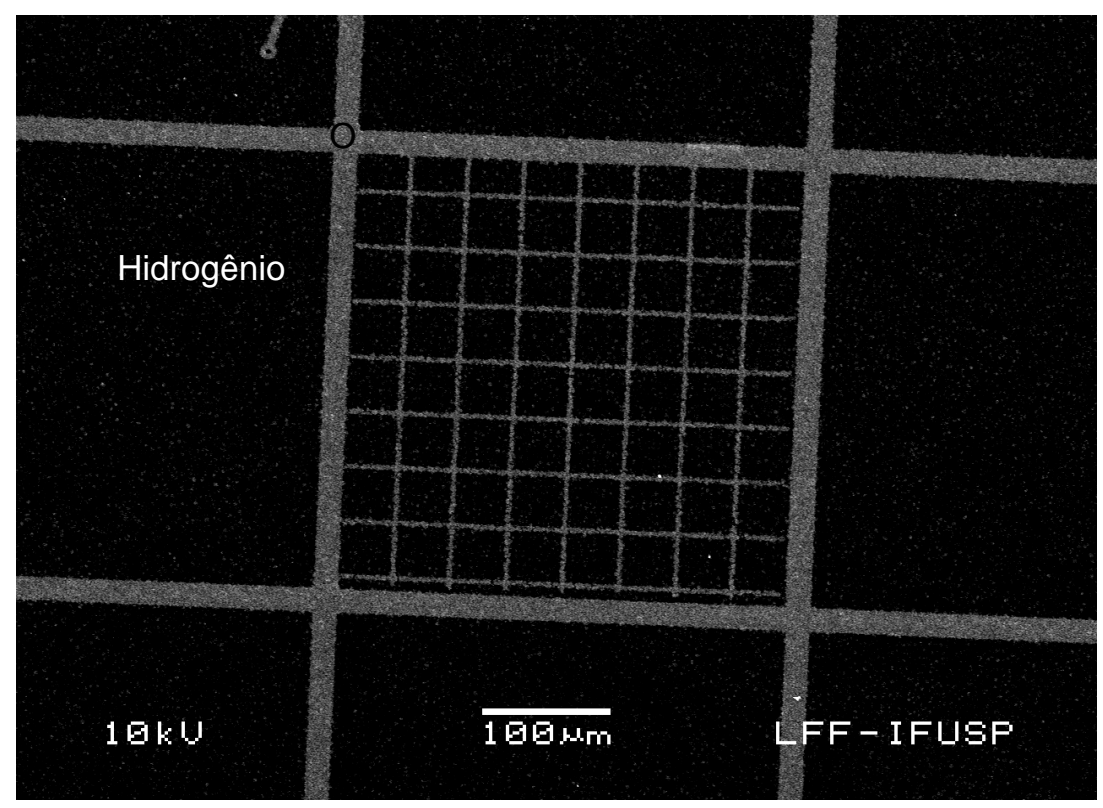

Figura A.1: Imagem MEV da superfície do filme de diamante apresentando regiões adjacentes com terminações de hidrogênio, nas regiões escuras, e de oxigênio nas regiões claras. 


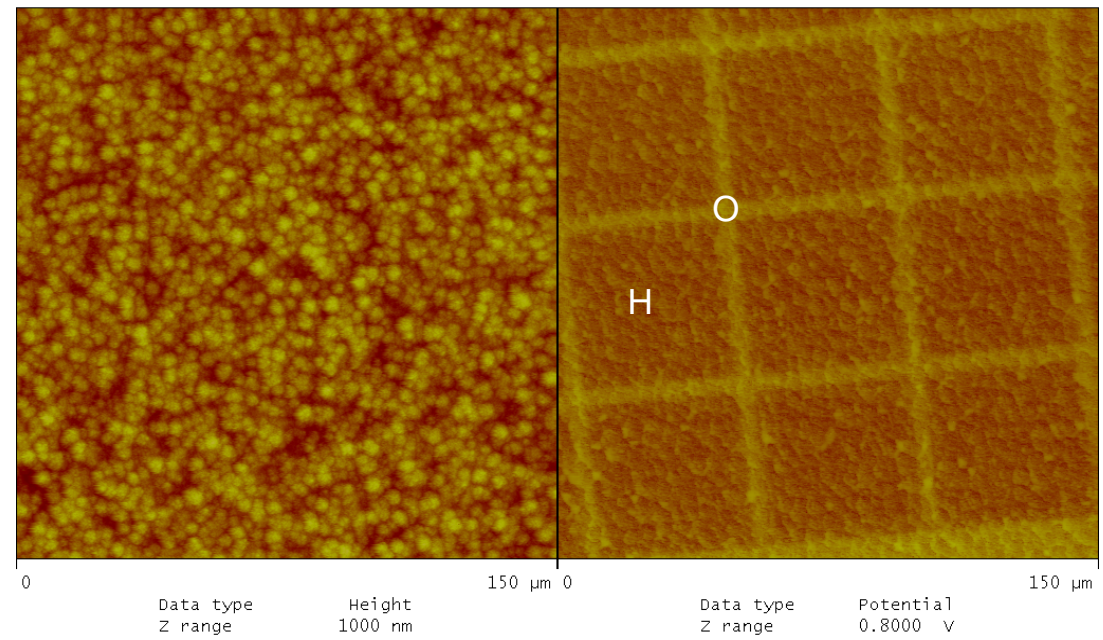

Figura A.2: Micrografia da Amostra do Filme de diamante exposto ao plasma de Oxigênio por 2 minutos. Na figura da esquerda temos a morfologia do filme de diamante obtido por AFM e na direita temos o respectivo mapeamento do potencial de superfície para a mesma região obtido por KFM.
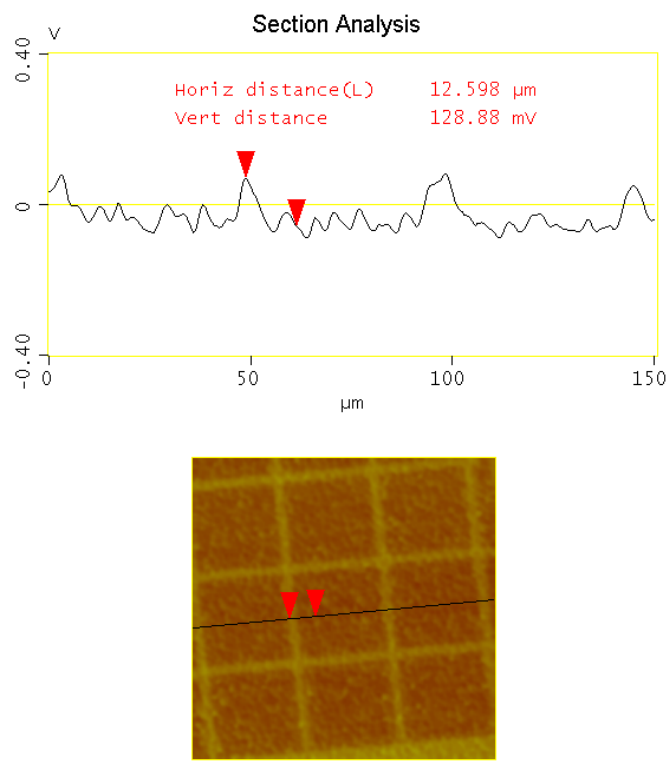

Figura A.3: Medida da diferença de potencial entre as regiões adjacentes de hidrogênio e de oxigênio obtido através da ferramenta cross section 


\section{A.2 Resultados da modificação de superfície utilizando gás de $S F_{6}$.}

Para a modificação da superfície do diamante com $S F_{6}$, utilizamos os parâmetros descritos na seção 2.5.2 página 19. Para tais amostras apresentamos os resultados obtidos, onde temos como grandeza variada o parâmetro tempo de exposição ao plasma de $S F_{6}$ sendo que os demais foram mantidos constante.

A Micrografia MEV da Amostra exposta ao plasma de $S F_{6}$ por 5 minutos pode ser vista na figura A.4, onde as regiões claras correspondem à terminações de flúor. Na figura A.5 temos micrografias obtidas simultaneamente de AFM e KFM onde, na imagem da esquerda é mostrada a topografia do filme de diamante policristalino e na imagem da direita temos o mapeamento do potencial da mesma superfície medido por KFM.

Na tabela A.2 são mostradas as diferenças de potencial medidas entre áreas adjacentes com terminações de hidrogênio e de flúor, para os diversos tempos de exposição ao plasma de gás SF6.

Tabela A.2: Diferença de potencial medido através da ferramenta de cross section para diversos tempos de exposição ao plasma de $S F_{6}$.

\begin{tabular}{|c|c|}
\hline \multicolumn{2}{|c|}{ Diferença de potencial entre regiões contendo terminações de hidrogênio e de flúor } \\
\hline Tempo de exposição & Diferença de Potencial \\
\hline 1 minuto & $\cong 63 \mathrm{mV}$ \\
\hline 3 minutos & $\cong 116 \mathrm{mV}$ \\
\hline 5 minutos & $\cong 114 \mathrm{mV}$ \\
\hline 7 minutos & $\cong 55 \mathrm{mV}$ \\
\hline
\end{tabular}




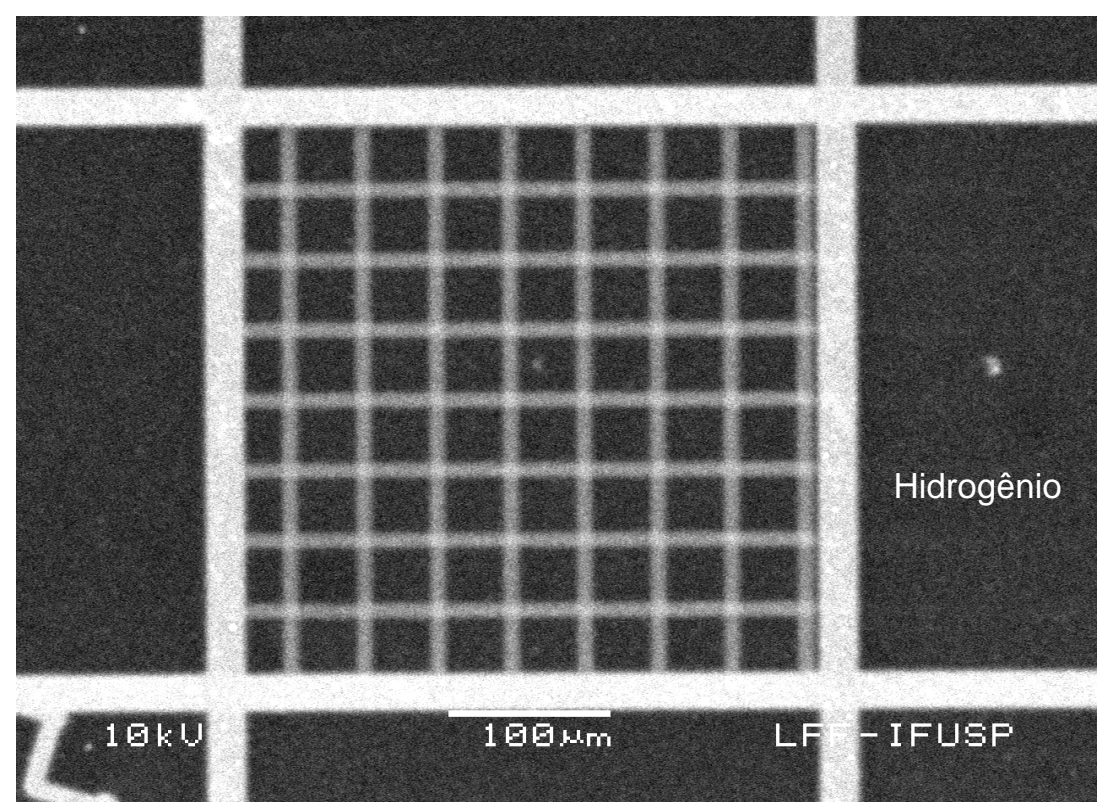

Figura A.4: Micrografia da Amostra do Filme de diamante exposto ao plasma de $S F_{6}$ por 5 minutos. As regiões claras correspondem à regiões com terminações de flúor.

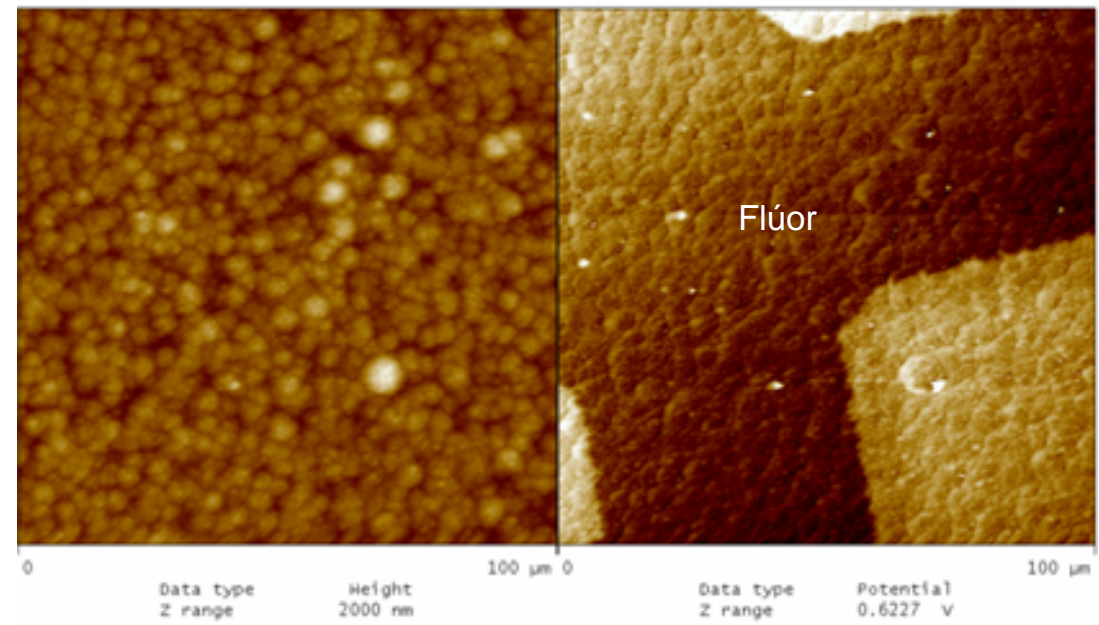

Figura A.5: AFM/KFM da Amostra do Filme de diamante exposto ao plasma de $S F_{6}$ por 5 minutos. As regiões escuras correspondem à regiões com terminações de flúor. 


\section{A.3 Resultados Para amostra contendo as terminações de su- perfície flúor e oxigênio.}

Para produzirmos superfícies de diamante com regiões contendo terminações de fluor e de oxigênio, utilizamos os métodos descritos na seção 2.6.

Na figura A.6 é mostrado uma micrografia obtida por AFM e simultaneamente KFM, onde a imagem da esquerda mostra a topografia da amostra de filme de diamante policristalino obtida por AFM e a imagem da direita temos o mapeamento do potencial da mesma superfície onde a região mais clara é correspondente a terminações de flúor e as regiões mais escuras correspondem a terminações de oxigênio.

Na tabela A.3 temos as diferenças de potencial medido entre áreas adjacentes com terminações de flúor e oxigênio, onde executamos a ferramenta de cross section, obtendo-se assim o perfil de potencial médio e através deste perfil medimos as diferenças de potencial para os diversos tempos de exposição ao plasma de gás $O_{2}$.

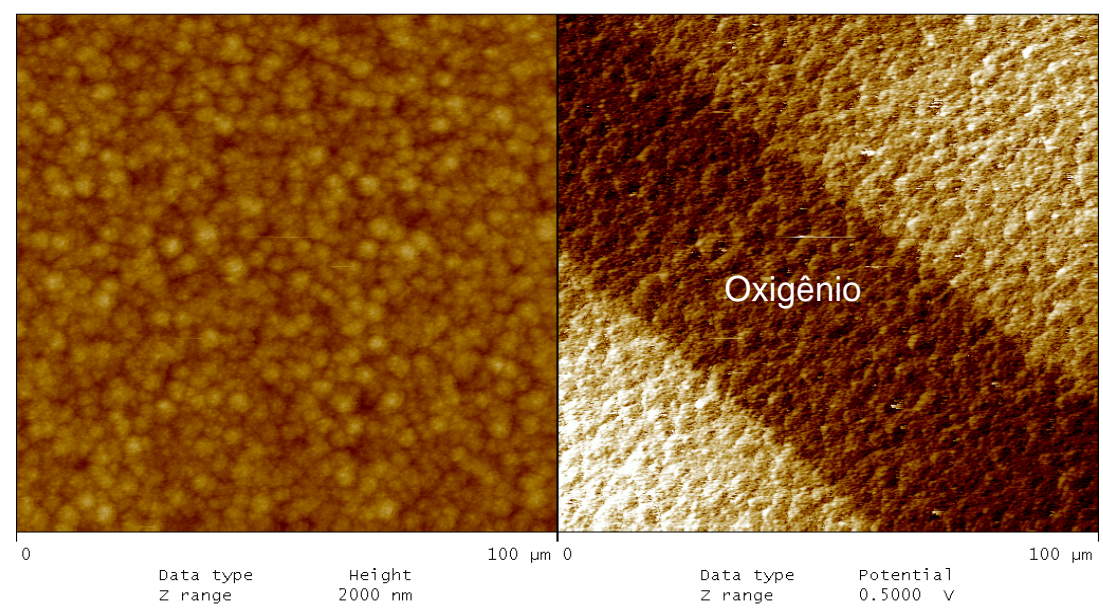

Figura A.6: AFM/KFM da Amostra do Filme de diamante exposto ao plasma de $S F_{6}$ por 5 minutos e em seguida, exposta ao plasma de oxigênio pelo tempo de 1 minuto. 
Tabela A.3: Diferença de Potencial medido através da ferramenta de cross section para superfície contendo regiões com terminações de flúor e de oxigênio.

\begin{tabular}{|c|c|}
\hline \multicolumn{2}{|c|}{ Diferença de potencial entre regiões contendo terminações de flúor e de oxigênio } \\
\hline Tempo de exposição & Diferença de Potencial \\
\hline 1 minuto & $\cong 140 \mathrm{mV}$ \\
\hline 2 minutos & $\cong 139 \mathrm{mV}$ \\
\hline 3 minutos & $\cong 36 \mathrm{mV}$ \\
\hline 4 minutos & $\cong 23 \mathrm{mV}$ \\
\hline
\end{tabular}




\section{A.4 Resultados Para amostra contendo as terminações de su- perfície de hidrogênio, flúor e oxigênio.}

Produzimos também uma amostra com regiões adjacentes contendo regiões adjacentes com terminações de hidrogênio, de flúor e de oxigênio seguindo uma metodologia similar a que foi usada na seção 2.6. Os tempos utilizados para expor ao plasma de $S F_{6}$ e posteriormente plasma de $\mathrm{O}_{2}$ foram determinados pelos resultados das melhores diferenças de potencial obtidas nas seções A.1 e A.2, respectivamente. Na figura A.7 é mostrado uma micrografia MEV utilizado para identificar a região de intersecção das 3 terminações de superfície.

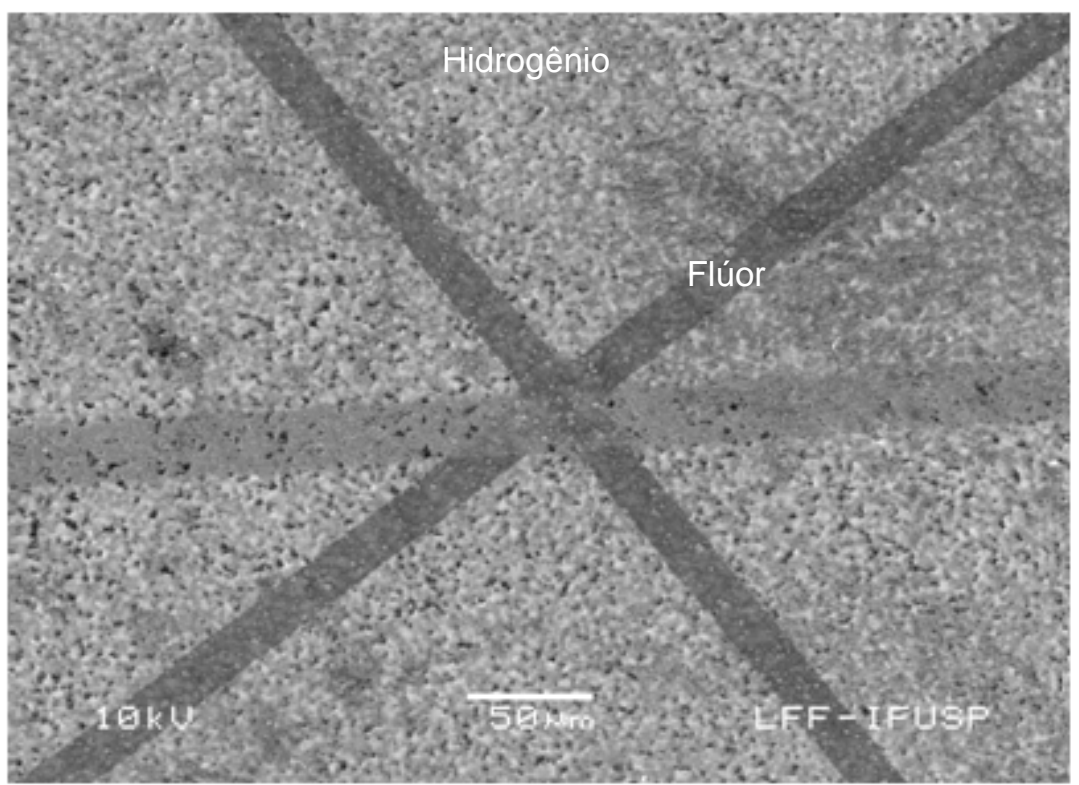

Figura A.7: Micrografia obtida por MEV, referente ao mapeamento do potencial de superfície, desde que o contraste é devido diferente propriedades elétricas, onde as regiões mais claras correspondem a terminações de hidrogênio a região mais escura corresponde a terminação de flúor e a região com tonalidade cinza corresponde a terminações de oxigênio.

Na figura A.8 é mostrado o mapeamento do potencial de superfície através do AFM/KFM, onde podemos ver claramente o potencial devido às 3 terminações diferentes. Para medida do Potencial de superfície devido às terminações, utilizamos a ferramenta de cross section através da linha preta mostrada na figura A.8, obtendo-se assim o perfil de potencial de superfície

Na figura A.9 temos o perfil de potencial médio de superfície medido para a amostra contendo regiões com terminações de hidrogênio, de flúor e de oxigênio, para esta amostra temos as diferenças de potencial medido entre as diferentes terminações na tabela A.4:

Podemos observar que o resultados mostrados na tabela A.4 são comparáveis ao resultados encontrados nas seções A.1, A.2 e A.3. 


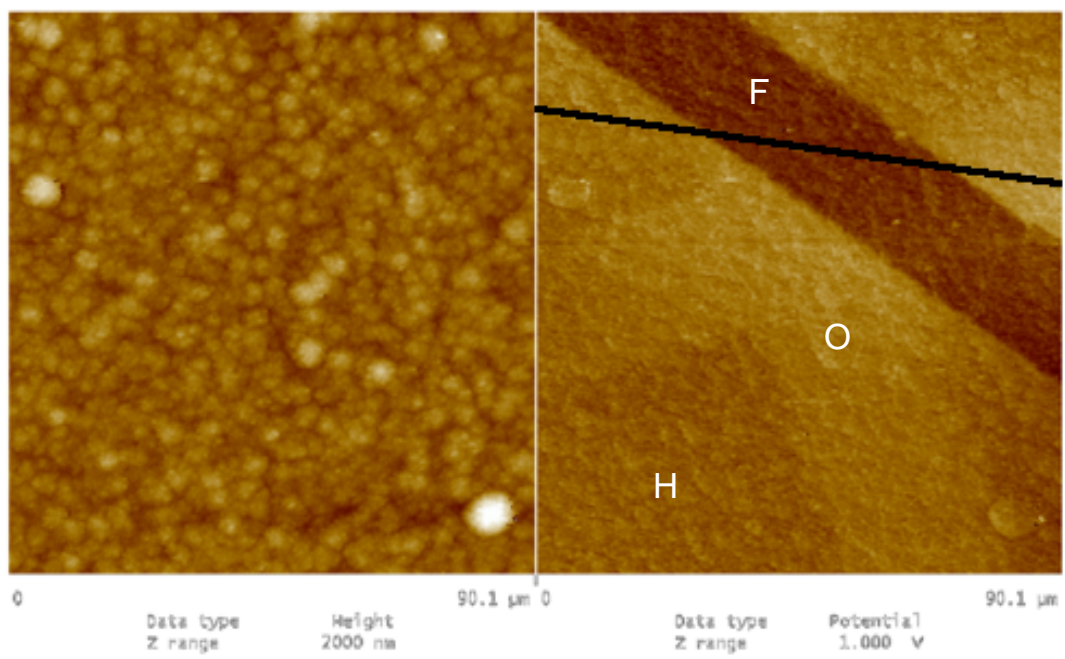

Figura A.8: Micrografia obtida por AFM e KFM, sendo a imagem da esquerda referente a topografia da amostra e a imagem da direita referente ao mapeamento do potencial de superfície, onde as regiões mais claras correspondem a terminações de oxigênio, a região mais escura corresponde a terminação de flúor e as.demais correspondem as terminações de hidrogênio.

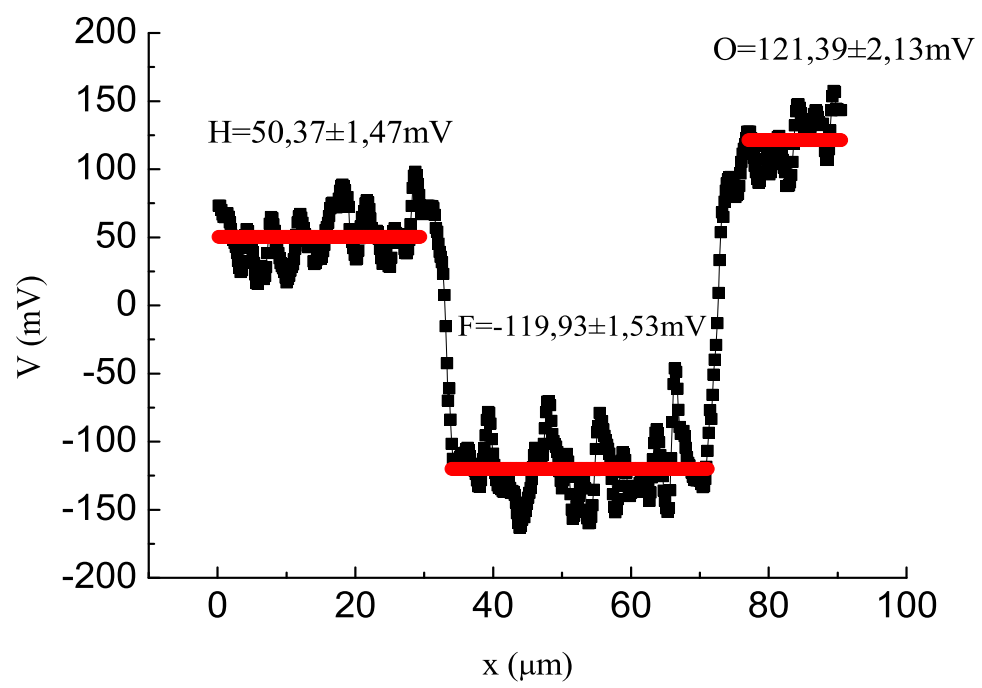

Figura A.9: Perfil de potencial médio obtido para a amostra contendo regiões com terminações de hidrogênio, de flúor e de oxigênio, medido utilizando a ferramenta de cross-section. 
Tabela A.4: Diferença de Potencial medido através da ferramenta de cross section para amostra contendo regiões com diferentes terminações.

Diferença de Potencial entre regiões com terminaçõesde hidrogênio, de flúor e de oxigênio.

\begin{tabular}{|c|c|}
\hline Terminações & Diferença de Potencial \\
\hline Hidrogênio/Oxigênio & $\cong 80 \mathrm{mV}$ \\
\hline Hidrogênio/Flúor & $\cong 150 \mathrm{mV}$ \\
\hline Flúor/Oxigênio & $\cong 230 \mathrm{mV}$ \\
\hline \hline
\end{tabular}




\section{Referências Bibliográficas}

1 ASMUSSEN, J.; REINHARD, D. K. Diamond Films Handbook. 1st. ed. [S.1.]: CRC Press, 2002.

2 SPEAR, K. E.; DISMUKES, J. P. (Ed.). Synthetic Diamond: Emerging CVD Science and Technology. [S.1.]: Wiley-Interscience, 1994.

3 DAVIS, R. F. Diamond Films and Coatings: Development, Properties and Applications. [S.1.]: Noyes Publications, 1993.

4 SUSSMANN, R. S. CVD Diamond for Electronic Devices and Sensors. [S.1.]: Wiley, 2009.

5 RISTEIN, J. Surface science of diamond: Familiar and amazing. Surface Science, v. 600, n. 18, p. 3677 - 3689, 2006. Berlin, Germany: 4-9 September 2005, Proceedings of the 23th European Conference on Surface Science.

6 TACHIKI, M.; SUMIKAWA, Y.; SHIGENO, M.; BANNO, T.; SONG, K. S.; UMEZAWA, H.; KAWARADA, H. Diamond nanofabrication and characterization for biosensing application. Physica Status Solidi (a), v. 199, n. 1, p. 39-43, 2003.

7 SHIRAFUJI, J.; SUGINO, T. Electrical properties of diamond surfaces. Diamond and Related Material, v. 5(6-8), p. 706-713, May 1996.

8 VAIJAYANTHIMALA, V.; CHANG, H. C. Functionalized fluorescent nanodiamonds for biomedical applications. Nanomedicine, v. 4, n. 1, p. 47-55, jan 2009.

9 XING, Y.; DAI, L. Nanodiamonds for nanomedicine. Nanomedicine, v. 4, n. 2, p. 207-218, feb 2009.

10 OSTROVSKAYA, L.; PEREVERTAILO, V.; RALCHENKO, V.; DEMENTJEV, A.; LOGINOVA, O. Wettability of nanocrystalline

diamond films. Diamond and Related Material, v. 16(12), p.2109-2113, March-June 2007.

11 KAIBARA, Y.; SUGATA, K.; TACHIKI, M.; UMEZAWA, H.; KAWARADA, H. Control wettability of the hydrogen-terminated diamond surface and the oxidized diamond surface using an atomic force microscope. Diamond and Related Material, v. 12(3-7), p. 560-564, March-July 2003. 
12 KAWARADA, H. Hydrogen-terminated diamond surfaces and interfaces. Surf. Sci. Rep., v. 26(7), p. 205-206, June 1996.

13 SALVADORI, M. C.; MAMMANA, V. P.; MARTINS, O. G.; DEGASPERI, F. T. Plasma Sources Science and Technology, v. 4, n. (3), p. 489-494, aug 1995.

14 C.POPOV; W.KULISCH; P.N.GIBSON; G.CECCONE; JELINEK, M. Growth and characterization of nanocrystalline diamond/amorphous carbon composite films prepared by mwcvd. Diamond and Related Materials, v. 13, n. 4-8, p. 1371-1376, April-August 2004.

15 SILVA, F.; BÉNÉDIC, F.; BRUNO, P.; GICQUEL, A. Formation of texture during nanocrystalline diamond growth: an x-ray diffraction study. Diamond and Related Materials, v. 14, n. 3-7, p. 398-403, March-July 2005.

16 REIMER, L. Scanning Electron Microscopy - Physics of Image Formation and Microanalysis. 2. ed.. ed. [S.1.]: Germany: Springer- Verlag Berlin Heidelberg, 1998.

17 MADOU, M. J. Fundamentals of Microfabrication-The Science of Miniaturization. 2. ed. [S.1.]: CRC Press, 2002.

18 NALLANI, A. K.; PARK, S. W.; LEE, J. B. Characterization of su-8 as a photoresist for electron-beam lithography. Proc. SPIE, v. 5116, p. 414, jul 2003.

19 TEIXEIRA, F. S. Anisotropia de Resistividade Elétrica em Filmes Finos Nanoestruturado. Dissertação (Mestrado) - Curso de Pós-graduação em Engenharia Elétrica, Escola Politécnica da Universidade de São Paulo, junho 2007. 92p.

20 MITSUDA, Y.; KOJIMA, Y.; YOSHIDA, T.; AKASHI, K. The growth of diamond in microwave plasma under low pressure. Journal of Materials Science, Springer Netherlands, v. 22, p. 1557-1562, 1987.

21 ROTTER, S. Z.; MADALENO, J. C. Diamond cvd by a combined plasma pretreatment and seeding procedure. Chemical Vapor Deposition, v. 15, p. 209-216, 2009.

22 VIZIR, A.; OKS, E. M.; SALVADORI, M. C.; TEIXEIRA, F. S.; BROWN, I. G. Small plasma source for materials application. Review of Scientific Instruments, v. 78, 0861032007.

23 CULLITY, B. D. Elements of X-ray crystallography. [S.1.]: Addison-Wesley Publishing Company, 1956.

24 VERMA, H. R. Atomic and Nuclear Analytical Methods. [S.1.]: (C)Springer-Verlag Berlin Heidelberg, 2007.

25 ALFORD, T. L.; FELDMAN, L. C.; MAYER, J. W. Fundamentals of Nanoscale Film Analysis. [S.1.]: (C)Springer Science+Business Media, Inc., 2007.

26 BERGER, R.; BUTT, H.-J.; RETSCHKE, M. B.; WEBER, S. A. L. Electrical modes in scanning probe microscopy. Macromolecular Rapid Communications, v. 30, n. 14, p. 1167-1178, 2009.

27 REZEK, B.; NEBEL, C. E. Kelvin force microscopy on diamond surfaces and devices. Diamond and Related Materials, v. 14 (3-7), p. 466-469, March-July 2005. 
28 SALVADORI, M. C. Notas de aula do curso de pós-graduação do Departamento de Física Aplicada Fap 5733. 2008.

29 SAMORI, P. (Ed.). Scannig Probe Microscopies beyond Imaging: Manipulation of Molecules and Nanostructures. [S.1.]: (c)Wiley-VCH Verlag GmbH \& Co. KGaA, 2006.

30 BHUSHAN, B.; GOLDADE, A. V. Kelvin probe microscopy measurements of surface potential change under wear at low loads. Wear, v. 244, n. 1-2, p. $104-117,2000$. ISSN 0043-1648.

31 OZCAN, C.; HASIRCI, N. Evaluation of surface free energy for pmma films. Journal of Applied Polymer Science, v. 108, n. 1, p. 438-446, 2008.

32 YU, G. Q.; TAY, B. K.; SUN, Z.; PAN, L. K. Properties of fluorinated amorphous diamond like carbon films by pecvd. Applied Surface Science, v. 219, n. 3-4, p. 228 - 237, 2003.

33 KWOK, S. C.; WANG, J.; CHU, P. K. Surface energy, wettability, and blood compatibility phosphorus doped diamond-like carbon films. Diamond and Related Materials, v. 14, n. 1, p. $78-85,2005$.

34 OSTROVSKAYA, L.; PEREVERTAILO, V.; RALCHENKO, V.; DEMENTJEV, A.; LOGINOVA, O. Wettability and surface energy of oxidized and hydrogen plasma-treated diamond films. Diamond and Related Materials, v. 11, n. 3-6, p. 845 - 850, 2002.

35 ZHAO, Q.; LIU, Y.; ABEL, E. Effect of temperature on the surface free energy of amorphous carbon films. Journal of Colloid and Interface Science, v. 280, n. 1, p. 174 - 183, 2004.

36 CELII, F. G.; BUTLER, J. E. Diamond chemical vapor deposition. Annual Review of Physical Chemistry, v. 42, n. 1, p. 643-684, 1991.

37 ZEBDA, A.; SABBAH, H.; ABABOU-GIRARD, S.; SOLAL, F.; GODET, C. Surface energy and hybridization studies of amorphous carbon surfaces. Applied Surface Science, v. 254, n. 16, p. $4980-4991,2008$.

38 BRITANNICA, I. E. Pierre-Eugène-Marcellin Berthelot. Retrieved June 14 2010. From Encyclopædia Britannica Online: http://www.britannica.com/EBchecked/topic/62792/PierreEugene-Marcellin-Berthelot.

39 MYERS, D. Surfaces, Interfaces, and Colloids: Principles and Applications. 2. ed. [S.1.]: Wiley-VCH, 1999.

40 ZENKIEWICZ, M. Methods for the calculation of surface free energy of solids. Journal of Achievements in Materials and Manufacturing Engineering, v. 24, n. 1, p. 137-145, September 2007.

41 CANTIN, S.; BOUTEAU, M.; BENHABIB, F.; PERROT, F. Surface free energy evaluation of well-ordered langmuir-blodgett surfaces: Comparison of different approaches. Colloids and Surfaces A: Physicochemical and Engineering Aspects, v. 276, n. 1-3, p. 107 115, 2006. 
42 ARORA, A. K.; RAVINDRAN, T. R.; REDDY, G. L. N.; SIKDER, A. K.; MISRA, D. S. Nature of confinement of phonons in nanocrystalline cvd diamond. Diamond and Related Materials, v. 10, n. 8, p. 1477-1485, 2001.

43 GRUEN, D. Nanocrystalline diamond films. Annual Review Materials Sci., v. 29, p. 211-259, january 1999.

44 H.KUZMANY; PFEIFFER, R.; SALK, N.; GUNTHER, B. The mystery of the $1140 \mathrm{~cm}^{-1}$ line in nanocrystalline diamond films. Carbon, v. 42, p. 911-917, february 2004.

45 WANG, S. G.; ZHANG, Q.; YOON, S. F.; AHN, J.; WANG, Q.; YANG, D. J.; ZHOU, Q.; YUE, N. L. Optical Materials, v. 24, p. 509-514, 2008.

46 CATLEDGE, S. A.; VOHRA, Y. K. Effect of nitrogen addition on the microstructure and mechanical properties of diamond films grown using high-methane concentrations. J. Appl. Phys, v. 86, n. 1, p. 698-700, jul 1999.

47 ORLANDUCCI, S.; FIORI, A.; SESSA, V.; TAMBURRI, E.; TOSCHI, F.; TERRANOVA, M. L. Nanocrystalline diamond films grown in nitrogen rich atmosphere: Structural and field emission properties. Journal of Nanoscience and Nanotechnology, v. 8, n. 6, p. 3228-3234, 2008.

48 SHARDA, T.; UMENO, M.; SOGA, T.; JIMBO, T. Growth of nanocrystalline diamond films by biased enhanced microwave plasma chemical vapor deposition: A different regime of growth. Appl. Phys. Lett., v. 77, n. 26, p. 4304-4306, december 2000.

49 POPOV, C.; VASILCHINA, H.; KULISCH, W.; DANNEIL, F.; STüBER, M.; ULRICH, S.; WELLE, A.; REITHMAIER, J. Wettability and protein adsorption on ultrananocrystalline diamond/amorphous carbon composite films. Diamond and Related Materials, v. 18, n. 5-8, p. 895 - 898, 2009. Proceedings of Diamond 2008, the 19th European Conference on Diamond, Diamond-Like Materials, Carbon Nanotubes, Nitrides and Silicon Carbide. 


\section{Index}

1000 Kelvin Force Microscopy, 21

1000 Raman, 21 